

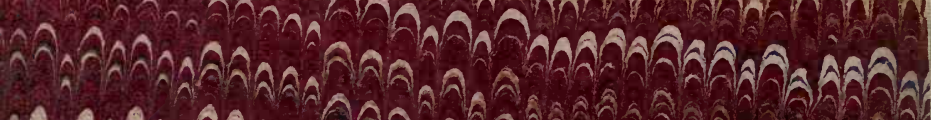

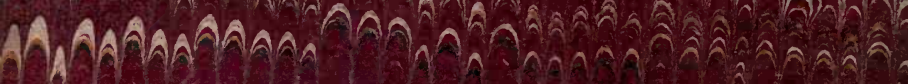

A A A

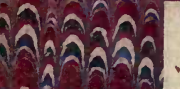

AnA AAAACA AAMA a. an Anคลำ A

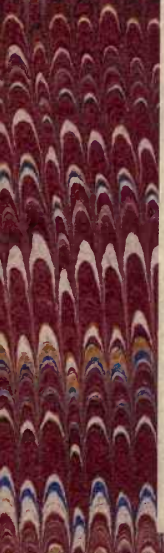

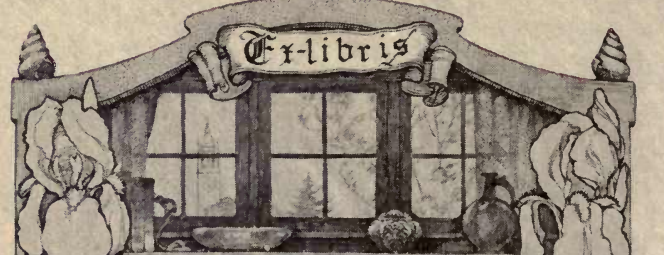

Aิ ลิ 12 $\sqrt{1}$

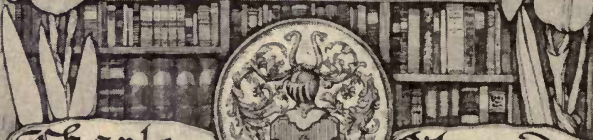

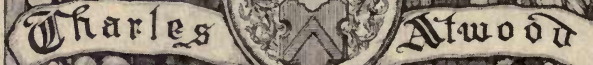

A

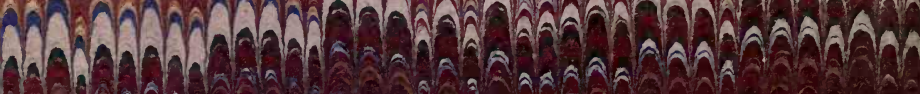

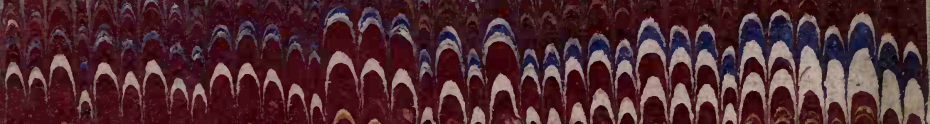




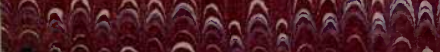

1 Añ

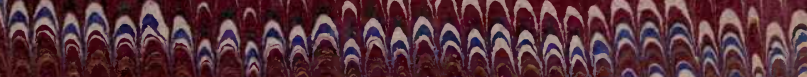

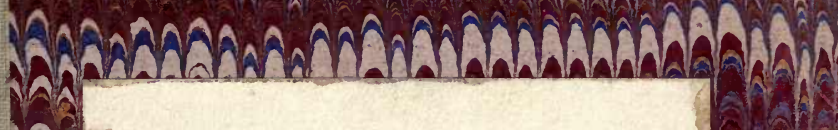

(n)

ลิA

คิ

Ban

1ล

12

THE LIBRARY

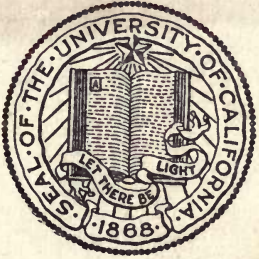

กิ?

$\mathrm{OF}$

(2)

- คิล

nâna

Aิ

PRESENTED BY

a)

Nalo

PROF. CHARLES A. KOFOID AND

ầ

THE UNIVERSITY

OF CALIFORNIA

An

$$
\text { MRS. PRUDENCE W. KOFOID }
$$

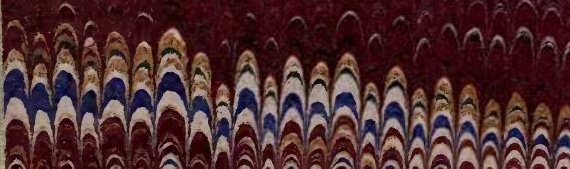





hargarew

\section{THE OCEAN AND ITS WONDERS.}



Charas a. Tleforid 


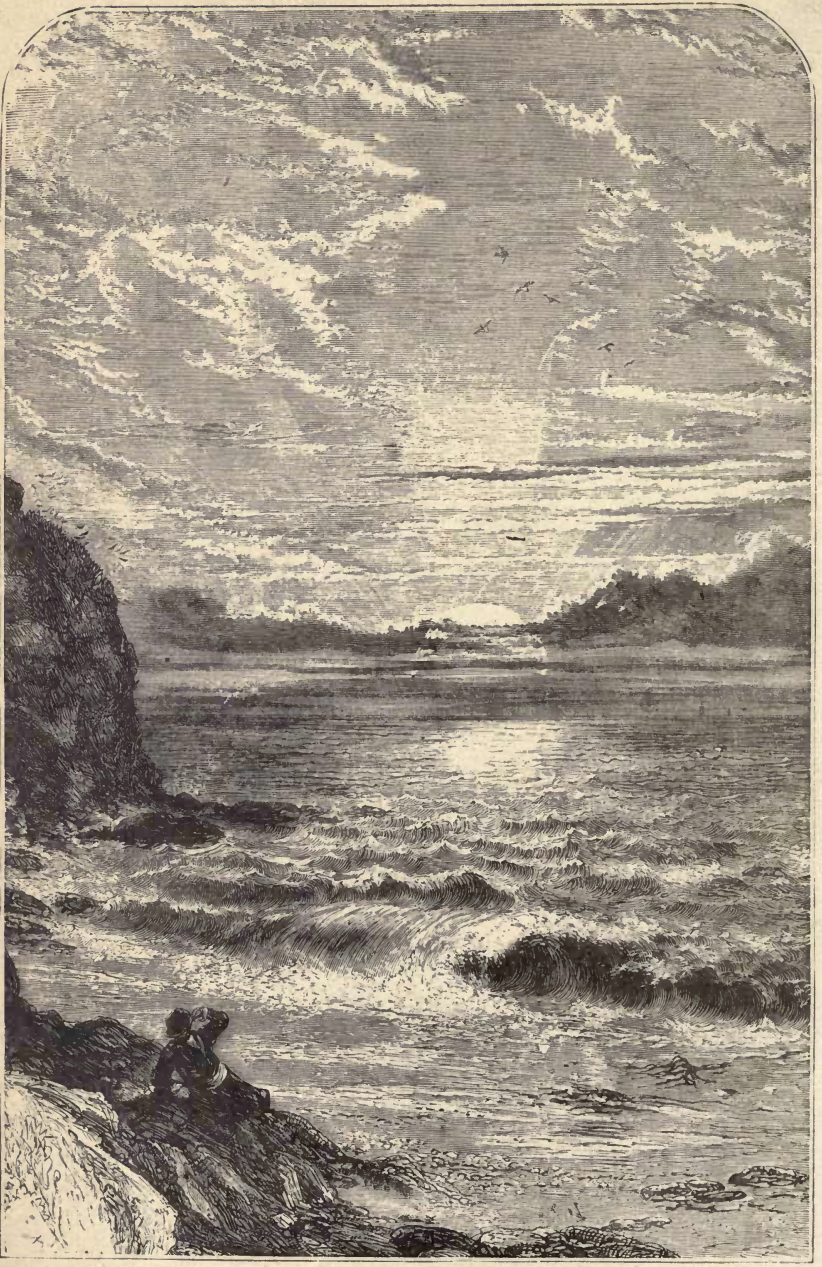

THE OCEAN, 


\section{THE OCEAN}

AND ITS WONDERS.

BY

R. M. BALLANTYNE,

AUTIOR OF "THE VOUNG FUR-TRADER,," "MAN ON THE OLEAN,"

" the gorilla iunters," etc.

\section{O N D O N :}

T. NELSON AND SONS, PATERNOSTER ROW; EDINBURGH ; AND NEW YORK. 


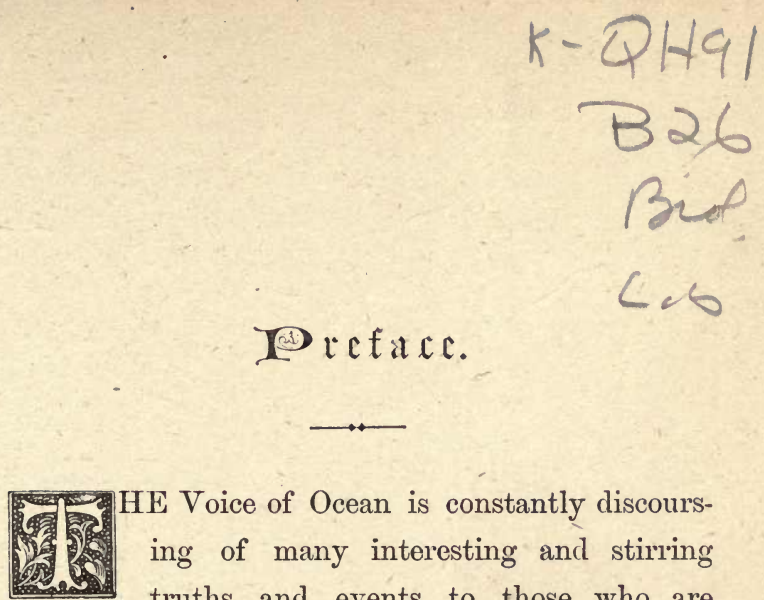

HE Voice of Ocean is constantly discoursing of many interesting and stirring truths and events to those who are disposed to listen.

The particular discourse recorded in this volume is that which treats chiefly of the causes and effects of those grand oceanic and atmospheric currents which modify the climates of the Earth, and diversify the face of Nature from the Equator to the Poles.

Our information has been gathered from many sources-chief among which we may mention that delightful book, "Maury's Physical Geography of the Sea."

\section{R. M. Ballantyne.}

Édinburgh, 1873. 



\section{Gerontents.}

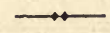

\section{CHAPTER I.}

WHAT THE OCEAN HAS TO SAY-ITS WHISPERS-ITS THUNDEKS-ITS SECRETS $\ldots \ldots \ldots \ldots \ldots \ldots \ldots \ldots \ldots \ldots \ldots \ldots \ldots \ldots \ldots \ldots \ldots \ldots \ldots$

\section{CHAPTER II.}

COMPOSITION OF THE SEA-ITS SALTS-POWER AND USES OF WATEIR -Advantage AND DISAdvantage OF SALTS-ANECDOTEDEEP-SEA SOUNDINGS-BROOKE'S APPARATUS-IMPORTANCE OF THE SEARCH AFTFR TRUTH-ILLUSTRATIONS-DISCOVERIES . RESULTING FROM DEEP-SEA SOUNDINGS .............. 17

\section{CHAPTER III.}

WAVES-SYSTEM IN ALL THINGS-VALUE OF SCIENTIFIC KNOWLEDGE -ILLTSTRATIVE ANECDOTE-HEIGHT OF WAVES-DR. SCORFSBY -SIZE, VELOCITY, AND AWFUL POWER OF WAVES-ANECDOTES REGARDING THEM-TIDES . . . . . . . . . . . . . . 32

\section{CHAPTER IV.}

THE GULF STREAM-ITS NATURE-CAUSE-ILLUSTRATION-EFFECT OF SMALL POWERS UNITED-ADVENTURES OF A PARTICLE OF WATER-FFFECT OFGULF STREAM ON CLIMATE-ITS COURSE-INFLUENCE ON NAVIGATION-SARGASSO SEA-SCIENTIFIC FFFORTS OF PRESENT DAY - WIND AND CURRENT CHARTS-EFFECTS ON COMMERCF - CAUSE OF STORMS - INFLUENCE OF GULF STREAM ON MARINE ANIMALS ....................... 50 


\section{CHAPTER V.}

THE ATMOSPHERIC OCEAN-ORDER IN ITS FLOW-OFFICES OF THE ATMOSPHERE-DANGERS LESSENED BY SCIENCE-CURRENTS OF ATMOSPHERE-CAUSE OF WIND-TWO GREAT CURRENTS-DISTURBING INFLUENCES-CALMS - VARIABLE WINDS-CAUSES THEREOF-LOCAL CAUSES OF DISTURBANCE-GULF STREAM'S INFLUENCE-THE WINDS MAPPED OUT-A SUPPOSED CASF. . 74

\section{CHAPTER VI.}

TRADE-WINDS-STORMS-THEIR EFFECTS-MONSUONS-THEIR VALUE -LAND AND SEA BREEZES-EXPERIMENTS - HURRICANESTHOSE OF 1831-ROTATORY STORMS-THEIR TERRIBLE EFFECTS -CHINA SEAS-HURRICANE IN 1837-WHIRLWINDS-WEIGHT OF ATMOSPHERE-VALUE OF ATMOSPHERIC CIRCULATIONHEIGHT OF ATMOSPHERE $\ldots \ldots \ldots \ldots \ldots \ldots \ldots \ldots \ldots \ldots \ldots \ldots . \ldots 9$

\section{CHAPTER VII.}

WATERSPOUTS-CAUSES OF-APPEARANCE-ELECTRICITY-EXPERIMENTS-ARTIFICIAL WATERSPOUTS-SHOWERS OF FISH-MR. ELLIS ON WATERSPOUTS IN THE SOUTH SEAS........... 111

\section{CHAPTER VIII.}

THE ARCTIC SEAS-THEIR CHARACTER, SCENERY, AND ATMOSPHERICAL ILLUSIONS $\ldots \ldots \ldots \ldots \ldots \ldots \ldots \ldots \ldots \ldots \ldots \ldots \ldots \ldots \ldots$

\section{CHAPTER IX.}

FORMATION OF ICE-DANGERS OF DISRUPTING ICE-ANECDOTEDRIFTING ICE-DRIET OF THE "FOX"- "NIPPING"-ANECDOTE -LOSS of THE " BREAdALbANE" .................. 134

\section{CHAP'TER $\mathbf{X}$.}

ICEBERGS - THEIR APPEARANCE AND FORMS - THEIR CAUSE GLACIERS-THEIR NATURE AND ORIGIN-ANECDOTE OF SCORESBY -RISK AMONG ICEBERGS-M'CLURE'S EXPERIENCE ...... 150 
CHAPTER XI.

ICE AN AGENT IN TRANSPORTING BOULDERS-HOW THIS COMES ABOUT -DR. KANE'S OBSERVATIONS-LONG NIGHT IN WINTER AND LONG DAY IN SUMMER-EXTREME DARKNESS-INFLUENCE ON DOGS -INTENSE COLD-EFFECT ON THE SEA................ 166

\section{CHAPTER XII.}

QUESTION OF AN OPEN SEA ROUND THE POLES-UPPER AND UNDER CURRENTS OF THE OCEAN-CAUSE THEREOF-HABITS OF THE WHALE AS BEARING ON THE QUESTION-DR. KANE'S DISCOVERY OF AN OPEN SEA IN THE FAR NORTH-NOTES ON THE EXPEDITION-A BEAR-HUNT ....................... 176

\section{CHAPTER XIII.}

Miscellaneous PHenomena of THE POLAR SEAS AND REgIONSTHE AURORA BOREALIS - ICE-BLINK - OPTICAL ILLUSIONSANECDOTE OF SCORESBY - HALOS - CORONA - MOCK SUNSREFRACTION_FROSTS .......................... 194

CHAPTER XIV.

ANIMAL LIFE IN THE SEA-MEDUSE-FOOD OF THE WHALEPHOSPHORIC LIGHT-CAUSE THEREOF-LUMINOSITY OF THE OCEAN......................................206

\section{CHAPTER XV.}

CORAL INSECTS AND CORAL ISLANDS - POLYNESIA-OPERATIONS OF THE CORAL INSECT-GROWTH OF CORAL REEFS........... 219

\section{CHAPTER XVI.}

VOLCANIC ISLANDS-OPINIONS OF THE ANCIENTS-" ATLANTIS"INSTANCE OF THE FORMATION OF A VOLCANJC ISLAND-CONchusion. ................................. 228 



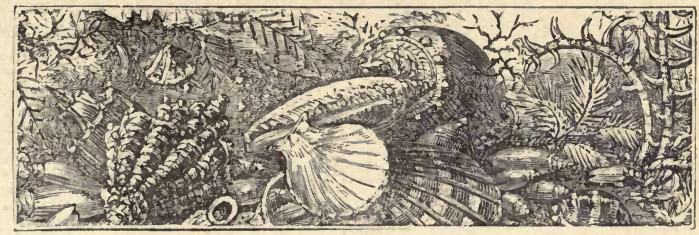

\section{THE OCEAN AND ITS WONDERS.}

\section{CHAPTER I.}

WHAT THE OCEAN HAS TO SAY-ITS WHISPERS-ITS THUNDERSITS SECRETS.

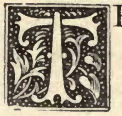

HERE is a voice in the waters of the great sea. It calls to man continually. Sometimes it thunders in the tempest, when the waves leap high and strong, and the wild winds shriek and roar, as if to force our attention. Sometimes it whispers in the calm, and comes rippling on the shingly beach in a still, small voice, as if to solicit our regard. But whether that voice of ocean comes in crashing billows or in gentle murmurs, it has but one tale to tell,-it speaks of the love, and power, and majesty of Him who rides upon the storm, and rules the wave.

Yes, the voice of ocean tells but one tale; yet 
there are many chapters in that wonderful story. The sea has much to say; far more than could possibly be comprehended in one volume, however large. It tells us of the doings of man on its broad bosom, from the day in which he first ventured to paddle along shore in the hollow trunk of a tree, to the day when he launched his great iron ship of 20,000 tons, and rushed out to sea, against wind and tide, under an impulse equal to the united strength of 11,500 horses. No small portion of the ocean's tale this, comprising many chapters of deeds of daring, blood, villany, heroism, and enterprise. But with this portion of its story we have nothing to do just now. It tells us, also, of God's myriad and multiform creatures that dwell in its depths, from the vast whale, whose speed is so great, that it might, if it chose, circle round the world in a few days, to the languid zoophyte, which clings to the rock, and bears more resemblance to a plant than to a living animal.

The sea has secrets, too, some of which it will not divulge until that day when its Creator shall command it to give up its dead; while others it is willing to part with to those who question it closely, patiently, and with intelligence.

Among the former kind of secrets are those foul deeds that have been perpetrated, in all ages, by abandoned men; when no human ears listened to the stifled shriek, or the gurgling plunge; when no human eyes beheld the murderous acts, the 
bloody decks, the blazing vessels, or the final hiss of the sinking wrecks.

Among the latter kind of secrets are the lives and habits of the creatures of the deep, and the causes and effects of those singular currents of air and water, which, to the eye of ignorance, seem to be nothing better than irregularity and confusion; but which, to the minds of those who search them out, and have pleasure therein, are recognised as a part of that wonderful, orderly, and systematic arrangement of things that we call Nature : much of which we now know, more of which. we shall certainly know, as each day and year adds its quota to the sum of human knowledge; but a great deal of which will, doubtless, remain for ever hidden in the mind of nature's God, whose ways are wonderful, and past finding out. It is the latter class of secrets to which we purpose directing the reader's attention in the following pages.

On approaching so vast a subject, we feel like the traveller who, finding himself suddenly transported into the midst of a new and magnificent region, stands undecided whither to direct his steps in the endlessly varied scene. Or, still more, like the visitor to our great International Exhibition of 1862, who,-entering abruptly that gigantic palace, where were represented the talent, the ingenuity, the wealth, and industry of every people and clime, - attempts, in vain, to systematize his explorations, or to fix his attention. It is probable 
that, in each of these supposed cases, the traveller and visitor, resigning the desire to achieve what is impossible, would give themselves up to the agreeable guidance of a wandering and wayward fancy.

Let us, reader, act in a somewhat similar manner. Let us touch here, and there, and everywhere, on the wonders of the sea, and listen to such notes of the Ocean's Voice as strike upon our ears most pleasantly.

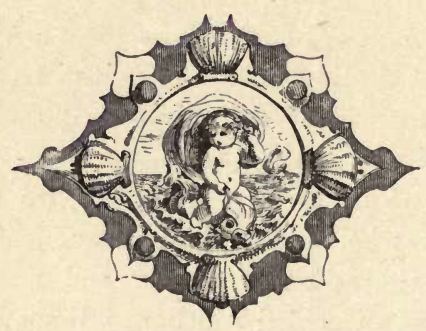




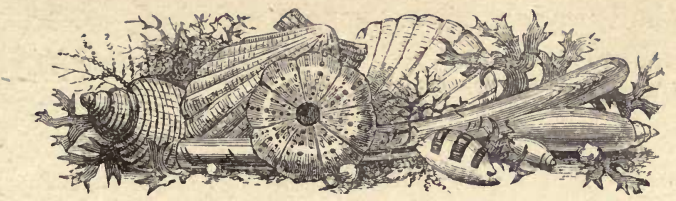

CHAPTER II.

COMPOSITION OF THE SEA-ITS SALTS-POWER AND USES OF WATER -Advantage AND Disadvantage of salts-ANecdoteDEEP-SEA SOUNDINGS - BROOKE'S APPARATUS-IMPORTANCE OF THE SEARCH AFTFR TRUTH-ILLUSTRATIONS-DISCOVERIHS RESULTING FROM DEEP-SEA SOUNDINGS

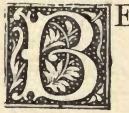

EFORE proceeding to the consideration of the wonders connected with and contained in the sea, we shall treat of the composition of the sea itself, and of its extent, depth, and bottom.

What is the sea made of? Salt water, is the ready reply that rises naturally to every lip. But to this we add the question,-What is salt water? or, as there are many kinds of salt water, of what sort of salt water does the sea consist? To these queries we give the following reply, which, we doubt not, will rather surprise some of our readers.

Fresh water, as most people are aware, is composed of two gases-oxygen and hydrogen. Sea water is composed of the same gases, with the addition of muriate of soda, magnesia, iron, lime, 
sulphur, copper, silex, potash, chlorine, iodine, bromine, ammonia, and silver. What a dose! Let bathers think of it next time they swallow a gulp of sea water.

Most of these substances, however, exist in comparatively small quantity in the sea, with the exception of muriate of soda, or common table salt; of whieh, as all bathers know from bitter experience, there is a very considerable quantity. The quantity of silver contained in sea water is very small indeed. Nevertheless, small though it be, the ocean is so immense, that, it has been calculated, if all the silver in it were collected, it would form a mass that would weigh about two hundred million tons !

The salt of the ocean varies considerably in different parts. Near the equator, the great heat carries up a larger proportion of water by evaporation than in the more temperate regions; and thus, as salt is not removed by evaporation, the ocean in the torrid zone is salter than in the temperate or frigid zones.

The salts of the sea, and other substances contained in it, are conveyed thither by the fresh-water streams that pour into it from all the continents of the world. Maury, in his delightful work, "The Physical Geography of the Sea," tells us that "water is Nature's great carrier. With its currents it conveys heat away from the torrid zone, and ice from the frigid; or, bottling the caloric away in the vesicles 
of its vapour, it first makes it impalpable, and then conveys it by unknown paths to the most distant parts of the Earth. The materials of which the coral builds the island, and the sea-conch its shell, are gathered by this restless leveller from mountains, rocks, and valleys, in all latitudes. Some it washes down from the Mountains of the Moon in Africa, or out of the gold-fields of Australia, or from the mines of Potosi; others from the battle-fields of Europe, or from the marble quarries of ancient Greece and Rome. The materials thus collected, and carried over falls and down rapids, are transported to the sea."

Here, as these substances cannot be evaporated, they would accumulate to such a degree as to render the ocean uninhabitable by living creatures, had not God provided against this by the most beautiful compensation. He has filled the ocean with innumerable animals and marine plants, whose special duty it is to seize and make use of the substances thus swept from the land, and reconvert them into solids. We cannot form an adequate conception of the extent of the great work carried on continually in this way; but we see part of it in the chalk cliffs, the marl beds of the sea shore, and the coral islands of the South Seas,-of which last more particular notice shall be taken in a succeeding chapter.

The operations of the ocean are manifold. Besides forming a great reservoir, into which what 
may be termed the impurities of the land are conveyed, it is, as has been shown, the great laboratory of Nature, where these are reconverted, and the general balance restored. But we cannot speak of these things without making passing reference to the operations of water, as that wonder-working agent of which the ocean constitutes but a part.

Nothing in this world is ever lost or annihilated. As the ocean receives all the water that flows from the land, so it returns that water, fresh and pure, in the shape of vapour, to the skies; where, in the form of clouds, it is conveyed to those parts of the earth where its presence is most needed, and precipitated in the form of rain and dew, fertilizing the soil, replenishing rivers and lakes, penetrating the earth's deep caverns; whence it bubbles up in the shape of springs, and, after having gladdened the heart of man by driving his mills and causing his food to grow, it finds its way again into the sea: and thus the good work goes on with ceaseless regularity.

Water beats upon the rocks of the sea-shore until it pounds them into sand, or rolls them into pebbles and boulders. It also sweeps the rich soil from the mountains into the valleys. In the form of snow it clothes the surface of the temperate and frigid zones with a warm mantle, which preserves vegetable life from the killing frosts of winter. In the form of ice it splits asunder the granite 


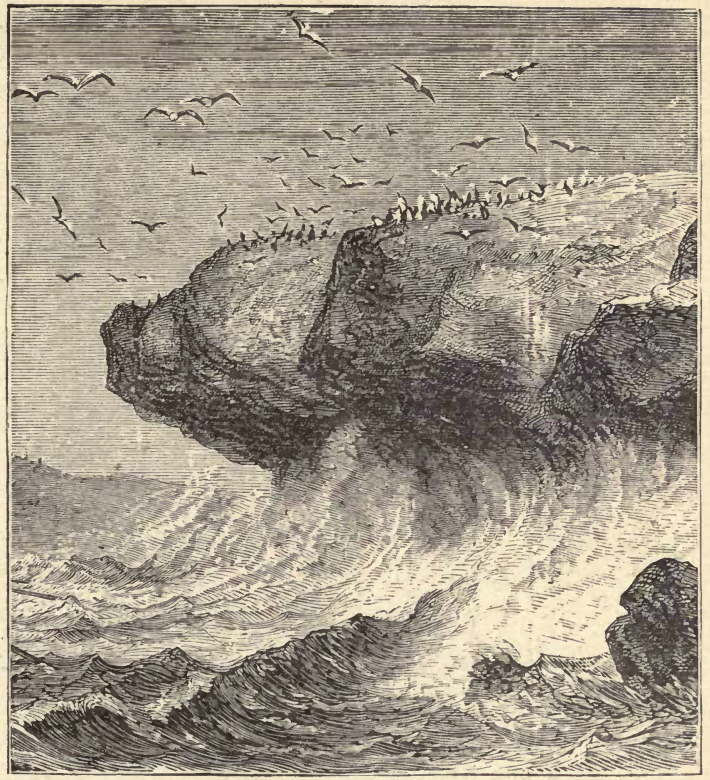

ACTION OF WAVES UPON A ROCKY SHORE.

hills; and in the northern regions it forms great glaciers, or masses of solidified snow, many miles in extent, and many hundred feet thick. These glaciers descend by slow, imperceptible degrees, to the sea; their edges break off and fall into it, and, floating southward, sometimes in great mountainous masses, are seen by man in the shape of icebergs. Frequently huge rocks, that have fallen upon these glaciers from cliffs in the arctic regions, are carried 
22 ADVANTAGE AND DISADVANTAGE OF SAlTs.

by them to other regions, and are deposited on flat beaches, far from their native cliffs.

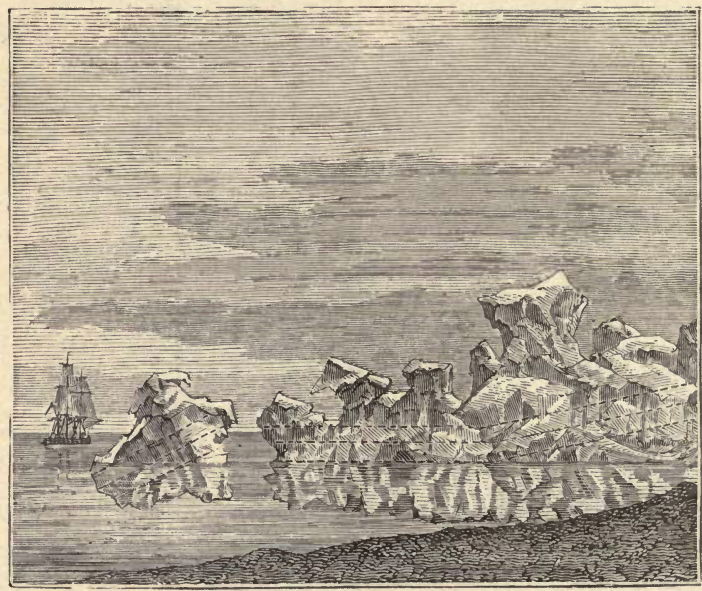

FORMATION OF ICEBERGS.

The saltness of the sea rendering it more dense, necessarily renders it more buoyant, than fresh water. This is obviously a great advantage to man in the matter of commerce. A ship does not sink so deep in the sea as it does in a fresh-water lake; hence it can carry more cargo with greater facility. It is easier to swim in salt than in fresh water.

The only disadvantage to commerce in the saltness of the sea is the consequent unfitness of its water for drinking. Many and harrowing are the 
accounts of instances in which sailors have been reduced to the most terrible extremities for want of fresh water ; and many a time, since navigation began, have men been brought to feel the dread reality of that condition which is so forcibly expressed in the poem of the "Ancient Mariner :" -

\footnotetext{
"Water, water everywhere, And not a drop to drink."
}

Science, however, at length enabled us to overcome this disadvantage of saltness. By the process of distillation, men soon managed to procure enough water at least to save their lives. One captain of a ship, by accident, lost all his fresh water; and, before he could put into port to replenish, a gale of wind, which lasted three weeks, drove him far out to sea. He had no distilling apparatus on board, and it seemed as if all hope of the crew escaping the most horrible of deaths were utterly taken away. In this extremity the captain's inventive genius came to his aid. He happened to have on board an old iron pitch-pot, with a wooden cover. Using this as a boiler, a pipe made of a pewter plate, and a wooden cask as a receiver, he set to work, filled the pot with sea water, put an ounce of soap therein to assist in purifying it, and placed it on the fire. When the pot began to boil, the steam passed through the pipe into the cask, where it was condensed into water, minus the saline particles, which, not being evaporable, were left behind in the pitch-pot. In less than an hour 
a quart of fresh water was thus obtained; which, though not very palatable, was sufficiently good to relieve the thirst of the ship's crew. Many ships are now regularly supplied with apparatus for distilling sea water; and on the African coasts and other unhealthy stations, where water is bad, the men of our navy drink no other water than that which is distilled from the sea.

The salts of the ocean have something to do with the creating of oceanic currents; which, in their turn, have a powerful influence on climates. They also retard evaporation to some extent, and have some effect in giving to the sea its beautiful blue colour.

The ocean covers about two-thirds of the entire surface of the Earth. Its depth has never been certainly ascertained; but from the numberless experiments and attempts that have been made, we are warranted in coming to the conclusion that it nowhere exceeds five miles in depth, probably does not quite equal that. Professor Wyville Thompson estimates the average depth of the sea at about two miles.

Of the three great oceans into which the sea is naturally divided-the Atlantic, the Pacific, and the Arctic - the Atlantic is supposed to be the deepest. There are profundities in its bosom which have never yet been sounded, and probably never will be.

The difficulty of sounding great depths arises 
from the fact that, after a large quantity of line has been run out, the shock of the lead striking the bottom cannot be felt. Moreover, there is sufficient force in the deep-sea currents to sweep out the line after the lead has reached the bottom; so that, with the ordinary sounding-lines in use-among navigators, it is impossible to sound great depths. Scientific men have, therefore, taxed their brains to invent instruments for sounding the deep sea-for touching the bottom in what sailors call " blue water." Some have tried it with a silk thread as a plumb-line, some with spun-yain threads, and various other materials and contrivances. It has even been tried by exploding petards and ringing bells in the deep sea, when it was supposed that an echo or reverberation might be heard, and, from the known rate at which sound travels through water, the depth might thus be ascertained. Deep-sea leads have been constructed having a column of air in them, which, by compression; would show the aqueous pressure to which they had been subjected; but the trial proved to be more than the instrument could stand.

Captain-Maury, of the -American Navy-whose interesting book has been already referred toinvented an instrument for sounding the deep sea. Here is his own description of it:- "To the lead was attached, upon the principle of the screwpropeller, a small piece of clock-work for registering the number of revolutions made by the little screw 
during the descent; and it having been ascertained by experiment in shoal water that the apparatus, in descending, would cause the propeller to make one revolution for every fathom of perpendicular descent, hands provided with the power of self-registering were attached to a dial, and the instrument was complete. It worked beautifully in moderate depths, but failed in blue water, from the difficulty of hauling it up if the line used were small, and from the difficulty of getting it down if the line used were large enough to give the requisite strength for hauling it up." One eccentric old sea captain proposed to sound the sea with a torpedo, or shell, which should explode the instant it touched the bottom. Another gentleman proposed to try it by the magnetic telegraph, and designed an instrument which should telegraph to the expectant measurers above how it was getting on in the depths below. But all these ingenious devices failed, and it is probable that the deepest parts of the ocean-bed still remained untouched by man.

At last an extremely simple and remarkably successful deep-sea sounding apparatus was invented by Mr. Brooke, an American officer. It consisted of nothing more than thin twine for a soundingline, and a cannon ball for a sinker. The twine was made for the purpose, fine but very strong, and was wound on a reel to the extent of ten thousand fathoms. The cannon ball, which was from thirtytwo to sixty-eight pounds' weight, had a hole quite 
through it, into which was fixed a sliding rod, the end of which, covered with grease, projected several inches beyond the ball. By an ingenious and simple contrivance, the cannon ball was detached

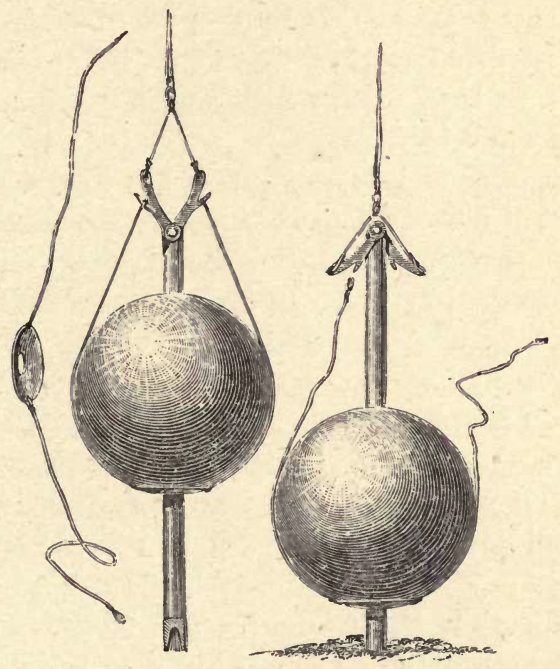

BROOKE'S SOUNDING APPARATUS.

when it reached the bottom of the sea, and the light rod was drawn up with specimens of the bottom adhering to the grease.

With this instrument the Americans went to work with characteristic energy, and, by always using a line of the same size and make, and a sinker of the same shape and weight, they at last ascer- 
tained the law of descent. This was an important achievement, because, having become familiar with the precise rate of descent at all depths, they wereenabled to tell very nearly when the ball ceased to carry out the line, and when it began to go out in obedience to the influence of deep-sea currents. The greatest depth reached by Brooke's sounding-line is said to have been a little under five miles-in the North Atlantic.

The value of investigations of this kind does not appear at first sight, to unscientific men. But those who have paid even a little attention to the methods and processes by which grand discoveries have been made, and useful inventions have been perfected, can scarcely have failed to come to the conclusion that the search after TRUTH, pure and simple, of any kind, and of every kind, either with or without reference to a particular end, is one of the most useful as well as elevating pursuits in which man can engage.

All truth is worth knowing and labouring after. No one can tell to what useful results the discovery of even the smallest portion of truth may lead. Some of the most serviceable and remarkable inventions of modern times have been the result of discoveries of truths which at first seemed to have no bearing whatever on those inventions. When James Watt sat with busy reflective mind staring at a boiling kettle, and discovered the expansive power of steam, no one could have for a moment 
imagined that in the course of years the inventions founded on the truth then discovered would result in the systematic driving of a fleet of floating palaces all round the world at the rate of from twelve to fifteen or twenty miles an hour! Instances of a similar kind might be multiplied without end. In like manner, deep-sea sounding may lead to great, as yet unimagined, results. Although yet in its infancy, it has already resulted in the discovery of a comparatively shallow platean or ridge in the North Atlantic Ocean, rising between Ireland and Newfoundland; a discovery which has been turned to practical account, inasmuch as the plateau has been chosen to be the bed of our electric telegraph between Europe and America. The first Atlantic cable was laid on it; and although that cable suffered many vicissitudes at first, as most contrivances do in their beginnings, communication between the two continents was successfully established. Soundings taken elsewhere showed that somewhat similar plateaus existed in other parts of the Atlantic, and now the whole of Western Europe is being bound more firmly, by additional cables, to the eastern sea-bord of America.

This great and glorious achievement has been the result of the discovery of two truths, - of a truth in science on the one hand, and a truth in regard to the structure of the bed of the sea on the other. The study of electricity and of deep-sea soundings was begun and carried on for the sake of the dis- 
covery of truth alone, and without the most distant reference to the Atlantic Telegraph,-yet that telegraph has been one of the results of that study. Who can tell how many more shall follow? And even were no other result ever to follow, this one may prove to be of the most stupendous importance to the human race.

Another discovery that has been made by deepsea sounding is, that the lowest depths of the ocean are always in a state of profound calm. Oceanic storms do not extend to the bottom. When the tempest is lashing the surface of the sea into a state of the most violent and tremendous agitation, the caverns of the deep are wrapped in perfect repose. This has been ascertained from the fact that in many places the bottom of the sea, as shown by the specimens brought up by Brooke's apparatus, and more recently by Professor 'Thompson's deep-sea dredge, is composed of exceedingly minute shells of marine insects. These shells, when examined by the microscope, are found to be unbroken and perfect, though so fragile that they must certainly have been broken to pieces had they ever been subjected to the influence of currents, or to the pulverizing violence of waves. Hence the conclusion that the bottom of the sea is in a state of perpetual rest and placidity.

Indeed, when we think of it, we are led to conclude that this must necessarily be the case. There are, as we shall presently show, currents of vast size 
and enormous power constantly flowing through the ocean; and when we think of the tremendous power of running water to cut through the solid rock, as exemplified in the case of Niagara, and many other rivers, what would be the result of the action of currents in the sea, compared with which Niagara is but a tiny rivulet? Ocean currents, then, flow on a bed of still water, that protects the bottom of the sea from forces which, by calculation, we know would long ago have torn up the foundations of the deep, and would probably have destroyed the whole economy of nature, had not this beautiful arrangement been provided by the all-wise Creator.

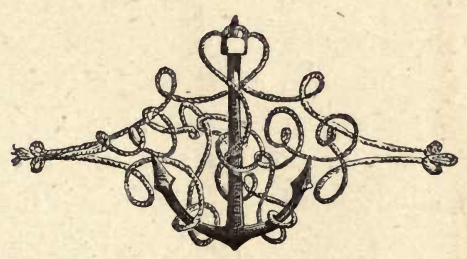




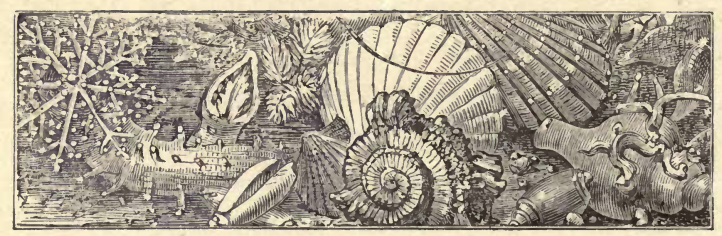

CHAPTER III.

WAVES-SYSTEM IN ALL THINGS-VALUE OF SCIENTIFIC KNOWLEDGE

-ILLTSTRATIVE ANECDOTE-HEIGHT OF WAVES-DR. SCORESBY - SIZE, VELOCITY, AND AWFUL POWER OF WAVES-ANECDOTES REGARDING THEM-TIDES.

HEN a man stands on the deck of some MV tight-built ship, holding on to the weather bulwarks, and gazing with unphilosophic eye through the'blinding spray at the fury of the tempest-by which the billows are made to roll around him like liquid mountains, and the ship is tossed beneath him like a mere chip, the sport and plaything of the raging waters-he is apt to think, should his thoughts turn in that direction at all, that all is unmitigated confusion; that the winds, which blew west yesterday and blow east to-day, shifting, it may be, with gusty squalls, now here, now there, in chaotic fury,-are actuated by no laws, governed by no directing power.

Yet no thought could be more unphilosophical than this. Apart altogether from divine revelation, by which we are informed that "all deeps, fire, and hail, snow, and vapour, and stormy wind," are 
"fulfilling God's word" (which information we are bound to receive as a matter of faith if we be Christians, and as a matter of necessity if we be men of common sense, because it is mere absurdity to suppose that the "stormy winds," \&c., are not fulfilling God's word-or will), we now know, to a great extent from practical experience and scientific investigation, that the winds blow and the waters of the ocean flow in grand, regular, uninterrupted currents. Amongst these there are numberless eddies, which, perhaps, have tended to fill our minds with the idea of irregularity and confusion; but which, nevertheless, as well as the grand currents themselves, are subject to law, and are utterly devoid of caprice.

In regard to these matters there is much about which we are still in ignorance. But the investigations of late years-especially those conducted under the superintendence of Captain Maury of the American Navy, and Drs. Carpenter and Thompson of England-have shown that our atmosphere and our ocean act in accordance with a systematic arrangement, many facts regarding which have been discovered, and turned, in some cases, to practical account.*

A very interesting instance of the practical use to which scientific inquiry can be turned, even in its beginnings, is given by Maury. After telling us of the existence and nature of a current in the ocean

* The gentlemen here referred to are agreed as to the fact of systematic arrangement of currents, though they differ in regard to some of the causes thereof and other matters. 
called the Gulf Stream, he gives the following account of the manner in which upon one occasion he made use of his theoretical knowledge :-

In the month of December 1853, the fine steam-ship San Francisco sailed from New York with a regiment of United States troops on board, bound for California by way of Cape Horn. She was overtaken, while crossing the Gulf Stream, by a gale of wind, in which she was dreadfully crippled. Her decks were swept, and, by one single blow of those terrible seas that the storms raise in the Gulf Stream, more than in any other part of the Atlantic, one hundred and seventy-nine souls, officers and soldiers, were washed overboard and drowned.

The day after this disaster she was seen by one vessel, and again, the next day, December 26 th, by another; but neither of them could render her any assistance.

When these two vessels arrived in the United States and reported what they had seen, the most painful apprehensions were entertained by friends for the safety of those on board the steamer. Vessels were sent out to search for and relieve her. But where should these vessels go? Where should they look?

An appeal was made to know what light the system of researches carried on at the National Observatory concerning winds and currents could throw upon the subject.

The materials they had been discussing were 
examined, and a chart was prepared to show the course of the Gulf Stream at that season of the year. Two revenue cutters were then appointed to proceed to sea in search of the steamer, and Maury was requested to "furnish them with instructions."

It will be observed here that the gentleman thus appealed to was at the time engaged in his study at Washington, utterly ignorant of all that had occurred within the previous few weeks on the stormy Atlantic, except through the reports brought thence by ships. These reports furnished him with meagre data to proceed upon: simply that a crippled steamer had been seen in a certain latitude and longitude on a particular day.

But this information was sufficient for the practical man of science. Proceeding upon the supposition that the steamer had been completely disabled, he drew two lines on the chart to define the limits of her drift. This his previous knowledge of the flow of the Gulf Stream at all seasons of the year enabled him to do. Between these two lines, he said, the steamer, if she could neither steam nor sail after the gale, had drifted. And that she could neither steam nor sail he had good reason to suppose from the account of her brought in by the vessels above mentioned. A certain point was marked on the chart as being the spot where the searching vessels might expect to fall in with the wreck.

While these preparations were being made, two 
ships fell in with the wreck and relieved the crew. This, however, was not known at the time by the anxious friends on shore. The cutters sailed on their mission, and reached the indicated spot in the sea, where, of course, their assistance was now unnecessary. But when the vessels that had relieved the crew of the wreck arrived in harbour and reported where the wreck had been last seen, it was found to be within a few miles of the spot indicated by Maury!

Thus, upon very slight data, a man of science and observation was enabled, while seated in his study, to follow the drift of a wrecked vessel over the pathless deep, and to indicate to a rescue party, not only the exact course they ought to steer, but the precise spot where the wreck should be found.

The waves of the ocean are by no means so high as people imagine. Their appearance in the Atlantic or Pacific, when raised by a violent storm, is indeed very awful, and men have come to speak of them as being "mountains of water." But their sublime aspect and their tumultuous state of agitation have contributed much to deceive superficial observers as to their real height. Scientific men have measured the height of the waves.

Not many years ago a vessel, while crossing the Atlantic, was overtaken by a violent storm. The sea rose in its might; the good ship reeled under the combined influence of wind and waves. While the majority of the passengers sought refuge from the 


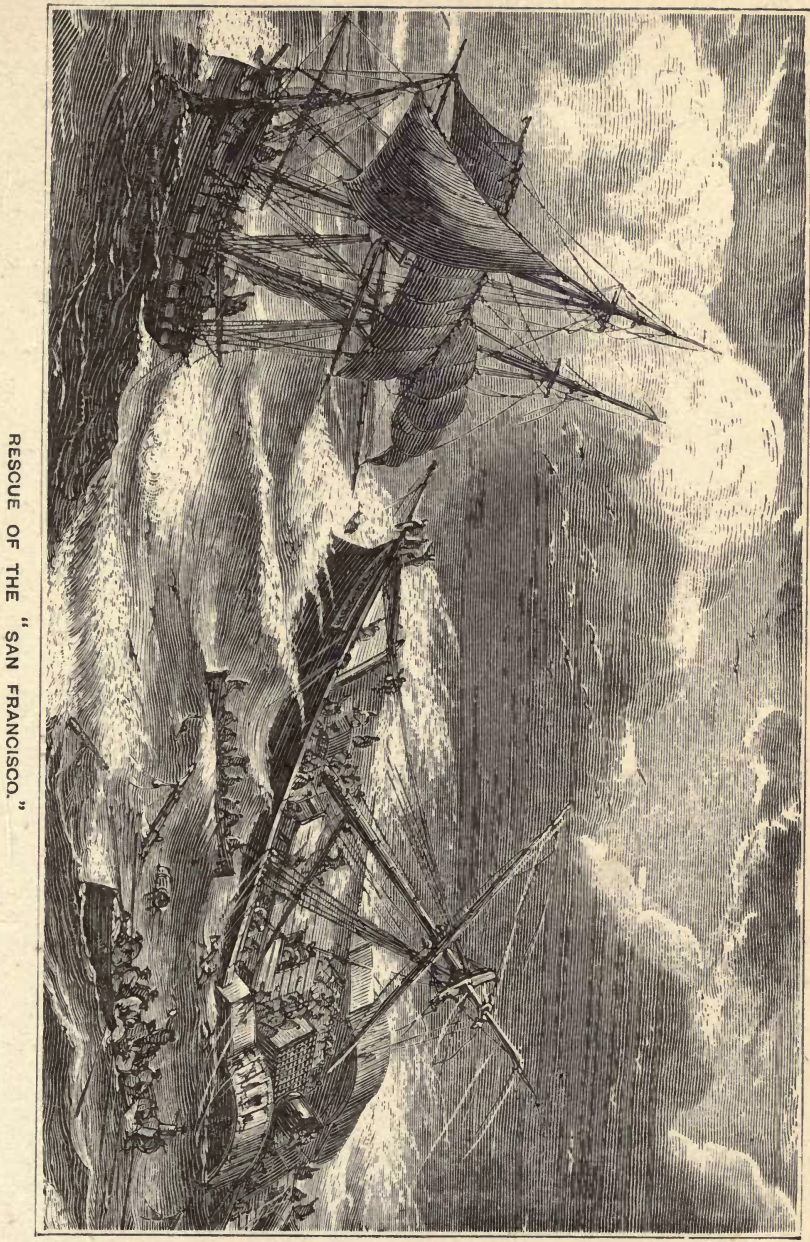



driving spray in the cabin, one eccentric old gentleman was seen skipping about the deck with unwonted activity - now on the bulwarks, now on the quarter-deck, and anon in the rigging; utterly regardless of the drenching sea and the howling wind, and seeming as though he were a species of human stormy petrel. This was the celebrated Dr. Scoresby; a man who had spent his youth and manhood in the whale-fishing; who, late in life, entered the Church, and, until the day of his death, took a special delight in directing the attention of sailors to Him whose word stilled the tempest and bade the angry waves be calm. Being an enthusiast in scientific research, Dr. Scoresby was availing himself of the opportunity afforded by this storm to measure the waves! Others have made similar measurements, and the result goes to prove that waves seldom or never rise much more than ten feet above the sea-level. The corresponding depression sinks to the same depth, thus giving the entire height of the largest waves an elevation of somewhere between twenty and thirty feet. When it is considered that sometimes the waves of the sea (especially those off the Cape of Good Hope) are so broad that only a few of them occupy the space of a mile, and that they travel at the rate of about forty miles an hour, we may have some slight idea of the grandeur as well as the power of the ocean billows. The forms represented in our illustration are only wavelets on the backs of these monster waves. 


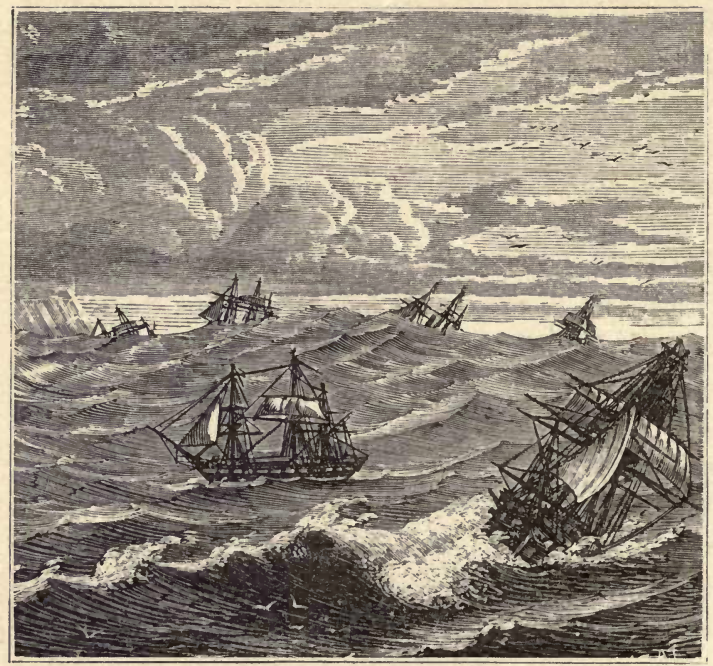

A GREAT WAVE AT THE CAPE OF GOOD HOPE.

Waves travel at a rate which increases in proportion to their size and the depth of water in which they are formed. Every one knows that on most lakes they are comparatively small and harmless. In some lakes, however, such as Lake Superior in North America, which is upwards of three hundred miles long, the waves are so formidable as to resemble those of the ocean, and they are capable of producing tremendous effects. But the waves of the sea, when roused to their greatest height, and travelling at their greatest speed, are terrible to behold. Their force is absolutely irresistible. Some- 
times waves of more than usually gigantic proportions arise, and, after careering over the broad sea in unimpeded majesty, fall with crushing violence on some doomed shore. They rush onward, pass the usual barriers of the sea-beach, and do not retire until horrible devastation has been carried far into the land.

Maury gives the following anecdote from the notes of a Russian officer, which shows the awful power of such waves:-

"On the 23rd of December 1854, at 9.45 A.M., the shocks of an earthquake were felt on board the Russian frigate Diana, as she lay at anchor in the harbour of Simoda, not far from Jeddo in Japan. In fifteen minutes afterwards (10 o'clock) a large wave was observed rolling into the harbour, and the water on the beach to be rapidly rising. The town, as seen from the frigate, appeared to be sinking. This wave was followed by another; and when the two receded, which was at fifteen minutes past ten, there was not a house, save an unfinished temple, left standing. These waves continued to come and go until half-past two P.M., during which time the frigate was thrown on her beam-ends five times; a piece of her keel, eighty-one feet long, was torn off; holes were knocked in her by striking on the bottom, and she was reduced to a wreck. In the course of five minutes the water in the harbour fell, it is said, from twenty-three to three feet, and the anchors of the ship were laid bare. 
There was a great loss of life; many houses were washed into the sea, and many junks carried upone two miles inland-and dashed to pieces on the shore. The day was beautifully fine, and no warning was given of the approaching convulsion: the sea was perfectly smooth when its surface was broken by the first wave."

Monster waves of this kind occur at regular intervals, among the islands of the Pacific, once and sometimes twice in the year; and this without any additional influence of an earthquake, at least in the immediate neighbourhood of the islands, though it is quite possible that earthquakes in some remote part of the world may have something to do with these waves.

One such wave is described as breaking on one of these islands with tremendous violence. It appeared at first like a dark line, or low cloud, or fog-bank, on the sea-ward horizon. The day was fine though cloudy, and a gentle breeze was blowing; but the sea was not rougher, or the breaker on the coral reef that encircled the island higher, than usual. It was supposed to be an approaching thunder-storm; but the line gradually drew nearer without spreading upon the sky, as would have been the case had it been a thunder-cloud. Still nearer it came, and soon those on shore observed that it was moving swiftly towards the island; but there was no sound until it reached the smaller islands out at sea. As it passed these, a cloud of white foam encircled each 
and burst high into the air. This appearance was soon followed by a loud roar, and it became evident that the object was an enormous wave. When it approached the outer reef, its awful magnitude became more evident. It burst completely over the reef at all points, with a deep, continuous roar; yet, although part of its force was thus broken, on it came, as if with renewed might, and finally fell upon the beach with a crash that seemed to shake the solid earth; then, rushing impetuously up into the woods, it levelled the smaller trees and bushes in its headlong course; and, on retiring, left a scene of wreck and desolation that is quite indescribable.

"Storm-waves," as those unusually gigantic billows are called, are said to be the result of the removal of atmospheric pressure in certain parts of the ocean over which a storm is raging. This removal of pressure allows the portion thus relieved to be forced up high above the ordinary sea-level by those other parts that are not so relieved.

The devastating effects of these storm-waves is still further illustrated by the total destruction of Coringa, on the Coromandel Coast, in 1789. During a hurricane, in December of that year, at the moment when a high tide was at its highest point, and the north-west wind was blowing with fury, accumulating the waters at the head of the bay, three monstrous waves came rolling in from the sea upon the devoted town, following each other at a short distance. The horror-stricken inhabitants had scarcely 
time to note the fact of their approach, when the first wave, sweeping everything in its passage, carried several feet of water into the town. The second swept still further in its destructive course, inundating all the low country. The third, rushing onward in irresistible fury, overwhelmed everything, submerging the town and twenty thousand of its inhabitants. Vessels at anchor at the mouth of the river were carried inland; and the sea on retiring left heaps of sand and mud, which rendered it a hopeless task either to search for the dead or for buried property.

We have spoken of waves "travelling" at such and such a rate, but they do not in reality travel at all. It is the undulation, or, so to speak, the motion of a wave, that travels; in the same manner that a wave passes from one end of a carpet to the other end when it is shaken. The water remains stationary, excepting the spray and foam on the surface, and is only possessed of a rising and sinking motion. This undulatory motion, or impulse, is transmitted from each particle of water to its neighbouring particle, until it reaches the last drop of water on the shore. But when a wave reaches shallow water it has no longer room to sink to its proper depth ; hence the water composing it acquires actual motion, and rushes to the land with more or less of the tremendous violence that has been already described.

Waves are caused by wind, which first ruffles the 
surface of the sea into ripples, and then, acting with ever-increasing power on the little surfaces thus raised, blows them up into waves, and finally into great billows. Sometimes, however, winds burst

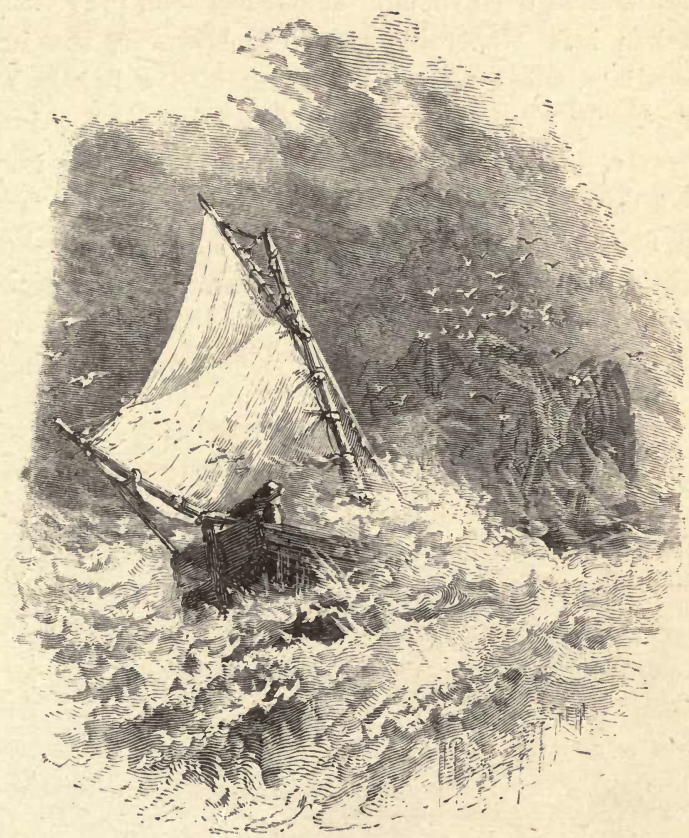

SCATTEREL INTO FOAM.

upon the calm ocean with such sudden violence that for a time the waves cannot lift their heads. The instant they do so, they are cast down and scattered 
in foam, and the ocean in a few minutes presents the appearance of a caldron of boiling milk! Such squalls are extremely dangerous to mariners, and vessels exposed to them are often thrown on their beam-ends, even though all sail has been previously taken in. Generally speaking, however, the immediate effect of wind passing either lightly or furiously over the sea is to raise its surface into waves. But these waves, however large they may be, do not affect the waters of the ocean more than a few yards below its surface. The water below their influence is comparatively calm, being affected only by ocean currents.

The tides of the sea-as the two great flowings

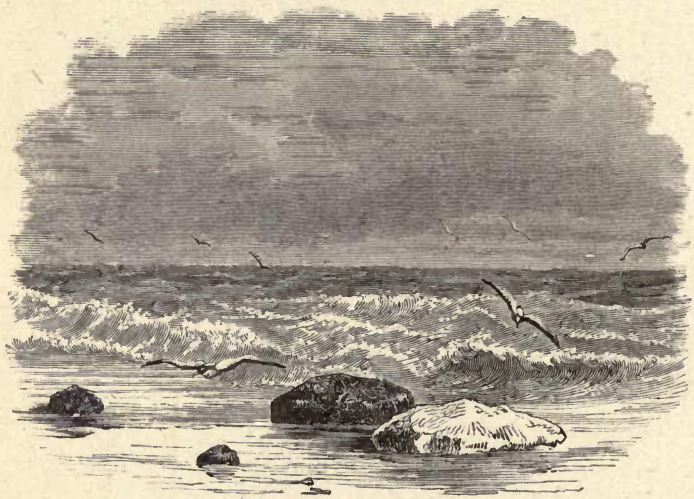

THE FLOWING TIDE.

and ebbings of the water every twenty-four hours are called-are caused principally by the attractive 
influence of the moon, which, to a small extent, lifts the waters of the ocean towards it as it passes over them, and thus causes a high wave. This wave, or current, when it swells up on the land, forms high tide. When the moon's influence has completely passed away, it is low tide. The moon raises this wave wherever it passes; not only in the ocean directly under it, but, strange to say, it causes a similar wave on the opposite side of the globe. Thus there are two waves always following the moon, and hence the two high tides in the twenty-four hours. This second wave has been accounted for in the following way: The cohesion of particles of water is easily overcome. The moon, in passing over the sea, separates the particles by her attractive power, and draws the surface of the sea away from the solid globe. But the moon also attracts the earth itself, and draws it away from the water on its opposite side, thus causing the high wave there, as represented in the diagram, fig. 1.

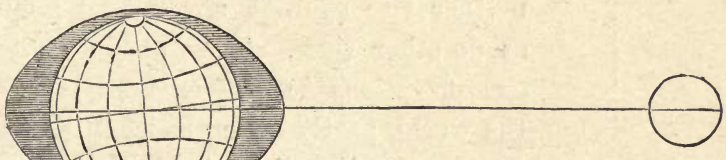

Fig. 1.

The sun has also a slight influence on the tides, but not to such an extent as the moon. When the two luminaries exert their combined influence in the same direction, they produce the phenomenon 
of a very high or spring-tide, as in fig. 2, where the tide at $a$ and $b$ has risen extremely high, while at $c$ and $d$ it has fallen correspondingly low. When
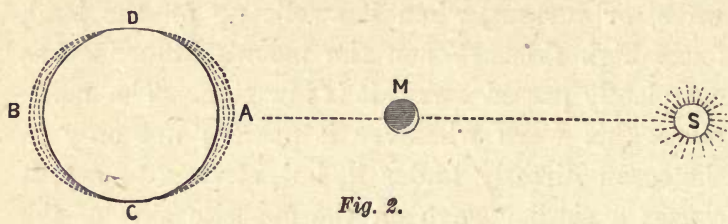

Fig. 2.

they act in opposition to each other, as at the moon's quarter, there occurs a very low or neap-tide. In fig. 3 the moon has raised high tide at $a$ and $b$, but the sun has counteracted its influence to some extent at $c$ and $d$, thus producing neap-tides, which

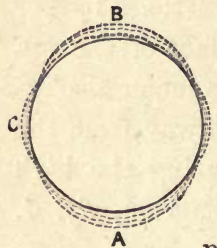

Fig. 3.

neither rise so high nor fall so low as do other tides. Tides attain various elevations in different parts of the world, partly owing to local influences. In the Bristol Channel the tide rises to nearly sixty feet, while in the Mediterranean it is extremely small, owing to the landlocked nature of that sea preventing the tidal wave from having its full effect. Up some gulfs and estuaries the tides sweep with the violence of a 
torrent, and any one caught by them on the shore would be overtaken and drowned before he could gain the dry land. In the open sea they rise and fall to an elevation of little more than three or four feet.

The value of the tides is unspeakable. They sweep from our shores pollution of every kind, purify our rivers and estuaries, and are productive of freshness and health all round the world.

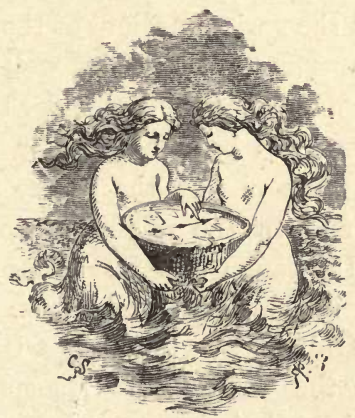




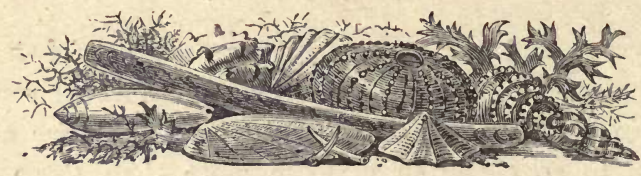

CHAPTER IV.

THE GULF STREAM-ITS NATURE-CAUSE-ILLUSTRATION-EFFECT OF SMALL TOWERS UNITED-ADVENTURES OF A PARTICLE OF WATER-EFFECT OFGULF STREAM ON CLIMATE-ITS COURSF-INFLUENCE ON NAVIGATION-SARGASSO SEA-SCIENTIFIO EFFORTS OF PRESENT DAY - WIND AND OURRENT CHARTS-EFFECTS ON COMMERCE - CAUSE OF STORMS - INFLUENCE OF GULF STREAM ON MARINE ANIMALs.

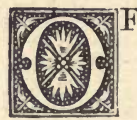

all the varied motions of the sea, the most important, perhaps, as well as the most wonderful, is the Gulf Stream. This mighty current has been likened by Maury to a " river in the ocean. In the severest droughts it never fails, and in the mightiest floods it never overflows. Its banks and its bottom are of cold water, while its current is of warm. It takes its rise in the Gulf of Mexico (hence its name), and empties into the arctic seas. Its current is more rapid than the Mississippi or the Amazon, and its volume more than a thousand times greater."

This great current is of the most beautiful indigoblue colour as far out as the Carolina coasts; and its waters are so distinctly separated from those of the 


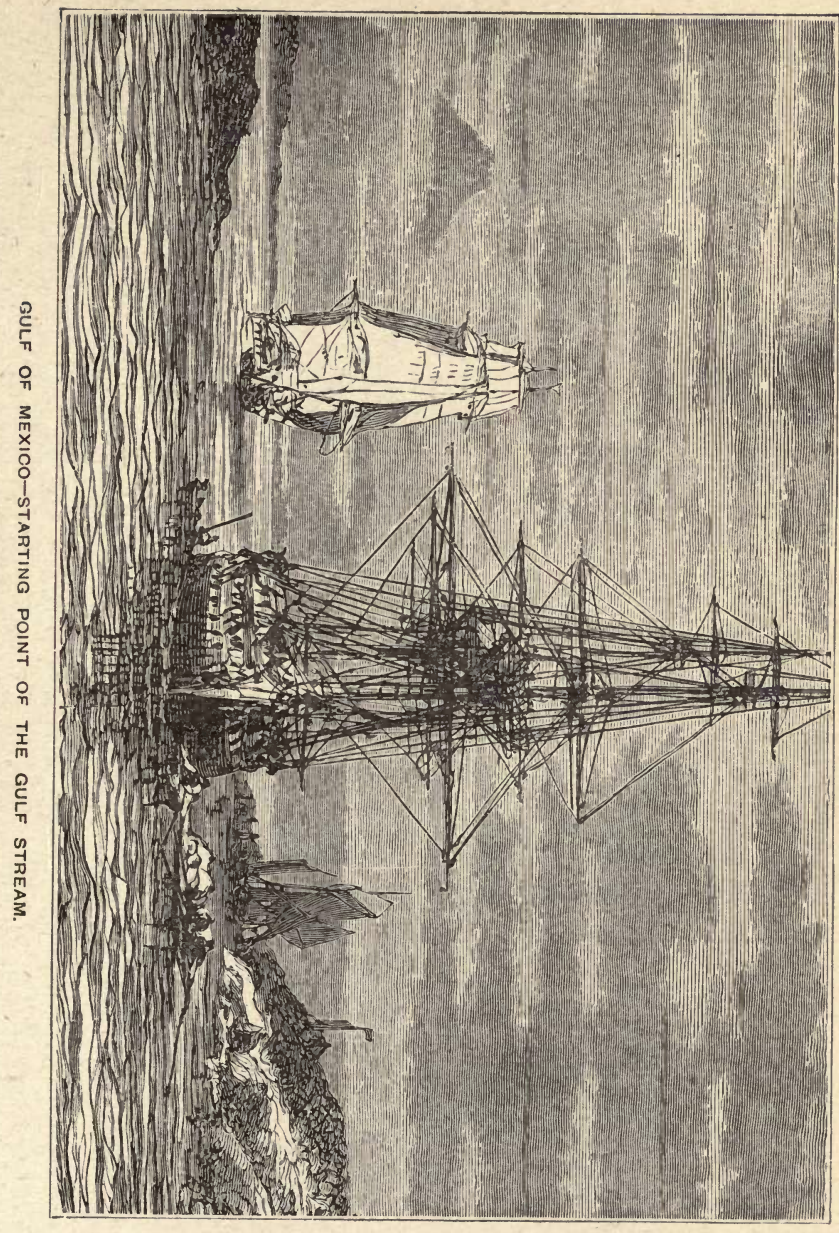



sea, that the line of demarcation may be traced by the eye. Its influences on the currents of the sea, and on the climates and the navigation of the world, are so great and important, that we think a somewhat particular account of it cannot fail to interest the reader.

The waters of the Gulf Stream are salter than those of the sea; which fact accounts for its deeper blue colour, it being well known that salt has the effect of intensifying the blue of deep water.

The cause of the Gulf Stream has long been a subject of conjecture and dispute among philosophers. Some have maintained that the Mississippi river caused it; but this theory is upset by the fact that the stream is salt-salter even than the sea-while the river is fresh. Besides, the volume of water emptied into the Gulf of Mexico by that river is not equal to the three thousandth part of that which issues from it in the form of the Gulf Stream.

Scientific men are still disagreed on this point. They all, indeed, seem to hold the opinion that difference of temperature has to do with the origination of the stream; but while some, such as Captain Maury, hold that this is the chief cause, others, such as Professor Thompson, believe the trade-winds to be the most important agent in the matter. We venture to incline to the opinion that not only the Gulf Stream, but all the constant currents of the sea are due chiefly to difference of temperature and saltness. These conditions alter the specific gravity of 
the waters of the ocean in some places more than in others ; hence the equilibrium is destroyed, and currents commence to flow as a natural result, seeking to restore that equilibrium. But as the disturbing agents are always at work, so the currents are of necessity constant. Other currents there are in the sea, but they are the result of winds and various local causes; they are therefore temporary and partial, while the great currents of the ocean are permanent, and are, comparatively, little affected by the winds. Every one knows that when a pot is put on the fire to boil, the water contained in it, as soon as it begins to get heated, commences to circulate. The heated water rises to the top, the cold descends. When heated more than that which has ascended, it in turn rises to the surface; and so there is a regular current established in the pot, which continues to flow as long as the heating process goes on. This same principle of temperature, then, is one of the causes of the Gulf Stream. The torrid zone is the furnace where the waters of the ocean are heated. But in this process of heating, evaporation goes on to a large extent; hence the waters become salter than those elsewhere. Here is another agent called into action. The hot salt waters of the torrid zone at once rush off to distribute their superabundant caloric and salt to the seas of the frigid zones; where the ice around the poles has kept the waters cold, and the absence of great heat, and, to a large extent, of evaporation, has kept them comparatively fresh. 
In fact, the waters of the sea require to be stirred, because numerous agents are at work day and night, from pole to pole, altering their specific gravity and deranging, so to speak, the mixture. This stirring is secured by the unalterable laws which the Creator has fixed for the carrying on of the processes of nature. The currents of the sea may be said to be the result of this process of stirring its waters.

It is curious and interesting to note the apparently insignificant instruments which God has seen fit to use in the carrying out of his plans. The smallest coral insect that builds its little cell in the southern seas exercises an influence in the production of the Gulf Stream. It has been said, with some degree of truth, that one such insect is capable of setting in motion the entire ocean! The coral insect has, in common with many other marine creatures, been gifted with the power of extracting from sea water the lime which it contains, in order to build its cell. The lime thus extracted leaves a minute particle of water necessarily destitute of that substance. Before that particle can be restored to its original condition of equality, every other particle of water in the ocean must part with a share of its superabundant lime! The thing must be done. That bereaved particle cannot rest without its lime. It forth with commences to travel for the purpose of laying its brother-particles under contribution; and it travels far and wide-round and round the world. Myriads upon myriads of coral insects are perpetu- 
ally engaged in thus robbing the sea water of its lime; shells are formed in a similar manner: so that

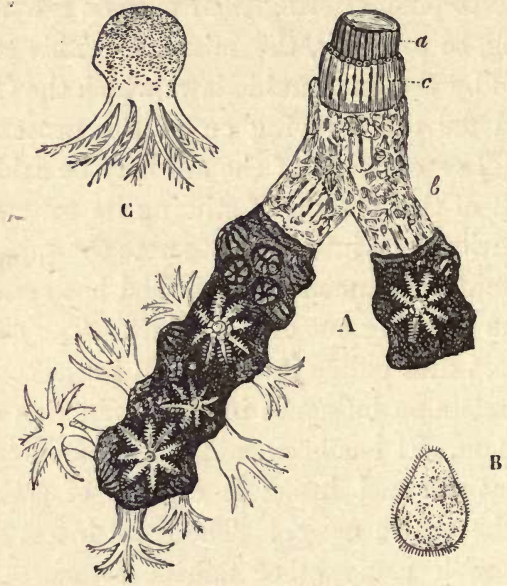

BRANCH OF RED CORAL WITH THE POLYPS IN.

A, branch of coral ; $a$, the stony stem ; $b$, vessels spreading ; $c$, vessels going in straight lines ; B, a germ set free; $c$, a full-grown polyp.

our particle soon finds itself in company with innumerable other particles of water in a like destitute condition. It rises to the surface. Here the sun, as if to compensate it for the loss of its lime, bestows upon it an unusual amount of heat; and the surrounding particles, not to be out-done, make it almost unlimited presents of salt. Full to overflow with the gifts of its new companions, it hastens to bestow of its superabundance on less favoured 
particles ; joins the great army of the ocean's currents ; enters, perchance, the Gulf of Mexico, where it is turned back, and hastens along with the Gulf Stream, with all its natural warmth of character, to ameliorate the climate of Great Britain and the western shores of Europe. Having accomplished this benevolent work, it passes on, with some of its heat and vigour still remaining, to the arctic seaswhere it is finally robbed of all its heat and nearly all its salt, and frozen into an icicle-there for many a long day to exert a chilling influence on the waters and the atmosphere around it. Being melted at last by the hot sun of the short arctic summer, it hurries back with the cold currents of the north to the genial regions of the equator, in search of its lost caloric and salt, taking in a full cargo of lime, \&c., as it passes the mouths of rivers. Arrived at its old starting-point, our wanderer receives once more heat and salt to the full, parts with its lime, and at once hastens off on a new voyage of usefulness-to give out of its superabundance in exchange for the superabundance of others: thus quietly teaching man the lesson that the true principles of commerce were carried out in the depths of the sea ages before he discovered them and carried them into practice on its surface.

Perchance another fate awaits this adventurous particle of water. Mayhap, before it reaches the cold regions of the north, it is evaporated into the clouds, and descends upon the earth in fresh and re- 
freshing rain or dew. Having fertilized the fields, it flows back to its parent ocean, laden with a superabundant cargo of earthy substances, which it soon parts with in exchange for salt. And thus on it goes, round and round the world; down in the ocean's depths, up in the cloudy sky, deep in the springs of earth; ever moving, ever active, never lost, and always fufilling the end for which it was created.

All ocean currents are composed of water in one or other of the conditions just described;-the hot and salt waters of the equator, flowing north to be cooled and freshened; the cold and fresh waters of the north, flowing south to be heated and salted. The Gulf Stream is simply the stream of equatorial hot water that flows towards the pole through the Atlantic. Its fountain-head is the region of the equator, not the Gulf of Mexico; but it is carried, by the conformation of the land, into that gulf and deflected by it, and from it out into the ocean in the direction of Europe. This stream in the Atlantic is well defined, owing to the comparative narrowness of that sea.

The Gulf Stream, then, is like a river of oil in the ocean,-it preserves its distinctive character for more than three thousand miles. It flows towards the polar regions, and the waters of those regions flow in counter-currents towards the equator, because of the fixed law that water must seek its equilibrium as well as its level, thus keeping up a continuous circulation of the hot waters towards the north and 
the cold towards the south. There are similar currents in the Pacific, but they are neither so large nor so regular as those of the Atlantic, owing to the wide formation of the basin of the former sea.

The effect of the Gulf Stream on climate is very great. The dreary fur-trading establishment of York Factory, on the shores of Hudson's Bay, is surrounded by a climate of the most rigorous character-the thermometer seldom rising up so high as zero during many months, and often ranging down so low as $50^{\circ}$ below zero, sometimes even lower, while the winter is seven or eight months long: the lakes and rivers are covered with ice upwards of six feet thick, and the salt sea itself is frozen. Yet this region lies in the same latitude with Scotland, York Factory being on the parallel of $57^{\circ}$ north, which passes close to Aberdeen! The difference in temperature between the two places is owing very much, if not entirely, to the influence of the Gulf Stream.

Starting from its caldron in the Gulf of Mexico, it carries a freight of caloric towards the North Atlantic. Owing partly to the diurnal motion of the Earth on its axis, its flow trends towards the east; hence its warm waters embrace our favoured coasts, and ameliorate our climate, while the eastern sea-bord of North America is left, in winter, to the rigour of unmitigated frost.

But besides the powerful influence of this current on climate, it exerts a very considerable influence 
on navigation. In former times, when men re. garded the ocean as a great watery waste-utterly ignorant of the exquisite order and harmonious action of all the varied substances and conditions which prevail in the sea, just as much as on the land-they committed themselves to the deep as to a blind chance, and took the storms and calms they encountered as their inevitable fate, which they had no means of evading. Ascertaining, as well as they could from the imperfect charts of those days, the position of their desired haven, they steered straight for it through fair weather and foul, regarding interruptions and delays as mere unavoidable matters of course.

But when men began to study the causes and effects of the operation of those elements in the midst of which they dwelt, they soon perceived that order reigned where before they had imagined that confusion revelled; and that, by adapting their operations to the ascertained laws of Providence, they could, even upon the seemingly unstable sea, avoid dangers and delays of many kinds, and oftentimes place themselves in highly favourable circumstances. Navigators no longer dash recklessly into the Gulf Stream, and try to stem its tide, as they did of yore; but, as circumstances require, they either take advantage of the counter-currents which skirt along it, or avail themselves of the warm climate which it creates even in the midst of winter. 


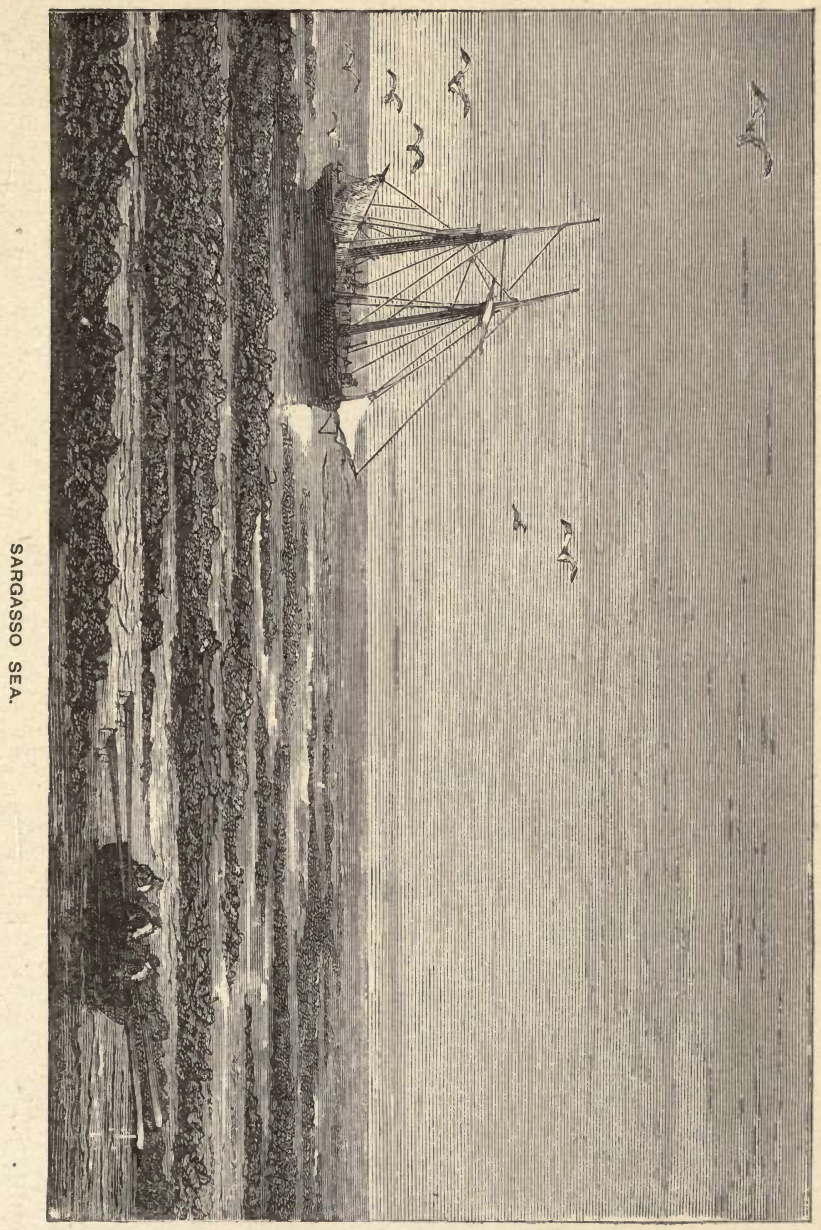



There is a certain spot in the Atlantic known by the name of the Sargasso Sea, which is neither more nor less than a huge ocean-eddy, in which immense quantities of sea-weed collect. The weed floats so thickly on the surface as to give to the sea the ap-

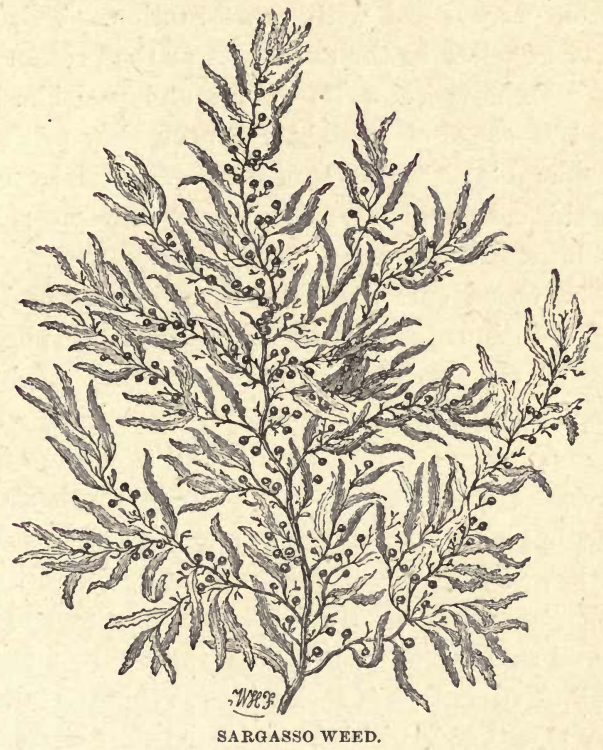

pearance of solid land; and ships find extreme diff. culty in getting through this region, which is rendered still further unnavigable by the prevalence of long-continued calms. This Sargasso Sea is of considerable extent, and lies off the west coast of Africa, a little to the north of the Cape Verd Islands. 
In former years, ships used to get entangled in this weedy region for weeks together, unable to proceed on their voyage. The great Columbus fell in with it on his voyage to America, and his followers, thinking they had reached the end of the world, were filled with constemation. This Sargasso Sea lies in the same spot at the present day, but men now know its extent and position. Instead of steering straight for port, they proceed a considerable distance out of their way, and by avoiding this calm region, accomplish their voyages with much greater speed.

The ocean currents have been, by repeated and long-continued investigation, ascertained and mapped out; so also have the currents of the atmosphere: so that, now-a-days, by taking advantage of some of these currents and avoiding others, voyages are performed, not only in much shorter time, but with much greater precision and certainty. As it was with ocean currents long ago, so was it with atmospheric. Navigators merely put to sea, steered as near as possible on their direct course, and took advantage of such winds as chanced to blow. Now they know whither to steer in order to meet with such winds and currents as will convey them in the shortest space of time to the end of their royage. The knowledge necessary to this has not been gained by the gigantic effort of one mind, nor by the accidental collocation of the results of the investigations of many ordinary minds. But a few 
master-ninds have succeeded in gathering within their own grasp the myriad facts collected by thousands of naval men, of all countries, in their various voyages; and, by a careful comparison and philosophical investigation of these facts, they have ascertained and systematized truths which were before unknown, and have constructed wind and current charts, by the use of which voyages are wonderfully shortened, commercial enterprises greatly facilitated, and the general good and comfort of nations materially advanced.

The truth of this has of late been proved by incontestable facts. For instance, one year particular note was taken of the arrival of all the vessels at the port of San Francisco, in California; and it was found that of 124 vessels from the Atlantic coast of the United States, 70 were possessed of Maury's wind and current charts. The average passage of these 70 vessels, on that long voyage round Cape Horn, was 135 days; while the average of those that sailed without the charts (that is, trusted to their own unaided wisdom and experience) was 146 days. Between England and Australia the average length of the voyage out used, very recently, to be 124 days. With the aid of these charts it has now been reduced to 97 days on the average.

The saving to commerce thus achieved is much greater than one would suppose. At the risk of becoming tedious to uninquiring readers, we will (451) 
make a brief extract from Hunt's "Merchants' Magazine" of 1854, as given in a foot-note in Maury's "Physical Geography of the Sea:"-

"Now, let us make a calculation of the annual saving to the commerce of the United States effected by these charts and sailing directions. According to Mr. Maury, the average freight from the United States to Rio Janeiro is 17.7 cents per ton per day; to Australia, 20 cts.; to California, also about $20 \mathrm{cts}$. The mean of this is a little over $19 \mathrm{cts}$. per ton per day; but, to be within the mark, we will take it at 15, and include all the ports of South America, China, and the East Indies.

"The sailing directions have shortened the passage to California 30 days; to Australia, 20 ; to Rio Janeiro, 10. The mean of this is 20 ; but we will take it at 15, and also include the above-named ports of South America, China, and the East Indies.

"We estimate the tonnage of the United States engaged in trade with these places at 1,000,000 tons per annum.

"With these data, we see that there has been effected a saving for each one of these tons, of 15 cents per day for a period of 15 days, which will give an aggregate of $\$ 2,250,000(£ 468,750)$ saved per annum. This is on the outward royage alone, and the tonnage trading with all other parts of the world is also left out of the calculation. Take these into consideration, and also the fact that there is a vast amount of foreign tonnage trading between 
these places and the United States, and it will be seen that the annual sum saved will swell to an enormous amount."

Before the existence of the Gulf Stream was ascertained, vessels were frequently drifted far out of their course in cloudy or foggy weather, without the fact being known, until the clearing away of the mists enabled the navigators to ascertain their position by solar observation. Now, not only the existence, but the exact limits and action of this stream are known and mapped; so that the current, which was formerly a hindrance to navigation, is now made to be a help to it. The line of demarcation between the warm waters of the Gulf Stream and the cold waters of the sea is so sharp and distinct, that by the use of the thermometer the precise minute of a ship's leaving or entering it can be ascertained. And by the simple application of the thermometer to the Gulf Stream the average passage from England to America has been reduced from upwards of eight weeks to little more than four !

But this wonderful current is useful to navigators in more ways than one. Its waters, being warm, carry a mild climate along with them through the ocean even in the depth of winter, and thus afford a region of shelter to vessels when attempting to make the Atlantic coast of North America, which at that season is swept by furious storms and chilled by bitter frosts. The Atlantic coasts of the United States are considered to be the most stormy in 
the world during winter, and the difficulty of making them used to be much greater in former days than now. The number of wrecks that take place off the shores of New England in mid-winter is frightful. All down that coast flows one of the great cold currents from the north. The combined influence of the cold atmosphere above it, and the warm atmosphere over the Gulf Stream, far out at sea, produces terrific gales. The month's average of wrecks off that coast has been as high as three a day. In making the coast, vessels are met frequently by snow-storms, which clothe the rigging with ice, rendering it unmanageable, and chill the seaman's frame, so that he cannot manage his ship or face the howling blast. Formerly, when unable to make the coast, owing to the fury of these bitter westerly gales, he knew of no place of refuge short of the West Indies, whither he was often compelled to run, and there await the coming of genial spring ere he again attempted to complete his voyage. Now, however, the region of the Gulf Stream is sought as a refuge. When the stiffened ropes refuse to work, and the ship can no longer make head against the storm, she is put about and steered for the Gulf Stream. In a few hours she reaches its edge, and almost in a moment afterwards she passes from the midst of winter into a sea of summer heat! "Now," as Maury beautifully expresses it, "the ice disappears from her apparel ; the sailor bathes his limbs in tepid waters. Feeling hịmself 
invigorated and refreshed with the genial warmth about him, he realizes out there at sea the fable of Antæus and his mother Earth. He rises up and attempts to make his port again, and is again, perhaps, as rudely met and beat back from the northwest; but each time that he is driven off from the contest, he comes forth from this stream, like the ancient son of Neptune, stronger and stronger, until, after many days, his freshened strength prevails, and he at last triumphs, and enters his haven in safety-though in this contest he sometimes falls to rise no more, for it is terrible."

The power of ocean currents in drifting vessels out of their course, and in sweeping away great bodies of ice, is very great; although, from the fact that there is no land to enable the eye to mark the flow, such drifts are not perceptible. One of the most celebrated drifts of modern times, and the most astonishing on account of its extent, was that of the Fox in Baffin's Bay in the year 1857, a somewhat detailed account of which will be found in a succeeding chapter.

The Gulf Stream is the cause of many of the most furious storms. The fiercest gales sweep along with it, and it is supposed that the spring and summer fogs of Newfoundland are caused by the immense volumes of warm water poured by it into the cold seas of that region. We are told that Sir Philip Brooke found the temperature of the sea on each side of this stream to be at the freezing-point, while 
that of its waters was $80^{\circ}$. From this it may be easily seen how great are the disturbing influences around and above it; for, as the warm and moist atmosphere over it ascends in virtue of its lightness, the cold air outside rushes in violently to supply its place, thus creating storms.

The warm waters of this stream do not, it is believed, anywhere extend to the bottom of the sea. It has been ascertained, by means of the deep-sea thermometer, that they rest upon, or rather flow over, the cold waters which are hastening from the north in search of those elements which, in their wanderings, they have lost. As cold water is one of the best non-conductors of heat, the Gulf Stream is thus prevented from losing its caloric on its way across the Atlantic to ameliorate the climates of the western coasts of Europe, and moderate the bitterness of the northern seas. Were it otherwise, and this great stream flowed over the crust of the Earth, so much of its heat would be extracted, that the climates of France and our own islands would probably resemble that of Canada. Our fields would be covered, for two, three, or four months, with deep snow; our rivers would be frozen nearly to the bottom; our land traffic would perhaps be carried on by means of sledges and carioles; our houses would require to be fitted with double window-frames and heated with iron stoves; and our garments would have to be made of the thickest woollens and the warmest furs! 
The presence and the unchanging regularity of these great hot and cold currents in the ocean is indicated very clearly by the living inhabitants of the deep. These, as certainly as the creatures of the land, are under the influence of climate; so much so, that many of them never quit their native region in the sea. All the beautiful and delicate marine creatures and productions which dwell in the warm waters of the south are utterly absent from those shores which are laved by the cold currents that descend from the north; while, owing to the influence of the Gulf Stream, we find many of those lovely and singular creatures upon our comparatively northern shores. Of late years, as every one knows; we have all over the land been gathering these marine gems, and studying their peculiar habits with deep interest in that miniature ocean the aquarium. In the same parallel on the other side of the Atlantic none of these little lovers of heat are to be found.

On the other hand, the whale, delighting as it does to lave its huge warm-blooded body in iced water, is never found to enter the Gulf Stream. Thus these fish, to some extent, define its position. Other fish there are which seem to resemble man in their ability to change their climate at will ; but, like him also, they are apt in so doing to lose their health, or, at least, to get somewhat out of condition. Some kinds of fish, when caught in the waters off Virginia and the Carolinas, are excellent for the 
table; but the same species, when taken off the warm coral banks of the Bahamas, are scarcely worth eating. In fact, we see no reason for doubting that when these fish find their health giving way in the warm regions of the south, they seek to reinvigorate themselves by change of water; and, quitting for a time the beauteous coral groves, spend a few of the summer-months of each year in gambolling in the cool regions of the north, or, what is much the same thing, in those cool currents that flow from the north in clearly defined channels.

Besides its other useful and manifold purposes, the Gulf Stream would seem to be one of the great purveyors of food to the whales. Sea-nettles, or medusæ, are well known to constitute the principal food of that species of whale which is termed the right whale. Navigators have frequently observed large quantities of these medusæ floating along with the Gulf Stream; and one sea captain in partic-

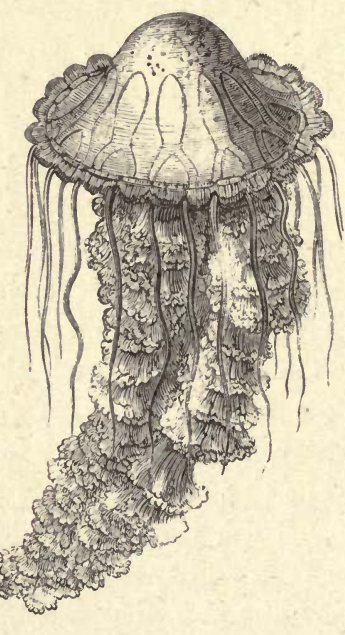

A MEdUSA. ular fell in with an extraordinarily large quantity of them, of a very peculiar species, off the coast of 
Florida. As we have said, no whales ever enter the warm waters of the Gulf Stream; therefore, at that time at least, the leviathan could not avail himself of this rich provision. The captain referred to was bound for England. On his return voyage he fell in with the same mass of medusæ off the Western Islands, and was three or four days in sailing through them. Now, the Western Islands is a great place of resort for the whale, and thither had the Gulf Stream been commissioned to convey immense quantities of its peculiar food.

We might enlarge endlessly on this great ocean current, but enough, we think, has been said to show that the sea, instead of being an ocean of unchanging drops, driven about at random by the power of stormy winds, is a mighty flood flowing in an appointed course-steady, regular, and systematic in its motions, varied and wonderful in its actions, benign and sweet in its influences, as it sweeps round and round the world, fulfilling the will of its great Creator.

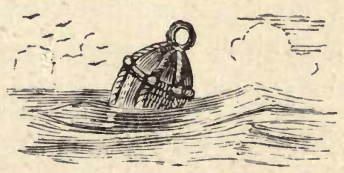




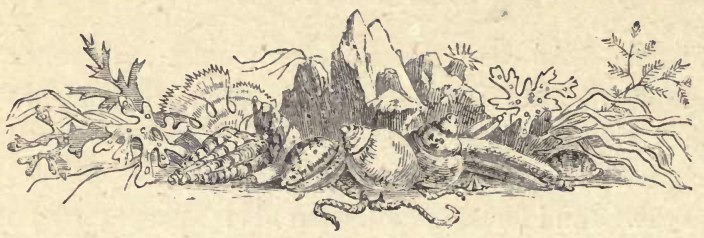

CHAPTER V.

THE ATMOSPHERIC OCEAN-ORDER IN ITS FLOW-OFFICES OF THE ATMOSPHERE-DANGERS LESSENED BY SCIENOE-CURRENTS OF ATMOSPHERE-CAUSE OY WIND-TWO GREAT CURRENTS-DISTURBING INFLUENUES - CALMS - VARIABLE WINDS - CAUSES THEREOF-LOCAL CAUSES OF DISTURBANCE-GULF STREAM'S INFLUENCE-THE WINDS MAPPED OUT-A SUPPOSED CASF.

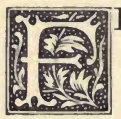

ISH are not the only creatures that live in an ocean. We, the human inhabitants of this Earth, dwell at the bottom of an ocean of air, which encircles the globe. Fish, however, have the advantage of us, inasmuch as they can float and dart about in their ocean, while we, like the crabs, can only crawl about at the bottom of ours.

This atmospheric ocean is so closely connected with the sea, and exercises upon it so constant, universal, and important an influence, that to omit, in a work of this kind, very special reference to the winds, would be almost as egregious an oversight as to ignore the waves.

Wind, or atmospheric air in motion, is the cause of storms, of waves, of water-transport through the sky, and of an incalculable amount of varied phe- 
nomena on land and sea. Without this great agent no visible motion would ever take place in the sea. Its great currents, indeed, might flow on (though even that is questionable), but its surface would never present any other aspect than that of an unruffled sheet of clear glass. The air, then, becomes in this place an appropriate subject of consideration. The Voice of Ocean has something very emphatic to say about the atmosphere.

In regard to its nature, it is sufficient to say that atmospheric air is composed of two gases-oxygen and nitrogen. Like the sea, the atmosphere is an ocean which flows, not in chaotic confusion, but in regular, appointed courses; acting in obedience to the fixed, unvarying laws of the Almighty, and having currents, counter-currents, and eddies also, just like the watery ocean, which exercise a specific and salutary influence where they exist.

The offices of the atmosphere are thus quaintly enumerated by Maury:- "The atmosphere is an envelope or covering for the distribution of light and heat over the Earth; it is a sewer into which, with every breath we draw, we cast vast quantities of dead animal matter; it is a laboratory for purification, in which that matter is recompounded, and wrought again into wholesome and healthful shapes ; it is a machine for pumping up all the rivers from the sea, and for conveying the water from the ocean to their sources in the mountains. It is an inexhaustible magazine, marvellously stored; and 
upon the proper working of this machine depends the well-being of every plant and animal that inhabits the Earth."

An element whose operations are so manifold and so important could not fail to engage the study of philosophic men in all ages; but so difficult has been that study that little progress was made until very recently, when men, acting in unison in all parts of the world, have, by collating their observations, become acquainted with some of those laws which govern the atmosphere, and direct its courses and velocities.

In early ages very little indeed was known about the wind beyond the palpable facts of its existence, its varied condition, and its tremendous power; and men's observations in regard to it did not extend much beyond the noting of those peculiar and obvious aspects of the sky which experience taught them to regard as evidences of approaching storm. But, although such aspects of the heavens were, and always will be, pretty safe and correct indicators of the weather, they are by no means infallible; and in some regions and under certain conditions they are wanting altogether.

When the sea captain observes a lowering aspect of the sky, with, it may be, a dark line above the distant edge of the sea, he knows-however calm and unruffled may be the ocean around him-that wind may be expected; and, calling the crew, he orders sail to be taken in, and preparation made 


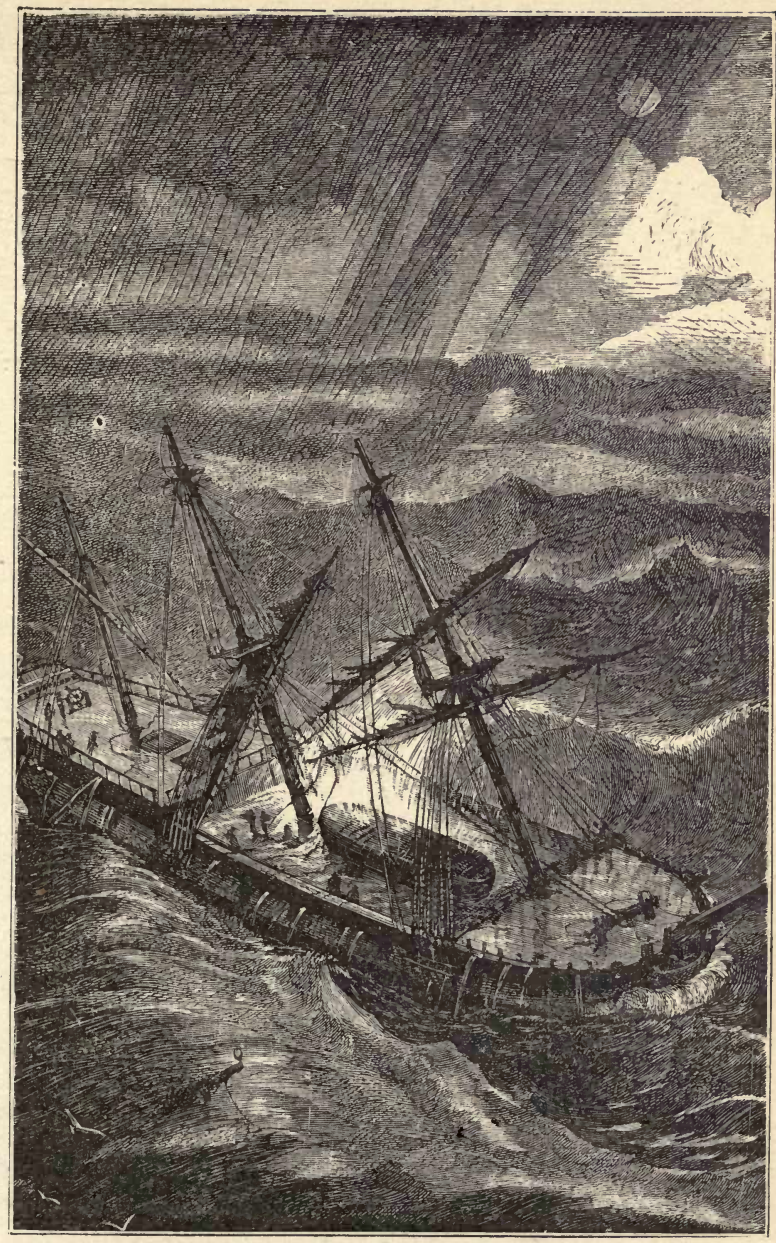

A HURRICANE AT SEA. 

for the approaching breeze. But there are times when no such warning is given-when the atmosphere is perfectly still, the sea calm as glass, and the vessel floats motionless with her sails hanging idly from the yards, as if she were

"A painted ship upon a painted ocean."

Suddenly, and before preparation can be made to withstand it, the hurricane bursts in appalling fury over the sea: the sails are blown to ribbons; the masts, perhaps, broken down; and frequently the vessel itself overwhelmed and sent to the bottom. Many a gallant ship, which has left the harbour ably commanded and well manned, and never more been heard of, has doubtless gone down in sudden storms such as those we have referred to.

But the inventions of science have now very much lessened the danger of these storms. The barometer, by the sudden fall of its column of mercury, tells, as plainly and certainly as if it spoke with an audible voice, that a storm is approaching, even though all nature should appear to contradict the fact by its calm and serene aspect; so that the crew thus warned have time to furl the sails, fasten down the hatches, and otherwise prepare to face the impending danger.

The atmosphere flows in a grand harmonious system of currents and counter-currents, with their corresponding eddies, just like the ocean; and the grand final results of its varied action are, to equalize 
in some degree the temperatures of the world, to carry off and distribute moisture where it is required, to sweep away noxious vapours, and generally to ventilate the Earth and gladden the heart of man.

The primary cause of all wind is the combined action of heat and cold. If the world were heated with perfect equality all round, there would be, as far at least as heat is concerned, a perfect and permanent stagnation of the atmosphere; and this would speedily result in the destruction of every living thing. But by the varied and beautiful arrangements which the Almighty has made in nature he has secured a regular flow of atmospheric currents, which will continue unalterably to move as long as the present economy of things exists. The intense and constant action of the sun's rays in the torrid zone produces great heat, while the less powerful and frequently interrupted influence of his rays in the frigid zones induces extreme cold. Hence we have in one region heated air, in another cool air. Now, the effect of heat upon air is to expand it, make it light, and cause it to rise. The moment it does so, the cold air rushes in to supply its place; and this rushing in of the cold air is what we call wind.

It may surprise many people to be told that there are only two great and never-ceasing courses of the winds of this world-namely, north and south. They flow perpetually from the equator to the poles, and from the poles to the equator. All the irregularities and interruptions that we observe are 
mere temporary and partial deflections from this grand course. The heated air at the equator rises continually and flows in an upper current towards the pole, getting gradually cooled on its way north. That from the pole flows in an under current towards the equator, getting gradually heated on its way south. We speak only of the Northern Hemisphere, for the sake of simplifying explanation, - the action of the great wind-current in the Southern Hemisphere is precisely similar.

But our broad simple statement about the upper current from the equator, and the under current from the pole, requires a slight modification, which we thought it best not to mingle with the statement itself. The heated air from the equator does indeed commence to flow in an upper current, and the cooled air from the pole in an under current; but, as the upper currents of air are speedily cooled by exposure to space, and the under currents are heated by contact with the earth's surface, they constantly change places-the lower current becoming the upper, and vice versâ. But they do not change direction. The Equatorial Current ascends, rushes north to a point about lat. $30^{\circ}$, where, being sufficiently cooled, it swoops down, and continues its northward rush along the earth. At another point the Polar Current quits the earth, and soaring up, in consequence of its recently acquired heat, becomes the upper current. This change in the two currents takes place twice in their course. 
Of course, the effect of these changes is to produce north winds in one latitude and south winds in another, according to the particular wind (equatorial or polar) that happens to be in contact with the earth. At the points where these two currents cross, in changing places, we necessarily have calms, or conflicting and variable winds.

Here, then, we have the first of the constant disturbing causes, and of apparent irregularities, in the winds. The Earth, as every one knows, whirls rapidly on its axis from west to east. At the equator the whirl is so rapid that the atmosphere does not at once follow the Earth's motion. It lags behind, and thus induces an easterly tendency to the winds, so that a north wind becomes a northeast, and a south wind a south-east. Here we have another constant cause of variation from the northerly and southerly flow. We thus account for an easterly tendency to the winds, but whence their westerly flow? It is simply explained thus :-

The motion of the Earth is greatest at the equator. It diminishes gradually towards the poles, where there is no motion at all. The atmosphere partakes of the Earth's motion when in contact with it; and when thrown upwards by heat, as at the equator, it keeps up the motion for some time, as it meets with no resistance there. Bearing this in mind, let us now follow a gush of warm atmosphere from the equator. It rushes up, and, turning north and south, seeks the poles. We follow the northern 
division. When it left the Earth it had acquired a very strong motion towards the east, - not so great as that of the Earth itself. but great enough to be equivalent to a furious gale from west to east. If we suppose this air to redescend whence it rose, it would, on reaching the equator, find the Earth going too fast for it. It would lag a little, and become a gentle easterly breeze. But now, throw aside this supposition;-our breeze rushes north; at lat. $30^{\circ}$ it has got cooled, and swoops down upon the Earth; but the Earth at this latitude is moving much slower than at the equator; the wind, however, has lost little or none of its easterly velocity. On reaching the Earth it rushes east much faster than the Earth itself, and thus becomes a westerly gale.

There are, however, many other agents at work, which modify and disturb what we may call the legitimate flow of the wind; and these agents are diverse in different places, so that the atmosphere is turned out of a straight course, and is caused to deflect, to halt, and to turn round : sometimes sweeping off, as if in haste; at other times pausing, as if in uncertainty; and often whirling round, as if in mad confusion. To the observer, who sees only the partial effects around his own person, all this commotion seems but the disorderly action of blind chance; but to the eye of Him who sees the end from the beginning, we may certainly conclude that naught is seen but order and perfect harmony. And to the eye of Science there now begins to appear, in what was 
formerly an atmospheric chaos, an evidence of design and system, which is not, indeed, absolutely clear, - but which is nevertheless abundantly perceptible to minds that cannot hope in this life to see otherwise than "through a glass, darkly."

The causes which modify the action of the winds are, as we have said, various. Local causes produce local currents. A clear sky in one region allows the sun's rays to pour upon, let us say, the ocean, producing great heat; the result of which is evaporation. Aqueous vapour is very light, therefore it rises; and in doing so the aqueous particles carry the air up with them, and the wind necessarily rushes in below to supply its place. The falling of heavy rain, in certain conditions of the atmosphere, has the effect of raising wind. Electricity has also, in all probability, something to do with the creation of motion in the atmosphere. Now, as these are all local causes, they produce local —or what, in regard to the whole atmosphere, may be termed irregulareffects. And as these causes or agents are in ceaseless operation at all times, so their disturbing influence is endless; and hence the apparent irregularity in the winds.

But these causes are themselves, not less than their results, dependent on other causes or laws, the workings of which are steady and unvarying; and the little irregularities that appear to us in the form of fluctuating and changing winds and calms may be compared to the varying ripples and shifting eddies 
of a river, whose surface is affected by the comparatively trifling influences of wind, rain, and drought, but whose grand onward course is never for a single moment interrupted.

Among these disturbing influences, the Gulf Stream is a very important one. It is constantly sending up large volumes of steam, which, rising into the air, induce a flow of wind from both sides towards its centre. And many of the storms that arise in other parts of the Atlantic make for this stream, and follow its course.

So much has been ascertained by scientific investigation of the winds, that we can now distinctly map out the great belts or currents which pass right round the world. We can tell in which parallels winds with easting, and in which those with westing, in them, will be most frequently found; and by directing our course to such places; we can to a certain extent count upon profiting by the winds that will be most suitable. Before the facts of atmospheric circulation were known, mariners sailed by chance. If they happened to get into the belt of wind that suited them, their voyages were favourable; if they got into the wrong region, their voyages were unfavourable,-that was all. But they had no idea that there was any possibility of turning the tables, and, by a careful investigation of the works of the Creator, coming at last to such knowledge as would enable them to reduce winds and waves, in a great degree, to a state 
86 ATMOSPHERIC PHENOMENA LONG UNKNOWN.

of slavery, instead of themselves being at their mercy.

The world may be said to be encircled by a succession of belts of wind, which blow not always in the same direction, but almost invariably with the same routine of variations. A vessel sailing from north to south encounters these belts in succession. To mariners of old, these varying winds seemed to blow in utter confusion. To men of the present time, their varied action is counted on with some degree of certainty. The reason why men were so long in discovering the nature of atmospheric circulation was, that they were not sufficiently alive to the immense value of united effort. They learned wisdom chiefly from personal experience-each man for himself; and in the great majority of cases, stores of knowledge, that would have been of the utmost importance to mankind, were buried with the individuals who had laid them up. Moreover, the life of an individual was too short, and his experience too limited, to enable him to discover any of the grand laws of Nature; and as there was no gathering together of information from all quarters, and all sorts of men, and all seswons (as there is now), the knowledge acquired by individuals was almost always lost to the world. Thus men were ever learning, but never arriving at a knowledge of the truth.

May we not here remark, that this evil was owing to another evil -namely, man's ignorance of, 
or indifference to, the duty of what we may term human communication? As surely as gravitation is an appointed law of God, so surely is it an appointed duty that men shall communicate their individual knowledge to each other, in order that the general knowledge of the species may advance; and just in proportion to the fidelity with which men obey this duty - the care and ability with which they collate and systematize and investigate their knowledge - will be the result of their efforts.

In order to make the above remarks more clear as regards atmospheric phenomena, let us suppose the case of a sailor who makes the same voyage every year, but not precisely at the same time each year (and it must be remembered that the rigid punctuality at starting which now holds good did not exist in former times). In his first voyage he had to cross, say, four of the wind-belts. While crossing belt number one, he experiences south-west winds chiefly, and, being an observant man, notes the fact. In belt number two he encounters westerly winds. In number three he is in a region of variable winds and calms. In this region the winds blow all round the compass, averaging about three months from each quarter. But our sailor does not know that; he does not stay there all the year to make notes; he passes on, having recorded his experience. In crossing belt number four, he finds the prevailing winds to be easterly.

Next year he sets forth again; but merchants 
are not always punctual. The lading cannot be completed in time, or adverse winds render the setting sail unadvisable. At length, after a month or six weeks' delay, he proceeds on his voyage, and finds belt number one perhaps much the same as last year. He congratulates himself on his good fortune, and notes his observations; but in belt number two, the wind is somewhat modified, owing to its being later in the season,-it is rather against him. In number three it is right in his teeth, whereas last year it was quite in his favour. In number four, which we will suppose is the tradewind belt (of which more hereafter), he finds the wind still easterly. Here, then, is the groundwork of confusion in our sailor's mind. He has not the remotest idea that in belt number one the wind blows chiefly, but not always, in one particular direction; that in number four it blows invariably in one way; and that in number three it is regularly irregular. In fact, he does not know that such belts exist at all, and his opportunities of observing are not sufficiently frequent or prolonged to enable him to ascertain anything with certainty.

Now, when we remember that in this imperfect experience of his he is still further misled by his frequently encountering local. vicissitudes-such as storms and calms resulting from local and temporary causes-we see how confusion becomes worse confounded. No doubt he does gather some few crumbs of knowledge; but he is called on, perhaps, 
to change his scene of action. Another ship is given to him, another route entered on, and he ceases altogether to prosecute his inquiries in the old region. Or old age comeśs on ; and even although he may have been beginning to have a few faint glimmerings as to laws and systems in his mind, he has not the power to make much of these. $\mathrm{He}$ dies; his knowledge is, to a very large extent, lost, and his log-books disappear, as all such books do, nobody knows or cares where.

Now this state of things has been changing during the last few years. Log-books are collected in thousands. The experiences of many men, in reference to the same spots in the same years, months, and even hours, are gathered, collated, and compared; and the result is, that although there are conflicting elements and contradictory appearances, order has been discovered in the midst of apparent confusion, and scientific men have been enabled to pierce through the chaos of littlenesses by which the world's vision has been hitherto obscured, and to lay bare many of those grand progressions of nature which move unvaryingly with stately step through space and time, as the river, with all its minor eddies and counter-currents, flows with unvarying regularity to the ocean. 


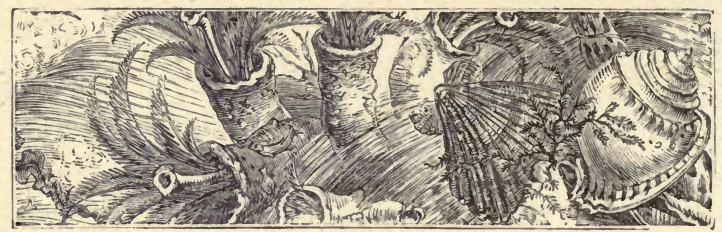

CHAPTER VI.

TRADE-WINDS-STORMS-THEIR EFFECTS-MONSOONS-THEIR VALUE -LAND AND SEA BREEZES- EXPERIMENTS- HURRICANESTHOSE OF 1831-ROTATORY STORMS-THEIR TERRIBLE EFFECTS -CHINA SEAS-HURRICANE IN 1837-WHIRLWINDS-WEIGHT OF ATMOSPHERE-VALUE OF ATMOSPHERIO CIROULATIONHEIGHT OF ATMOSPHERE.

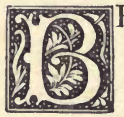

EFORE proceeding to speak of the power and the dreadful effects of wind, it is necessary,to say a word or two about the trade-winds.

It is supposed that the "trades" derived their name from the fact of their being favourable to navigation, and, therefore, to trade. They consist of two belts of wind, one on each side of the equator, which blow always in the same direction.

In the last chapter it was explained that the heated atmosphere at the equator rises, and that the cooler atmosphere from the poles rushes in to supply its place. That which I'shes from the south pole is, of course, a south wind, that from the north pole a north wind; but, owing to the Earth's motion on its axis from west to east, the 
one becomes a north-east, the other a south-east wind. These are the north-east and the southeast "trades." They blow regularly-sometimes gently, sometimes fiercely-all the year round. Between the two is a belt of calms and changeable

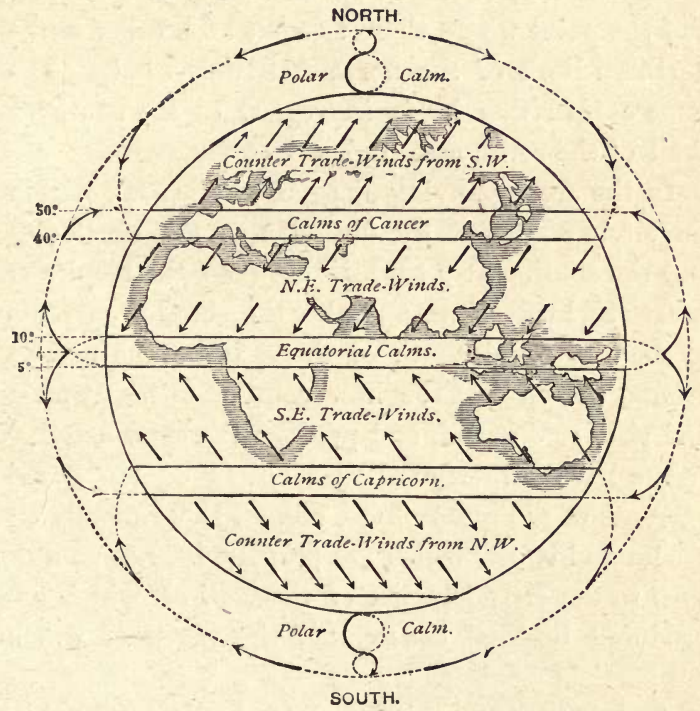

DIAGRAM OF THE TRADE-WINDS.

breezes, varying from 150 to 500 miles broadaccording to the time of the year-where there are frequent and violent squalls, of very short duration, accompanied with heavy rains. This region is called by seamen the "doldrums," and considerable 
trouble and difficulty do ships experience in crossing it.

It has already been explained that about lat. $30^{\circ}$, the upper current of wind from the south descends. At the same point the upper current from the north also descends. They cut through each other, and the point where these two cut each other is the northern limit of the north-east trade-winds. The same explanation holds in regard to the southern limit of the south-east trades.

In the accompanying diagram the arrows within the circle point out the direction of the north-east and the south-east "trades" between the tropics of cancer and capricorn, and also the counter currents to the north and south of these, while the arrows around the circle show how counter currents meet and rise, or descend, and produce the calm belts.

We have hitherto enlarged chiefly on the grand currents of the atmosphere, and on those modifying causes and effects which are perpetual. Let us now turn to the consideration of those winds which are produced by local causes, and the effects of which are partial.

And here we are induced to revert to the Gulf Stream, which has been already referred to as a local disturber of the regular flow of the atmosphere. This immense body of heated water, passing through cold regions of the sea, has the effect of causing the most violent storms. The hurricanes of the West Indies are among the most violent in 
the world. We have read of one so violent that it "forced the Gulf Stream back to its sources, and piled up the water in the Gulf to the height of thirty feet. A vessel named the Ledbury Snow attempted to ride it out. When it abated, she found herself high up on the dry land, having let go her anchor among the tree-tops of Elliott's quay! The Florida quays were inundated many feet; and it is said the scene presented in the Gulf Stream was never surpassed in awful sublimity on the ocean. The water thus dammed up rushed out with frightful velocity against the fury of the gale, producing a sea that beggared description."

The monsoons of the Indian Ocean are among the most striking and regular of the locally-caused winds. Before touching on their causes, let us glance at their effects. They blow for nearly six months in one direction, and for the other six in the opposite direction. At the period of their changing, terrific gales are frequent-gales such as we, in our temperate regions, never dream of.

What is termed the rainy season in India is the result of the south-west monsoon, which for four months in the year deluges the regions within its influence with rain.

The commencement of the south-west monsoon is described as being sublime and awful beyond description. Before it comes, the whole country is pining under the influence of long-continued drought and heat; the ground is parched and rent; scarcely 
a blade of verdure is to be seen except in the beds of rivers, where the last pools of water seem about to evaporate, and leave the land under the dominion of perpetual sterility. Man and beast pant for fresh air and cool water; but no cool breeze comes. A blast, as if from the mouth of a furnace, greets the burning cheek; no blessed drops descend; the sky is clear as a mirror, without a single cloud to mitigate the intensity of the sun's withering rays. At last, on some happy morning, small clouds are seen on the horizon. They may be no bigger than a man's hand, but they are blessed harbingers of rain. To those who know not what is coming, there seems at first no improvement on the previous sultry calms. There is a sense of suffocating heat in the atmosphere; a thin haze creeps over the sky, but it scarcely affects the broad glare of the sun.

At length the sky begins to change. The horizon becomes black. Great masses of dark clouds rise out of the sea. Fitful gusts of wind begin to blow, and as suddenly to cease; and these signs of coming tempest keep dallying with each other, as if to tantalize the expectant creation. The lower part of the sky becomes deep red, the gathering clouds spread over the heavens, and a deep gloom is cast upon the earth and sea.

And now the storm breaks forth. The violent gusts swell into a continuous, furious gale. Rain falls, not in drops, but in broad sheets. The black sea is crested with white foam, which is quickly 


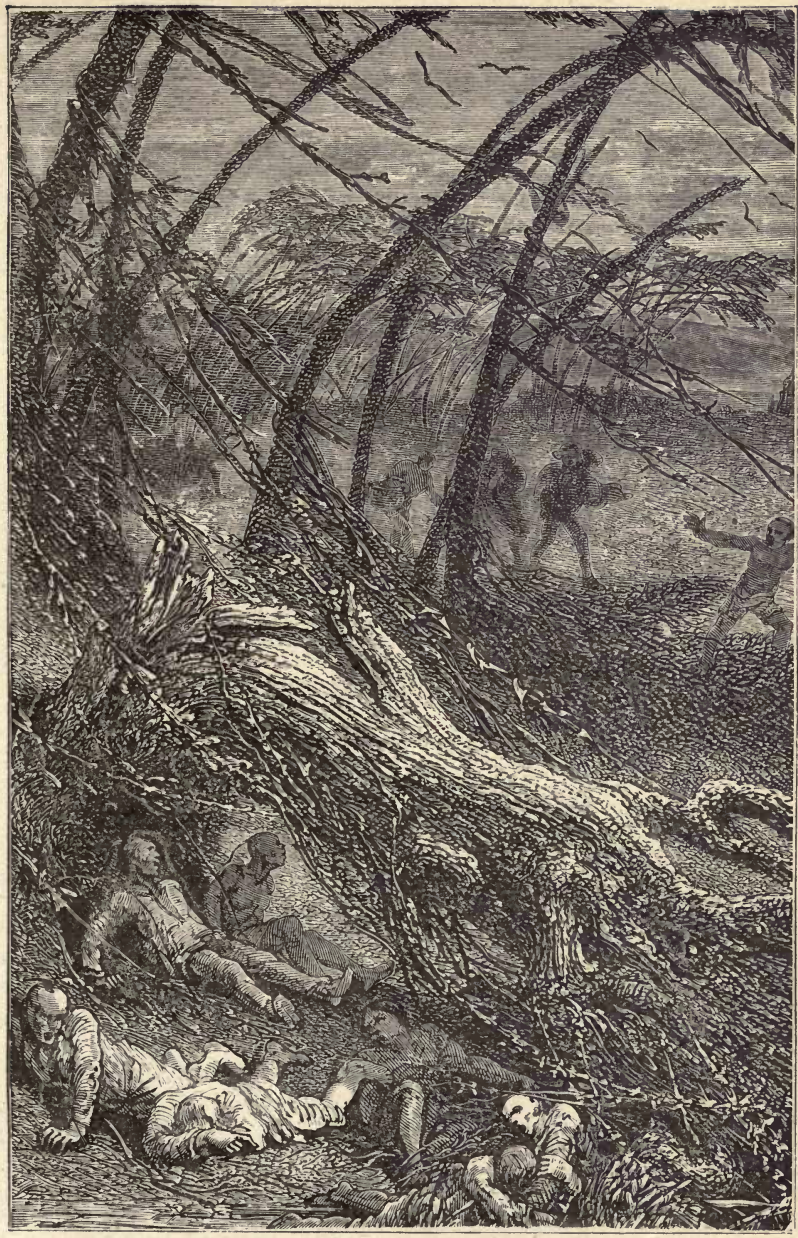

A HURRICANE ON LAND. 

swept up and mingled with the waters above; while those below heave up their billows, and rage and roar in unison with the tempest. On the land everything seems about to be uprooted and hurled to destruction. The tall straight cocoa-nut trees are bent over till they almost lie along the ground; the sand and dry earth are whirled up in eddying clouds, and everything movable is torn up and swept away.

To add to the dire uproar, thunder now peals from the skies in loud, continuous roars, and in sharp angry crashes, while lightning plays about in broad sheets all over the sky, the one following so close on the other as to give the impression of perpetual flashes and an unintermitting roar; the whole scene presenting an aspect so awful, that sinful man might well suppose the season of the Earth's probation had passed away, and that the Almighty were about to hurl complete destruction upon his offending creatures.

But far other intentions are in the breast of Him who rides upon the storm. His object is to restore, not to destroy - to gladden, not to terrify. This tempestuous weather lasts for some days, but at the end of that time the change that comes over the face of nature seems little short of miraculous. In the words of Mr. Elphinstone, who describes from personal observation-" The whole earth is covered with a sudden but luxuriant verdure, the rivers are full and tranquil, the air is pure and (451) 
delicious, and the sky is varied and embellished with clouds.

"The effect of this change is visible on all the animal creation, and can only be imagined in Europe by supposing the depth of a dreary winter to start at once into all the freshness and brilliancy of spring. From that time the rain falls at intervâls for about a month, when it comes on again with great violence; and in July the rains are at their height. During the third month they rather diminish, but are still heavy. In September they gradually abate, and are often suspended till near the end of the month, when they depart amid thunders and tempests, as they came."

Such are the effects of the ir, insoons upon land and sea. Of course the tr ific gales that usher them in and out could not be expected to pass without doing a good deal of damage, especially to shipping. But this is more than compensated by the facilities which they afford to navigation.

In many parts of the world, especially in the Indian Ocean, merchants calculate with certainty on these periodical winds. They despatch their ships with, say, the north-east monsoon, transact business in distant lands, and receive them back, laden with foreign produce, by the south-west monsoon. If there were no monsoons, the voyage from Canton to England could not be accomplished in nearly so short a time as it is at present.

And now as to the cause of monsoons. They are, 
for the most part, deflected trade-winds. And they owe their deflection to the presence of large continents. If there were no land near the equator, the trade-winds would always blow in the same manner right round the world; but the great continents, with their intensely-heated surfaces, cause local disturbance of the trade-winds. When a trade-wind is turned out of its course, it is regarded as a monsoon. For instance, the summer sun, beating on the interior plains of Asia, creates such intense heat in the atmosphere that it is more than sufficient to neutralize the forces which cause the trade-winds to blow. They are, accordingly, arrested and turned back. The great general law of the trades is in this region temporarily suspended, and the monsoons are created.

It is thus that the heated plains of Africa and Central America produce the monsoons of the Atlantic, the Pacific, and the Gulf of Mexico.

We think it unnecessary to explain minutely the causes that produce variation in the monsoons. Every intelligent reader will readily conceive how the change of seasons and varied configuration as well as unequal arrangement of land and water, will reverse, alter, and modify the direction and strength of the monsoons.

Land and sea breezes are the next species of wind to which we would direct attention. They occur in tropical countries, and owe their existence to the fact that the land is much more easily affected by 
sudden changes of temperature than the sea. Thus, the land in warm regions is much heated by the sun's rays during the day; the atmosphere over it becomes also heated, in virtue of which it rises: the cool atmosphere over the sea rushes in to supply its place, and forms the sea breeze: which occurs only during the day.

At night the converse of this takes place. Land heats and cools rapidly; water heats and cools slowly. After the sun sets, the cooling of the land goes on faster than that of the sea. In a short time the atmosphere over the land becomes cooler than that over the sea; it descends and flows off out to sea; thus forming the land breeze. It occurs only at night, and when the change from one to the other is taking place there is always a short period of calm. Land and sea breezes are of the greatest use in refreshing those regions which, without them, would be almost, if not altogether, uninhabitable.

In "The Tempest," an interesting work on the origin and phenomena of wind, published by the Society for Promoting Christian Knowledge, a curious and simple experiment is described, whereby the existence of upper and under currents of air and the action of land and sea breezes may be clearly seen and understood. We quote the passage :-

"The existence of the upper and under currents of air which mark the phenomena of the tradewinds, and of land and sea breezes, may be beauti- 
fully illustrated in two adjoining rooms, in one of which a good fire is burning, while in the other there is none. If the door between the two rooms be thrown open, the cold air will enter the heated room in a strong current, or, in other words, as a violent wind. At the same time the heated air of the warm room ascends and passes the contrary way into the cold room, at the upper part of the same doorway; while in the middle of this opening, exactly between the two currents, the air appears to have little or no motion. The best way to show this experiment is to introduce the flame of a candle into the doorway between a hot and a cold room. If the flame be held near the bottom of the doorway, where the air is most dense, it will be strongly drawn towards the heated room; and if held near the top of the door it will be drawn towards the cold room with somewhat less force; while midway between the top and bottom the flame will be scarcely disturbed.

"There is also another pretty experiment which illustrates well the theory of land and sea breezes. Take a large dish, fill it with cold water, and in the middle of this put a water-plate or a saucer filled with warm water. The first will represent the ocean, and the latter an island made hot by the rays of the sun, and rarefying the air above it. Take a lighted wax candle and blow it out; and, if the air of the room be still, on applying it successively to every side of the saucer, the smoke will be seen 
moving towards the saucer and rising over it, thus indicating the course of the air from sea to land. On reversing the experiment, by filling the saucer with cold water (to represent the island at night) and the dish with warm water, the land breeze will be shown by holding the smoking wick over the edge of the saucer; the smoke will then be wafted to the warmer air over the dish."

We have just tried the first of these experiments, with complete success. We would, however, recommend a piece of twisted brown paper, lighted and blown out, instead of a wax candle, because it gives out more smoke and is probably more obtainable on short notice. The experiment of the doorway, moreover, does not require that there should be two rooms with a door between. We have found that the door of our study, which opens into a cold passage, serves the purpose admirably.

Were we treating chiefly of the atmosphere in this work, it would be necessary that we should enlarge on all the varieties of winds, with their causes, effects, and numerous modifications. But our main subject is the Ocean. The atmosphere, although it could not with justice have been altogether passed over, must hold a secondary place here; therefore we will conclude our remarks on it with a brief reference to hurricanes.

It has been ascertained that most of the great storms that sweep with devastating fury over the land and sea are not, as was supposed, rectilinear in their 
motion, but cireular. They are, in fact, enormous whirlwinds, sometimes upwards of one hundred and fifty miles in diameter; and they not only whirl round their own centres, but advance steadily forward through space.

In the year 1831, a memorable and dreadful series of storms passed over some of the West India Islands, and caused terrible havoc, especially in the island of Barbadoes. The peculiarity of these hurricanes was that they ravaged the different islands at different dates, and were therefore supposed to be different storms. Such, however, was not the case. It was one mighty cyclone, or circular storm, - a gigantic whirlwind,- -which traversed that region at the rate of about sixteen miles an hour. It was not its progressive, but its rotatory motion, that constituted its terrible power. On the 10th of August it reached Barbadoes; on the 11th, the islands of St. Vincent and St. Lucia; on the 12th it touched the southern coast of Porto Rico; on the 13th it swept over part of Cuba; on the 14th it encountered Havanna; on the 17th it reached the northern shores of the Gulf of Mexico and travelled on to New Orleans, where it raged till the 18th. It thus, in six days, passed, as a whirlwind of destruction, over two thousand three hundred miles of land and sea. It was finally dissipated amid heavy rains.

The effect of a hurricane is well described by Washington Irving. " About mid-day," he says, "a furious gale sprang up from the east, driving before 
it dense volumes of cloud and vapour. Encountering another tempest from the west, it appeared as if a violent conflict ensued. The clouds were rent by incessant flashes, or rather streams, of lightning. At one time they were piled up high in the sky, at another they descended to the earth, filling the air with a baleful darkness, more impenetrable than the obscurity of midnight. Wherever the hurricane passed, whole tracts of forest were shivered and stripped of their leaves and branches; and trees of gigantic size, which resisted the blast, were torn up by the roots and hurled to a great distance. Groves were torn from the mountain-precipices, and vast masses of earth and rock precipitated into the valleys with terrific noise, choking the course of the rivers.

"The fearful sounds in the air and on the earth, the pealing thunder, the vivid lightning, the howling of the wind, the crash of falling trees and rocks, filled every one with affright, and many thought that the end of the world was at hand. Some fled to caverns for safety, for their frail houses were blown down, and the air was filled with the trunks and branches of trees, and even with fragments of rocks, carried along by the fury of the tempest. When the hurricane reached the harbour, it whirled the ships round as they lay at anchor, snapped their cables, and sunk three of them to the bottom with all who were on board. Others were driven about, dashed against each other, and tossed mere wrecks 
upon the shore by the swelling surges of the sea, which in some places rolled for three or four miles upon the land. This tempest lasted for three hours."

The China seas are the most frequently visited by severe tempests, or typhoons ; yet of all vessels, the Chinese junks, as they are called, seem to be least adapted by their build for encountering such storms.

A terrible hurricane burst upon the China seas - in the month of January 1837, as we learn from the "United Service Journal" of that year. An English vessel was exposed to it. The sea, rising in mountains around and over the ship's sides, hurled her rapidly on her passage homeward, when suddenly a wreck was discovered to the westward. The order to shorten sail was given, and promptly obeyed; and when they neared the wreck they found her to be a Chinese junk without mast or rudder - a helpless log on the breast of that boiling sea.

There were many Chinamen on deck vehemently imploring assistance. The exhibition of their joy on beholding the approach of the stranger was of the wildest and most extravagant nature; but it was doomed to be suddenly turned to despair, as the violence of the storm drove the ship past the wreck. It became necessary to put her on the other tack, a manœuvre which the poor creatures construed into abandonment, and the air rang with the most agonizing shrieks of misery. But hope was again 
raised, when a boat was lowered and a rope thrown on board for the purpose of towing the junk to the ship. This intention was frustrated by the windlass breaking. At sight of this, one man, in a paroxysm of despair, jumped overboard after the rope; but he missed it. Being a good swimmer, he tried to reach the boat; but his feeble power could avail him nothing in the midst of such raging elements: he speedily sank to rise no more.

Another rope, however, was secured to the junk, and by means of it the rest of the crew (eighteen in number) were saved. Their gratitude was boundless. They almost worshipped the officers, the crew, and the vessel, prostrating themselves and kissing the feet of the former, and the very planks of the latter.

Well-built ships, however, are not always able to withstand the violence of rotatory storms. Instances occur in which the tightest built and best manned ships are destroyed as suddenly as the clumsiest of ill-managed junks. Not many years ago, a vessel was proceeding prosperously on her voyage, when signs of a coming tempest induced the wary captain to reduce, and, finally, to take in all sail. But his precautions were in vain. The storm burst on the devoted ship, and in a few minutes the masts went over the side, and the hull lay a total wreck upon the sea.

These hurricanes or cyclones, although in reality whirlwinds, are so large that man's eye cannot 


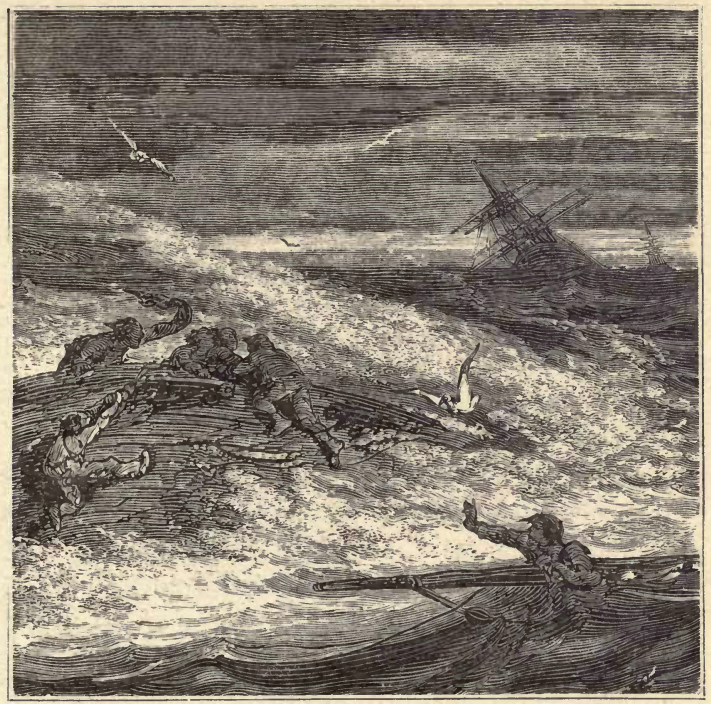

EFFECTS OF A CYCLONE ON THE COAST OF MOZAMBIQUE,

measure them, and it is only by scientific investigation that we have arrived at the knowledge of the fact. The whirlwind, properly so called, is a much smaller body of atmosphere. Sometimes we see miniature whirlwinds, even in our own temperate land, passing along a road in autumn, lifting the leaves and dust into the air and carrying them along in the form of a rotatory pillar. In other regions they exert a power quite equal to the tempest, though in a more limited space, overturning houses, uprooting trees, cutting a track twenty or thirty yards 
wide through the dense forest as thoroughly as if a thousand woodmen had been at work there for many years.

When whirlwinds pass from the land to the sea they create waterspouts; of which we shall have something to say in another chapter. Meanwhile, we think it may be interesting to give the following miscellaneous information regarding the atmosphere, gathered from the work of Dr. Buist, who devoted much earnest study to the subject of atmospheric phenomena.

"The weight of the atmosphere is equal to that of a solid globe of lead sixty miles in diameter. Its principal elements are oxygen and nitrogen gases, with a vast quantity of water suspended in them in the shape of vapour; and, commingled with these, a quantity of carbon in the shape of fixed air, suffi. cient to restore from its mass many-fold the coal that now exists in the world...... Water is not compressible or elastic ; it may be solidified into ice or vaporized into steam: but the air is elastic and compressible. It may be condensed to any extent by pressure, or expanded to an infinite degree of tenuity by pressure being removed from it. It is not liable to undergo any changes in constitution beyond these, by any of the ordinary influences by which it is affected."

If the heating and cooling process-which we have described as being carried on between the equator and the poles-were to cease, we should 
have a furious hurricane rushing perpetually round the globe at the rate of one thousand miles an hour, -ten times the speed of the most violent tornado that has ever carried devastation over the surface of the earth.

The air, heated and dried as it sweeps over the arid surface of the soil, drinks up by day myriads of tons of moisture from the sea,-so much, indeed, that, were none restored to it, the surface of the ocean would be depressed eight or ten feet annually.

We do not certainly know the height of the atmosphere. It is said that its upper surface cannot be nearer to us than fifty, and can scarcely be further off than five hundred, miles. "It surrounds us on all sides, yet we cannot see it; it presses on us with a weight of fifteen pounds on every square inch of the surface of our bodies-in other words, we are at all times sustaining a load of between seventy and one hundred tons of it on our personsyet we do not feel it! Softer than the finest down, more impalpable than the lightest gossamer, it leaves the cobweb undisturbed, and, at times, scarcely stirs the most delicate flower that feeds on the dew it supplies; yet it bears the fleets of nations on its wings round the world, and crushes the most refractory substances with its weight...... It bends the rays of the sun from their path to give us the aurora of the morning and the twilight of evening. It disperses and refracts their various tints to beautify the approach and the retreat of the orb of day. 
But for the atmosphere, sunshine would burst on us in a moment and fail us in the twinkling of an eye, removing us in an instant from midnight darkness to the blaze of noon."

We have written a good deal on this subject, yet the thousandth part has not been told of even the grand and more obvious operations of the atmosphere, much less the actions and results of its minor and invisible processes. Were we to descend with philosophers into the minuter laboratories of the world, and consider the permeating, ramifying, subtle part the atmosphere plays in the innumerable transformations that are perpetually going on around and within us, we should be constrained to feel more deeply than we have ever yet felt, that the works of the Creator are indeed wonderful beyond all expression or conception.

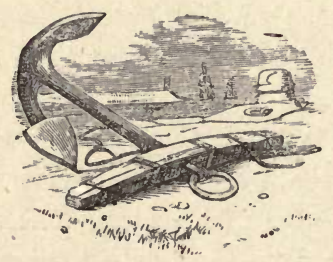




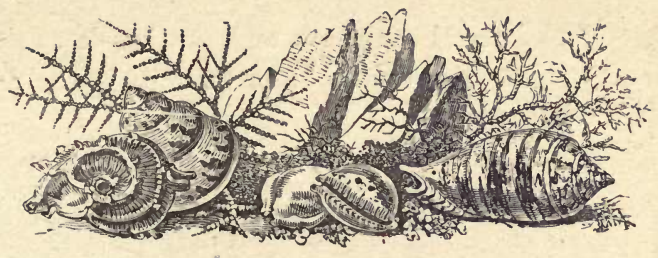

CHAPTER VII.

WATERSPOUTS-CAUSES OF-APPEARANCE-ELECTRICITY-EXPERIMENTS-ARTIFICIAL WATERSPOUTS-SHOWERS OF FISH-MR. ELLIS ON WATERSPOUTS IN THE SOUTH SEAS.

19 9 E turn back now from the atmospheric to 17 the aqueous ocean. Yet so intimate is 12. 1he connection between the two, that we shall find it impossible to avoid occasional reference to the former.

Our present subject, waterspouts, obliges us to recur for a little to the atmosphere, which we dismissed, or attempted to dismiss, in the last chapter.

There is no doubt that waterspouts are to a great extent, if not altogether, due to the presence of electricity in the air. When the clouds have been raging for some time in the skies of tropical regions, rendering the darkness bright, and the air tremulous with their dread artillery, they seem to grow unusually thirsty; the ordinary means of water-supply through the atmosphere do not appear to be sufficient for the demand, or war-tax in the shape of water-duty, that is levied on nature. The clouds 
therefore descend to the sea, and, putting down their dark tongues, lick up the water thirstily in the form of waterspouts.

These whirling pillars of water frequently appear

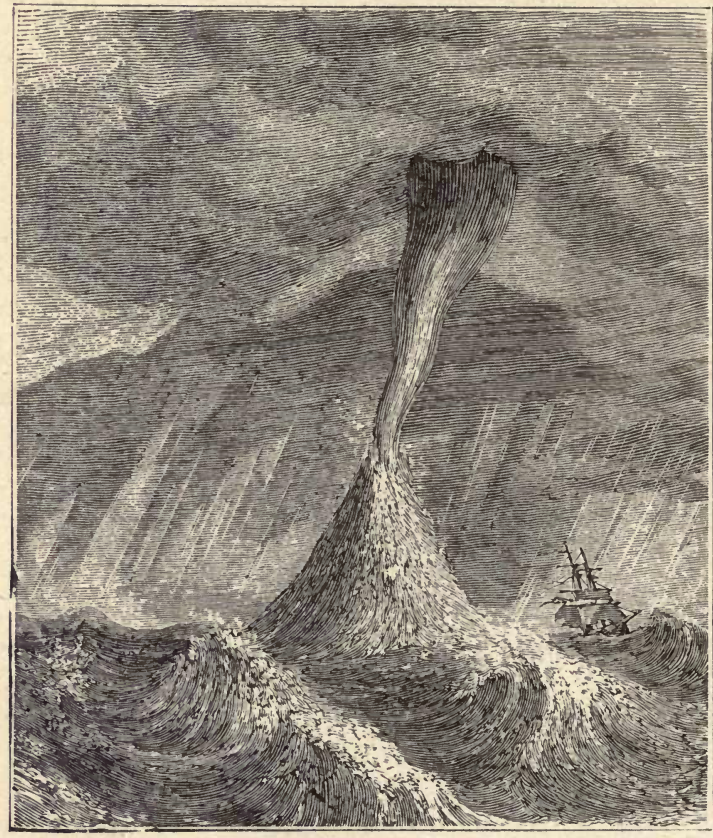

WATERSPOUT.

in groups of several at a time. They are of various heights, sometimes ranging up to seven hundred yards, with a thickness of fifty yards, and are very 
dangerous to ships that happen to come within their influence.

That they are caused by electricity has been proved by experiment-miniature waterspouts have been produced by artificial means; and as Dr. Bonzano of New York gives particular directions how the thing ought to be done, we quote his words for the benefit of those who happen to possess. electrical machines :-

"From the conductor of an electrical machine suspend, by a wire or chain, a small metallic ball (one of wood covered with tinfoil); and under the ball place a rather wide metallic basin, containing some oil of turpentine, at the distance of about three-quarters of an inch. If the handle of the machine be now turned slowly, the liquid in the basin will begin to move in different directions and form whirlpools. As the electricity on the conductor accumulates, the troubled liquid will elevate itself in the centre, and at last become attached to the ball. Draw off the electricity from the conductor, to let the liquid resume its position; a portion of the turpentine remains attached to the ball. Turn the handle again very slowly, and observe now the few drops adhering to the ball assume a conical shape, with the apex downward; while the liquid under it assumes also a conical shape, the apex upward, until both meet. As the liquid does not accumulate on the ball, there must necessarily be as great a current downward as upward, giving (451) 
the column of liquid a rapid circular motion, which continues until the electricity from the conductor is nearly all discharged silently, or until it is discharged by a spark descending into the liquid. The same phenomena take place with oil or water. Using the latter liquid, the ball must be brought much nearer, or a much greater quantity of electricity is necessary to raise it.

"If, in this experiment, we let the ball swing to. and fro, the little waterspout will travel over its miniature sea, carrying its whirlpools along with it. When it breaks up, a portion of the liquid-and with it anything it may contain-remains attached to the ball. The fish, seeds, leaves, \&c., that have fallen to the earth in rain-squalls, may have owed their elevation to the clouds to the same cause that attaches a few drops of the liquid, with its particles of impurities, to the ball."

There can be no doubt whatever that fish are carried up in waterspouts, because the descent of those creatures from the skies in rain is a wellestablished fact; and if they did not get there in waterspouts-which, when we consider it, seems most natural-then we are driven to the conclusion that their native region is the sky, which is by no means so natural or so probable. Many travellers have recorded the fact that small fish have descended in rain. In a letter written not long ago by a gentleman in Singapore we have the following account of a shower of fish :- 


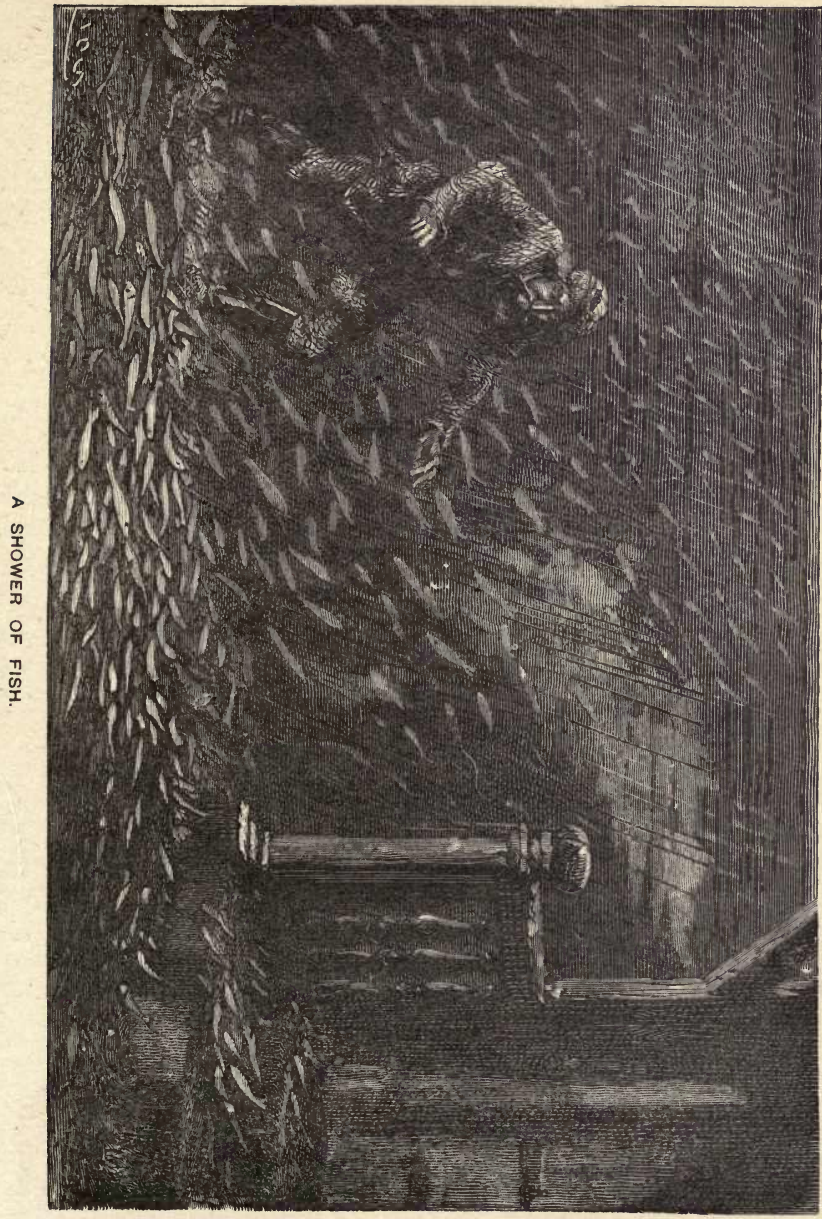



"We experienced a shock of earthquake here on the 16th February last. Its duration was about two minutes. Although it caused no damage, its undulatory motion was sufficiently strong to affect certain persons with a sensation akin to sea-sickness. It was followed by rain in torrents, on the 20th, 21 st, and $22 \mathrm{nd}$. On the latter day especially, we were, for half an hour, surrounded with water to a considerable depth. We could not see three yards before us. When the sun came out again, I saw a number of Malays and Chinese filling their baskets with fish contained in the pools formed by the rain.

"They told me the fish had 'fallen from heaven;' and three days later, when the pools were all dried up, there were still many dead fish lying about...... As they lay in my court-yard, which is surrounded by a wall, they could not have been brought in by the overflowing of a torrent; indeed, there is none of any considerable size in the neighbourhood.

"The space covered by these fish might be about fifty acres, comprising the eastern part of the town. They were very lively, and seemed to be in good health."

The writer of the above suggests, with some degree of hesitation, that these fish were sucked up by waterspouts. We think that there need be no hesitation in the matter!

The appearance usually presented by a waterspout is that of a column of aqueous vapour reaching from the sea to the clouds, sometimes straight, 
more frequently a little bent, and thicker above and below than in the centre of the column.

Mr. Ellis, the missionary, in his "Polynesian Researches," mentions having, with a companion, met and narrowly escaped being overwhelmed by several waterspouts, when passing on one occasion in an open boat between two islands about thirty miles apart. On the passage they were overtaken by a sudden and violent squall, which lasted several hours; and, in order to avoid being sunk, they tied their masts, oars, and sails in a bundle, and attaching a rope to them, and to the boat, cast them into the sea. Thus they lay, as it were, at anchor in the lee of this extemporized breakwater. It was but a feeble barrier, however, against so wild a storm, and the native boatmen were so overcome by fear, that they sat down in the bottom of the boat, and covered their eyes with their hands.

After a time the rain diminished, the sky began to clear, and the boat's crew to revive, when suddenly one of the men uttered a cry of consternation, and pointed to an object towards which all eyes were instantly turned. They beheld a large cylindrical waterspout, extending, like a massive column, from the ocean to the dark and impending clouds. It was not far distant, and seemed to move slowly towards the boat.

Had Mr. Ellis had any doubt as to the danger of a waterspout, the extreme terror exhibited by the natives on this occasion must have removed it ; for 
it was not probable that, just after escaping from the most imminent peril, they would fall back into a much more violent state of terror, unless former experience had given them too good reason to dread the presence of the object they now saw before them.

The roughness of the sea forbade their attempting to hoist a sail in order to avoid the waterspout. They were compelled, therefore, to summon all the resolution they possessed, to enable them calmly to await its approach, and put their trust in the arm of Jehovah.

The helm was in the hands of a seaman whose steadiness could be depended on. The natives were down in the bottom of the boat; they had given way to despair.

Two other waterspouts now came into view, and subsequently a third, if not more, so that they felt as if completely surrounded by them. Some were well defined, extending in an unbroken line from the sea to the sky, like pillars resting on the ocean as their basis, and supporting the clouds; others, assuming the shape of a funnel or inverted cone attached to the clouds, extended their sharp points to the ocean below. From the distinctness with which they were seen, it was judged that the furthest could not have been many miles distant. In some they imagined they could trace the spiral motion of the water as it was drawn up to the clouds, which were every moment being augmented in their por- 
tentous darkness. The sense of personal danger, 'Mr. Ellis confesses, and the certainty of instant destruction if brought within their vortex, prevented a very careful observation of their appearance and accompanying phenomena.

The storm continued all day, and at intervals the party in the boat beheld, through the driving clouds and rain; one or other of those towering waterspouts; which, however, did not come nearer to them.

It is interesting to read the record left by a Christian missionary of his conflicting feelings on that terrible occasion. Mr. Ellis believed that all hope of escape was over, and his mind went through that ordeal which must be the experience of every one who sees the steady approach of speedy death. He says that during those hours when he sat awaiting his doom, the thought of death itself did not make a deep impression. "The struggle, the gasp, as the wearied arm should attempt to resist the impetuous waves; the straining vision, that should linger on the last ray of retiring light, as the deepening veil of water would gradually conceal it for ever; and the rolling billows heaving over the sinking and dying body, which, perhaps ere life should be extinct, might become the prey of voracious inhabitants of the deep;"- these things caused scarcely a thought, compared with the immediate prospect of the disembodied spirit being ushered into the presence of its Maker; the account to be rendered, and the awful and unalterable destiny that would await 
it there. "These momentous objects," he says, "absorbed all the powers of the mind, and produced an intensity of feeling, which, for a long time, rendered me almost insensible to the storm, or the liquid columns which threatened our destruction."

It was now that the missionary could look back with deepest gratitude upon that mercy which had first brought him to a knowledge of the Saviour. "Him and Him alone," he adds, "I found to be a refuge, a rock in the storm of contending feelings, on which my soul could cast the anchor of its hope for pardon and acceptance before God......I could, not but think how awful would have been my state, had I in that hour been ignorant of Christ, or had I neglected or despised the offers of his mercy...... Our prayers were offered to Him who is a present help in every time of danger, for ourselves and those who sailed with us; and under these and similar exercises several hours passed away."

Those prayers were answered, for the waterspouts gradually disappeared, and the boat got safe to land.

In speaking of another waterspout, seen on a subsequent voyage, Mr. Ellis tells us that it was well defined,- an unbroken column from the sea to the clouds, which on this occasion were neither dense nor lowering. Around the outside of the liquid cylinder was a kind of thick mist; and within, a substance resembling steam, ascending apparently with a spiral motion. The water at its base was considerably agitated with a whirling motion; while 
the spray which was thrown off from the circle formed by the lower part of the column, rose several feet above the level of the sea. It passed about a mile astern of the ship.

Occasionally, when passing nearer to a ship than was deemed safe, a waterspout has been dissipated by a cannon-shot, as represented in our engraving.

Such are the usual appearances and actions of waterspouts. They are not, however, properly named, being simply whirlwinds at sea, instead of whirlwinds on land. Professor Oersted suggests .the name "storm-pillar," as being a more appropriate term.

It does not follow that a large ship would inevitably be destroyed if brought within the vortex of a waterspout; but it is certain that she would run the risk of being dismasted, and perhaps thrown on her beam-ends. Navigators have not had sufficient experience of the power of waterspouts to pronounce authoritatively on that point, - and it is to be hoped they never will.

Captain Beechy, in his narrative of a voyage to the Pacific, describes one into which his ship actually entered, and from which he received extremely rough handling before he was set free. But this might not have been a very large waterspout; and it is not absolutely certain whether he was quite within its vortex, or was merely brushed by the skirts of its outer garment. 


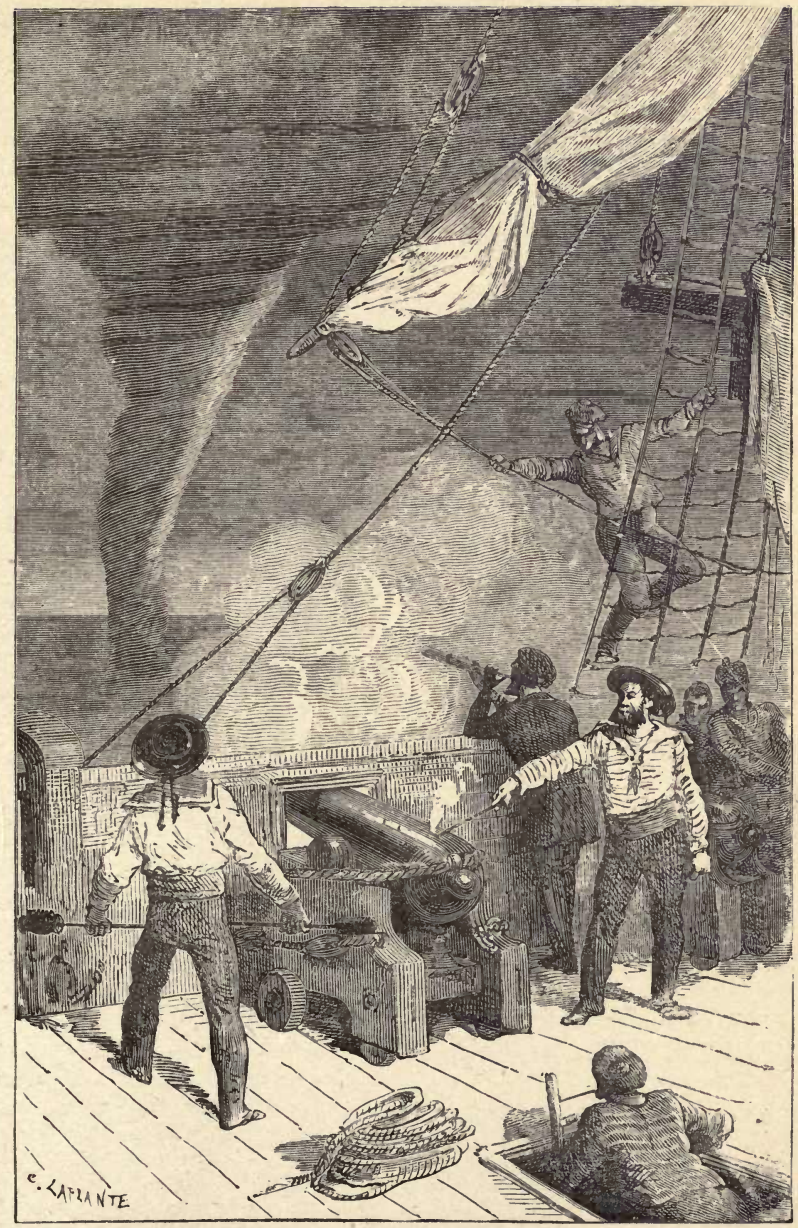

SAILORS FIRING AT A WATERSPOUT. 

Certain it is that waterspouts vary in size and in power; for we read of them passing from the sea to the land, and there rooting up trees, unroofing and overturning houses, dismounting cannon, emptying fish ponds, half emptying harbours, and otherwise exhibiting a degree of force that would undoubtedly sink the largest vessel that ever was. built, if brought thoroughly to bear upon it.

The rate of motion in waterspouts varies. Sometimes they revolve slowly, sometimes with the utmost rapidity. They often produce violent noise, as, indeed, might be expected; and they are generally accompanied by thunder and lightning, though not invariably so, for they are sometimes observed when the heavens are clear and the sea calm.

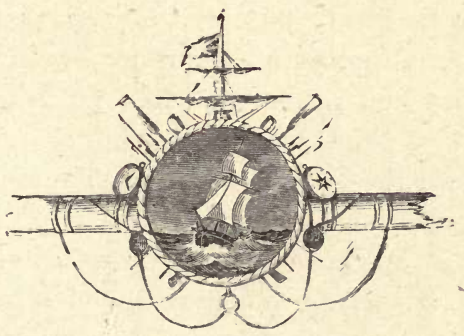




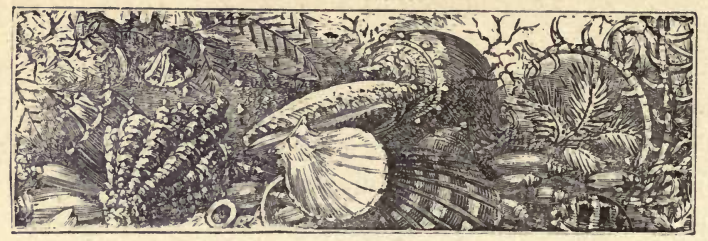

\section{CHAPTER VIII.}

THE ARCTIC SEAS-THEIR CHARACTER, SCENERY, AND ATMOSPHERICAL ILLUSIONS.

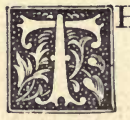

HERE is a tendency on the part of most writers on the subject of Polar Regionsespecially compilers-to dwell disproportionately on the gloomy side of the picture; insomuch that readers are led, not to over-estimate the grand and the terrible aspects of the polar oceans, but to under-estimate the sweet and the beautiful influences that at certain periods reign there.

We quarrel not with authors for dwelling on the tremendous and the awful. Too much cannot be said on these points ; but while they do not by any means paint the dark side of their picture too black, they fail to touch in the lights with sufficient brilliancy. We have had some personal experience of the arctic regions, and have found it extremely difficult to get many persons-even educated men and women-to understand that there is a summer there, though a short one; that in many places it is an uncommonly hot and excessively brilliant 
summer; and that the sun, as if to make amends for its prolonged absence in winter, shines all night as well as all day, blazing on the crystal icebergs and pure snow (which never disappear from those seas) with a degree of splendour that renders the far north transcendently beautiful and pre-eminently attractive.

We admit freely that the prevailing character of arctic seas, during the greater part of the year, is dark, gloomy, forbidding. But this is the very reason why their brief but cheering smiles should be brought prominently into the foreground, and, if they cannot in justice be dwelt on long, at least be touched upon with emphasis.

Why, in some of our cyclopædia accounts of the realms of "thick-ribbed ice," so much prominence is given to "the horrors and wide desolation of the scene," and so much graphic power is expended in working up the reader's imagination to a conception of the dreadful dangers and the appalling terrors that await the madman who should dare to venture within the arctic circle, that persons who have not been there might well be tempted to shrink in affright from the very contemplation of a region in which there does not appear to be one redeeming quality.

We repeat, that we do not think the one side of the picture has been too darkly painted,--but the other side has been painted too slightly.

At the same time, we would caution our readers 
against jumping to the opposite extreme. The dark side of the picture is in reality out of all proportion to the light. And we do not hesitate to state our confirmed opinion, that the arctic regions are more interesting to read about than pleasant to dwell in.

Having, then, defended the lights, let us commence our investigations with the shadows.

Those oceans lying within the arctic circle exhibit phenomena so grand, so wonderful, and so varied, that they claim distinct and separate treatment from the ocean as a whole. Here the extreme cold acts with such power, and produces such extraordinary results, that it is difficult to find words or similes by which to convey a just conception of nature's aspects to the general reader.

During nearly two-thirds of the year the arctic regions are under the absolute dominion of winter; and for many weeks of that bitter season they are shrouded with the mantle of a dark, sunless night. The entire ocean is locked in the embrace of a covering of ice many feet thick, so that its liquid aspect is thoroughly removed; and, owing to icemasses scattered over its surface, together with mounds of drifted snow, it bears a much stronger resemblance to the land than to the sea. Gales of wind sometimes sweep over those frozen plains in bitter fury, hurling the snow into the air in vast eddying masses, and threatening destruction to any living creature that may chance to be exposed to them-not so much from their violence, however, 


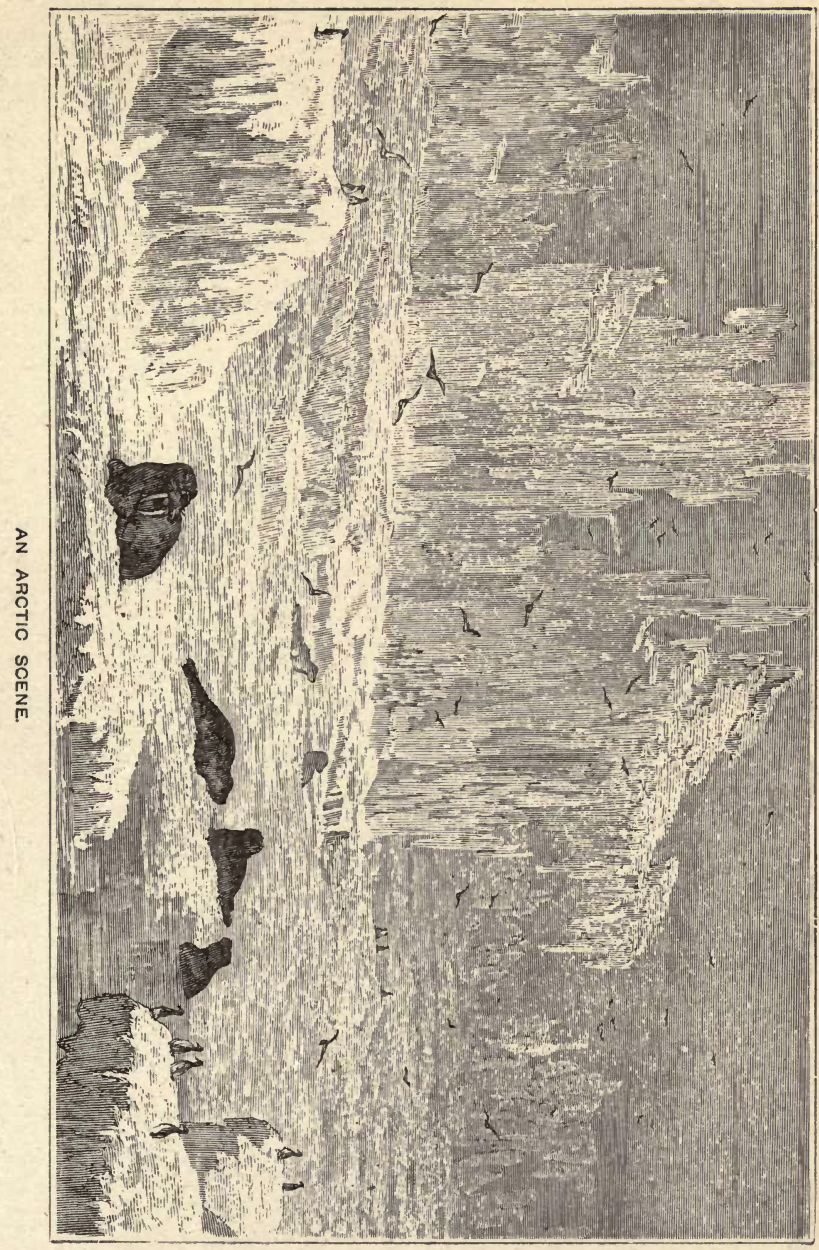



as from the intense cold of the atmosphere which is put in motion. But in regard to gales, although there are no lack of them, they are neither so fierce nor so frequent as are those of the torrid zone.

It might be supposed that in such a climate animal life could scarcely exist; but such is not the case. The inhabitants of part of the arctic regions, named Esquimaux (more correctly Eskimos, with the accent on the last syllable), are a stout, hardy, healthy race; and the polar bears, foxes, wolves, seals, musk-oxen, walruses, \&c., that dwell there, seem to enjoy their existence just as much as do the animals of more favoured and warmer climes.

During the short but hot summer of the arctic regions, the immense masses of ice formed in winter are by no means cleared away. A great part of the heat of early summer (there is no season there that merits the name of spring) is spent in breaking up the solid crust of ice on the sea, a large proportion of which is carried south by the currents that flow to the equator, and melted long before they reach the temperate zones. But a considerable quantity of broken ice-masses get locked in narrow places or stranded on shallows; and although they undergo the process of melting the whole summer, they are not much diminished ere the returning frost stops the process and locks them in the new ice of a succeeding winter.

Thus there is no period of the year in which large 
quantities of ice may not be seen floating about in the arctic seas.

This fact it is that enables us to speak appropriately of the scenery of the Arctic Ocean. And assuredly this scenery of the ice is exceedingly and

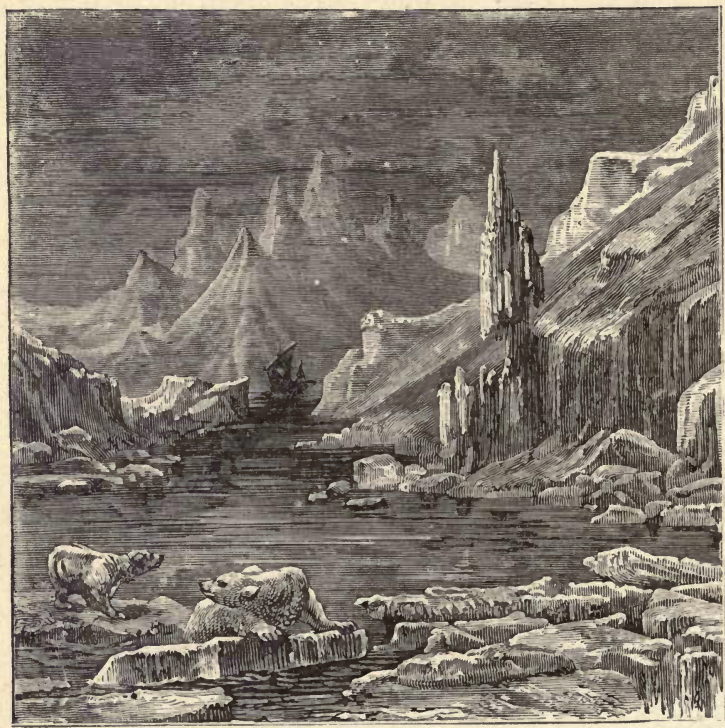

THE POLAR SEA.

strikingly beautiful. The imagination cannot conceive the dazzling effect of a bright summer day in those regions, when the ocean is clear as glass, and ice-lumps and ice-mountains of every shape and size are glittering in the sun's rays with intense 
brilliancy, while the delicate whiteness of these floating islands, and the magical atmospheric illusions by which they are frequently surrounded, render the scene pre-eminently fairy-like.

All the navigators who have penetrated into the arctic seas speak with enthusiasm of the splendour of floating ice-masses. They take the most curious and fantastic shapes; sometimes appearing like great cities of white marble, with domes and towers and spires in profusion; sometimes looming huge and grand like fortresses, and many of them with their summits overhanging so much as to suggest the idea that they are about to fall. This, indeed, they often do, adding to the grandeur of the scene, and not a little to the danger, should ships chance to be in the neighbourhood.

The atmospheric illusions, before mentioned, are the result of different temperatures existing within a few miles of each other, and which are caused by the presence of large bodies of ice. The effect of this is to cause the ice-masses on the horizon to appear as if floating in the air, and to distort them into all sorts of shapes, even turning them upside down, and thus affording to an imaginative mind a most ample and attractive field wherein to expatiate.

To ascertain the causes of facts and effects so curious must prove interesting to all who have inquiring minds. We will, therefore, attempt to describe and account for arctic phenomena in the following chapters as simply as may be. 


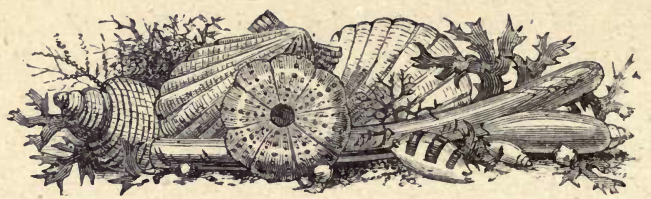

CHAPTER IX.

FORMATION OF ICE-DANGERS OF DISRUPTING ICE-ANECDOTEDRIFTING ICE-DRIFT OF THE "FOX"- " NIPPING"-ANECDOTE -LOSS OF THE "BREADALBANE."

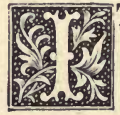

$\mathrm{T}$ is well known that when fresh water becomes so cold that its temperature is $32^{\circ}$ of Fahrenheit's scale, it loses its liquid form and becomes ice. A somewhat lower temperature than this is necessary to freeze salt water; the reason being, that greater force is required to expel the salt which the sea holds in solution,which salt is always more or less expelled in the process of freezing.

Ice commences to form in the shape of needles, which shoot out at angles from each other. In smooth water, under the influence of intense cold, the process is rapid, and a thin cake soon covers the water, and increases in thickness hour by hour. But when the sea is agitated the process is retarded, and the fine needles are broken up into what arctic navigators call sludge. This, however, soon begins to cake, and is broken by the swell into small cakes; 
which, as they thicken, again unite, and are again broken up into larger masses. These masses, by rubbing against each other, have their edges slightly rounded up, and in this form receive the name of pancake ice.

When a quantity of ice covers the ocean in a wide level sheet of considerable extent, it is called an ice-field. Fields of this kind are often seen by navigators hundreds of miles in extent, and nearly thirty feet thick. Ice of such thickness, however, only shows five or six feet above water. When fields are broken by heavy ocean-swells, the edges are violently forced up, and fall in débris on the surface; thus hummocks or mounds are formed.

When field-ice breaks up under the influence of an ocean-swell, caused by a storm, the results are terrific.

An exceedingly graphic account of an incident of this kind is given by Dr. Brown, in his "History of the Propagation of Christianity." He writes :-

"The missionaries met a sledge with Esquimaux, turning in from the sea, who threw out some hints. that it might be as well for them to return. After some time, their own Esquimaux hinted that there was a ground-swell under the ice. It was then scarcely perceptible, except on lying down and applying the ear close to the ice, when a hollow, disagreeable, grating sound was heard ascending from the abyss. As the motion of the sea under the ice had grown more perceptible, they became alarmed, 


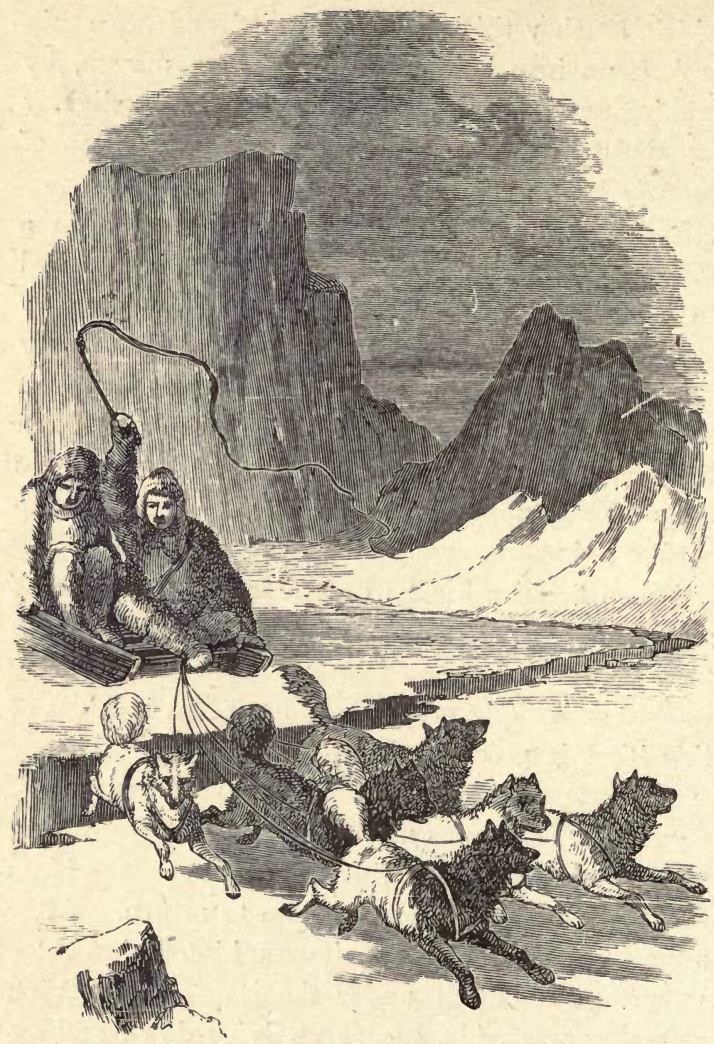

ESQUIMAUX LEAPING OVER A CHASM.

and began to think it prudent to keep close to the shore. The ice also had fissures in many places, some of which formed chasms of one or two feet; 
but as these are not uncommon in ice even in its best state, and the dogs easily leap over them, they are frightful only to strangers.

"As the wind rose to a storm, the swell had now increased so much that its effects on the ice were extraordinary, and really alarming. The sledges, instead of gliding smoothly along as on an even surface, sometimes ran with violence after the dogs, and sometimes seemed with difficulty to ascend a rising hill. Noises, too, like the report of cannon, were now distinctly heard in many directions, from the bursting of the ice at a distance. Alarmed by these frightful phenomena, our travellers drove with all haste towards the shore ; and, as they approached it, the prospect before them was tremendous. The ice having burst loose from the rocks, was tossed to and fro, and broken in a thousand pieces against the precipices with a dreadful noise; which, added to the raging of the sea, the roaring of the wind, and the driving of the snow, so overpowered them as almost completely to deprive them of the use of their eyes and ears.

"To make the land was now the only resource that remained, but it was with the utmost difficulty that the frightened dogs could be driven forward; and as the whole body of the ice frequently sank below the summits of the rocks, and then rose above them, the only time for landing was the moment it gained the level of the coast-a circumstance which rendered the attempt extremely nice and hazardous. 
"Both sledges, however, succeeded in gaining the shore, and were drawn up on the beach, though not without great difficulty. Scarcely had they reached it, when that part of the ice from which they had just escaped burst asunder, and the water, rushing up from beneath, instantly precipitated it into the ocean. In a moment, as if by a signal, the whole mass of ice for several miles along the coast, and extending as far as the eye could reach, began to break up, and to be overwhelmed by the waves. The spectacle was awfully grand. The immense fields of ice rising out of the ocean clashing against each other, and then plunging into the deep with a violence which no language can describe, and with a noise like the discharge of a thousand cannon, was a sight which must have filled the most unreflecting mind with feelings of solemnity.

"The Brethren were overwhelmed with amazement at their miraculous escape, and even the Esquimaux expressed gratitude to God for their deliverance."

Such is the terrible aspect in which field-ice is seen when broken up and converted into smaller masses or floes. When these lie closely together the mass is called pack-ice; in which shape it usually drifts away with the southern currents, and, separating as it travels south, is met with in loose, floating inasses, of every fantastic form. There is always, as we have said, a large quantity of floe and pack-ice in the polar seas, which becomes incorpo- 
PACK-ICE.

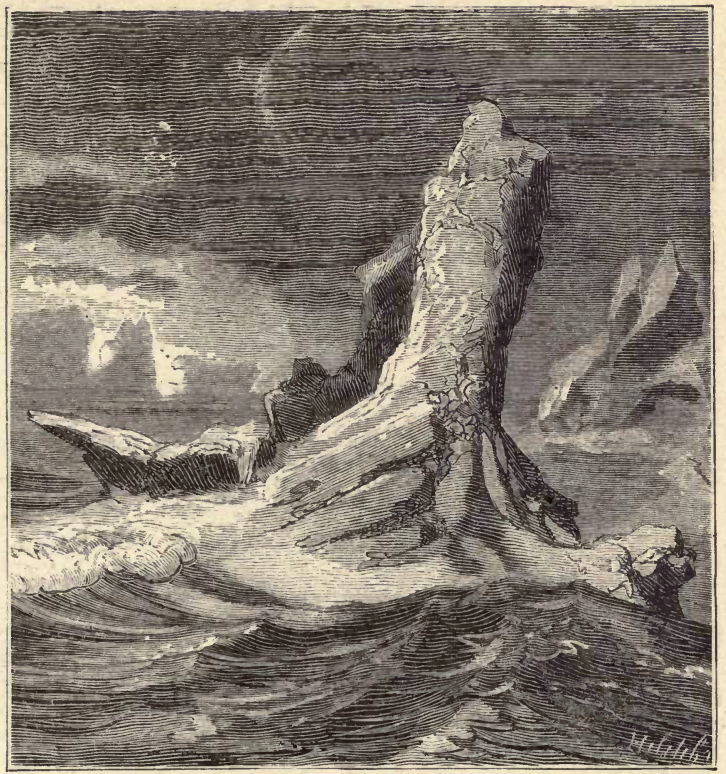

FLOATING ICE.

rated with the new ice of the succeeding winter; and not unfrequently whale and discovery ships get frozen into the pack, and remain there as firmly embedded as if they lay high and dry on land. When the pack is thus re-frozen, it usually remains stationary; but there are occasions and circumstances in which the entire body of a pack drifts slowly southward even during the whole year; showing clearly that oceanic circulation is by no 
means arrested by the icy hand of the hyperborean winter.

A very remarkable drift of this kind is recorded by Captain $M^{\prime}$ Clintock of the $F^{\prime} o x$, which is worthy of being noticed here, as illustrative of the subject we are now considering, and also as showing in a remarkable manner the awful dangers to which navigators may be exposed by the disruption of the pack in spring, and the wonderful, almost miraculous, manner in which they are delivered from imminent destruction.

In attempting to cross Baffin's Bay, by penetrating what is called the "middle ice," the Fox was beset, and finally frozen in for the winter ; and here, although their voyage may be said to have just commenced, they were destined to spend many months in helpless inactivity and comparative peril and privation. Their little vessel lay in the centre of a field of ice of immense extent; so large, indeed, that they could not venture to undertake a journey to ascertain its limits. Yet this field slowly and steadily descended Baffin's Bay during the whole winter, and passed over no fewer than 1385 statute miles in the space of 242 days, during which period the $F o x$ was firmly embedded in it!

It is with difficulty the mind can form any adequate conception of the position of those voyagers;unable to move from their icy bed, yet constantly drifting over miles and miles of ocean; uncertain 
as to the where or the when of their deliverance from the pack; exposed to the terrible dangers of disrupting ice, and surrounded by the depressing gloom of the long aretic night.

At length deliverance came; but it came surrounded by terrors. In February, M:Clintock writes thus: "Daylight reveals to us evidences of vast ice-movements having taken place during the dark months, when we fancied all was still and quiet; and we now see how greatly we have been favoured, what innumerable chances of destruction we have unconsciously escaped. A few days ago, the ice suddenly cracked within ten yards of the ship, and gave her such a smart shock that every one rushed on deck with astonishing alacrity. One of these sudden disruptions occurred between me and the ship, when $I$ was returning from the iceberg. The sun was just setting as I found myself cut off.......At length I reached a place where the jagged edges of the floes met; so crossed, and got safely on board."

Again, in March, he says : "Last night the ice closed, shutting up our lane; but its opposite sides continued for several hours to move past each other, rubbing off all projections, crushing and forcing out of the water masses four feet thick. Although one hundred and twenty yards distant, this pressure shook the ship and cracked the intervening ice."

Soon after that, a heavy gale burst upon them from the south-east, encircling them with snow- 
drift so dense that they could neither hear nor see what was going on twenty yards off. At night the ship became suddenly detached from her wintry bed, and heeled over to the storm, inducing them to believe that the whole pack had been broken up and was pressing against them. This was not the case. A large mass of ice had protected them; but at a distance of about fifty yards, ice of four and a half feet thick had been crushed to atoms. Soon after, the protecting mass yielded, and the Fox received a "nip" which lifted her stern about a foot, while occasional groaning from her sturdy little hull replied to the wild surgings of the ice without.

But all this was as nothing compared with the scene of desperate turmoil and confusion which took place when the ice finally broke up, and a gale raised a fearful swell ; so that the Fox found herself surrounded by huge masses, which tossed and ground against each other furiously, and any two of which pieces could have crushed in her sides as if she had been made of walnut shell. Gradually the pack opened out, and the vessel, by aid of wind and steam, was mercifully delivered from her dangerous position.

Before passing from the subject of risk to navigators to the consideration of other forms and aspects of polar ice, let us take a glance at an effectual case of nipping. There have been many partial and severe nips, the descriptions of which are all more or less graphic; but few ships have come so sud. 
denly to the end of their career as did the Breadalbane, a small vessel that was used as a transport ship to the expedition in search of Sir John Franklin in 1852. One who was on board when it occurred thus describes it:-

"Sunday, August 21st.-About ten minutes past four, the ice passing the ship awoke me, and the door of my cabin, from the pressure, opened. I hurriedly put on my clothes, and on getting on deck found some hands on the ice endeavouring to save the boats ; but the latter were instantly crushed to pieces. They little thought, when using their efforts to save the boats, that the ship was in so perilous a situation.

"I went forward to hail the Phoenix (another ship that was fortunately near) for men to save the boats; and whilst doing so, the ropes by which we were secured parted, and a heavy nip took us, making every timber creak, and the ship tremble all over. I looked in the main hold, and saw the beams giving way. I hailed those on the ice, and told them of our critical situation, they not for one moment suspecting it. I then rushed to my cabin, hauled out my portmanteau on deck, and roared like a bull to those in their beds to jump out and save their lives. The startling effect on them might be more easily imagined than described. On reaching the deck, those on the ice called out to me to jump over the side, that the ship was going over. I left my portmanteau, and jumped over the side on 
the loose ice, and with difficulty, and with the assistance of those on the ice, succeeded in getting on the unbroken part, with the loss of the slippers I had on when quitting the vessel, with wet feet, \&c. The cold was little thought of at the exciting momentlife, not property, being the object to be saved.

"After being on the ice about five minutes, the timbers, \&c., in the ship cracking up as matches would in the hand, it eased for a short time; and I, with some others, returned to the ship, with the view of saving some of our effects.

"Captain Inglefield now came running towards the ship, and ordered me to see if the ice was through it. On looking down into the hold, I saw all the beams, \&c., falling about in a manner that would have been certain death to me had I ventured down there. But there was no occasion for that (I mean to ascertain the fact of the ice being through), it being too evident that the ship could not last many minutes. I then sounded the well, and found five feet in the hold; and, whilst in the act of sounding, a heavier nip than before pressed out the starboard bow, and the ice was forced right into the forecastle. Every one then abandoned the ship, with what few clothes they saved-some with only what they had on. The ship now began to sink fast, and from the time her bowsprit touched the ice until her mast-heads were out of sight, did not occupy above one minute and a half !

"It was a very sad and unceremonious way of 
being turned out of our ship. From the time the first nip took her, until her disappearance, did not occupy more than fifteen minutes."

Such is the account of the fate of the Breadalbane. While we read it, we cannot help feeling that many arctic ships must have perished in a similar manner. It is wonderful, nevertheless, how many of those that dare the dangers of the ice survive the conflict. Undoubtedly this is owing, to a large extent, to the fact that ships' bottoms are rounded; so that when a severe nip takes place, there is a tendency in the ice to slip under their rounded bottoms, and squeeze the vessels up out of the water. Were it not for this, few ships that have gone to those seas would ever have returned.

A catastrophe such as that which befell the Breadalbane shows the immense power of field-ice. Hundreds of somewhat similar incidents might be cited to illustrate this power; but we content ourselves with the selection of one instance, which exhibits it in a remarkable manner, and at the same time shows the way in which heavy vessels are sometimes forced out of the water.

In the year 1836, Captain Back commanded the Terror, which was sent out to make geographical discoveries in the polar regions, and spent the winter of that year in the ice. Few ships have undergone severer tests than did the Terror on that voyage. The severest treatment she experienced was in the spring, when the disruption of the win- 
ter ice began to take place. The evening of the 7 th of March was specially fraught with danger. We quote the gallant commander's graphic account :-

"Ominous rushing sounds were heard far off to the north-east and north-west. These gradually drew nearer as the flood made its way, either under the compact bodies that withstood the shock, or along the cracks and openings-gaining in these latter a furious velocity, to which everything seemed to yield.

"It happened that there were several of these around the ship; and when they opened on us like so many conduits pouring their contents to a common centre, the concussion was absolutely appalling, rending the lining and bulkheads in every part, loosening some shores and stanchions, so that the slightest effort would have thrown them down, and compressing others with such force as to make the turpentine ooze out of their extremities. One fir plank, placed horizontally between the beams and the shores actually glittered with globules. At the same time the pressure was going on from the larboard side, where the three heaviest parts of the ruin of the floe remained, cracked here and there, but yet adhering in firm and solid bodies. These, of course, were irresistible ; and after much groaning, splitting, and cracking, accompanied by sounds like the explosion of cannon, the ship rose fore and aft, and heeled over about ten degrees to starboard." 
Again, on the 11th, Back says: "At this time she showed symptoms of suffering in the hull, which was evidently undergoing a severe ordeal. Inexplicable noises, in which the sharp sounds of splitting and the harsher ones of grinding were most distinct, came in quick succession, and then again stopped suddenly, leaving all so still that not even a breath was heard.

"In an instant the ship was felt to rise under our feet, and the roaring and rushing commenced with a deafening din alongside, abeam and astern, at one and the same instant. Alongside, the grinding masses held the ship tight as in a vice; while the overwhelming pressure of the entire body, advancing from the west, so wedged the stern and starboard quarter, that the greatest apprehensions were entertained for the stern-post and framework abaft.

"Some idea of the power exerted on this occasion may be gathered from this :-At the moment which I am now describing, the fore-part of the ship was literally buried as high as the flukes of the anchors in a dock of perpendicular walls of ice; so that, in that part, she might well have been thought immovable. Still, such was the force applied to her abaft, that after much cracking and perceptible yielding of the beams, which seemed to curve upwards, she actually rose by sheer pressure above the dock forward; and then, with sudden jerks, did the same abaft. During these convulsions, many of the 
carpenters and others stationed below were violently thrown down on the deck, as people are in an earthquake. It was a moment of intense suspense.

"On the 16th, another rush drove irresistibly on the larboard quarter and stern, and forcing the ship ahead, raised her on the ice. A chaotic ruin followed......The ship was careened fully four streaks, and sprang a leak as before. Scarcely were ten minutes left us for the expression of our astonishment that anything of human build could outlive such assaults, when another equally violent rush succeeded; and in its way toward the starboard quarter threw up a rolling wave thirty feet high, crowned by a blue square mass of many tons, resembling the entire side of a house, which, after hanging for some time in doubtful poise on the ridge, at length fell with a crash into the hollow, in which, as in a cavern, the after-part of the ship seemed embedded. It was, indeed, an awful crisis, rendered more frightful from the mistiness of the night and dimness of the moon.

"The poor ship cracked and trembled violently, and no one could say that the next minute would not be her last-and, indeed, his own too, for with her our means of safety would probably perish."

It is unnecessary to give additional instances of this kind, in order to show the terrible power of field-ice. Indeed, it requires little in the way of 
illustration to prove that masses of solid matter, many thousands of tons in weight, can, when in motion, utterly destroy the most powerful engines of human construction.

We shall now turn our attention to another, and a very prominent form, in which arctic ice presents itself-namely, that of icebergs.

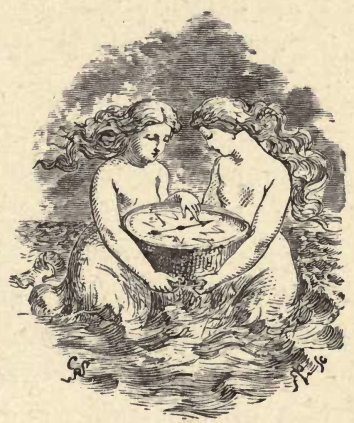




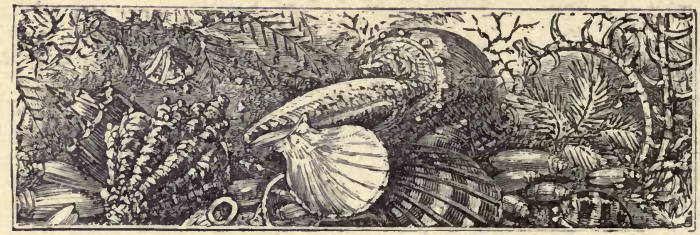

\section{CHAPTER X.}

ICEBERGS - THEIR APPEARANCE AND FORMS - THEIR CAUSE GLACIERS - THEIR NATURE AND ORIGIN-ANECDOTE OF SCORESBY -RISK AMONG ICEBERGS-M'CLURE'S EXPERIENCE.

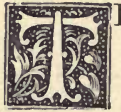

HERE are not only ice-fields, ice-floes, \&c., in the polar seas, but there are ice-mountains, or bergs.

It was long a matter of uncertainty as to where and how those immense mountains, that are met with occasionally at sea, were formed. We are now in a position to tell definitely where they originate, and how they are produced. They are not masses of frozen sea water. Their birth-place is in the valleys of the far north, and they are formed by the accumulation of the snows and ice of ages. This is a somewhat general way of stating the matter; but our subsequent explanations will, we trust, make our meaning abundantly clear.

Icebergs are found floating in great numbers in the arctic seas. They drift southward each spring with the general body of polar ice, and frequently travel pretty far south in the Atlantic before the 


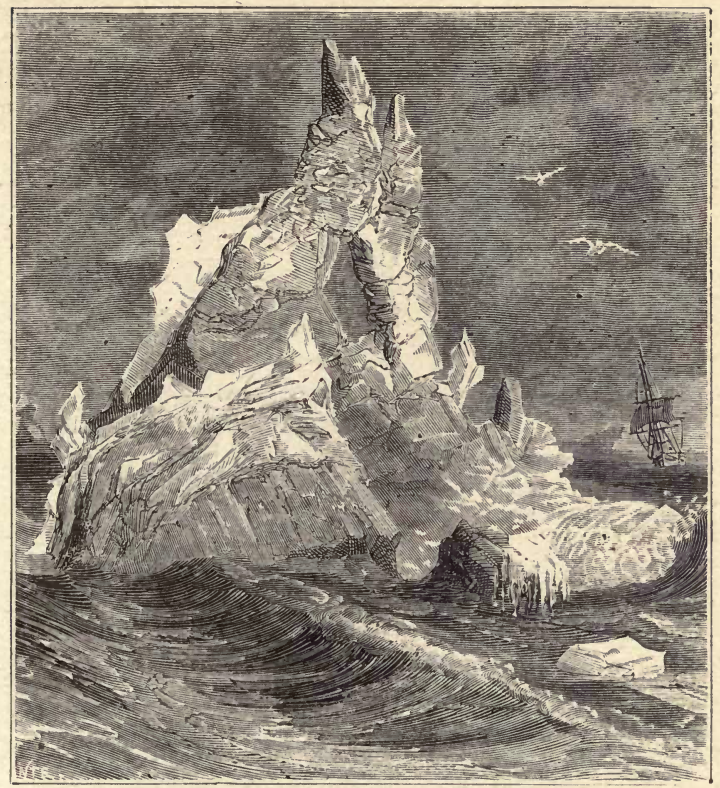

ICEBERGS.

heat of the water and atmosphere united accomplishes their dissolution. They sometimes travel as far south as Florida with the southerly current that flows along that coast; but the warm waters of the Gulf Stream, together with its northerly flow, form an impassable barrier between these ice-mountains and Europe.

Icebergs assume every variety of form, and almost every size. They sometimes resemble eastles, 
sometimes churches with glittering spires, and sometimes the peaked and jagged mountains of Norway. They are also frequently seen in the form of immense misshapen and top-heavy masses.

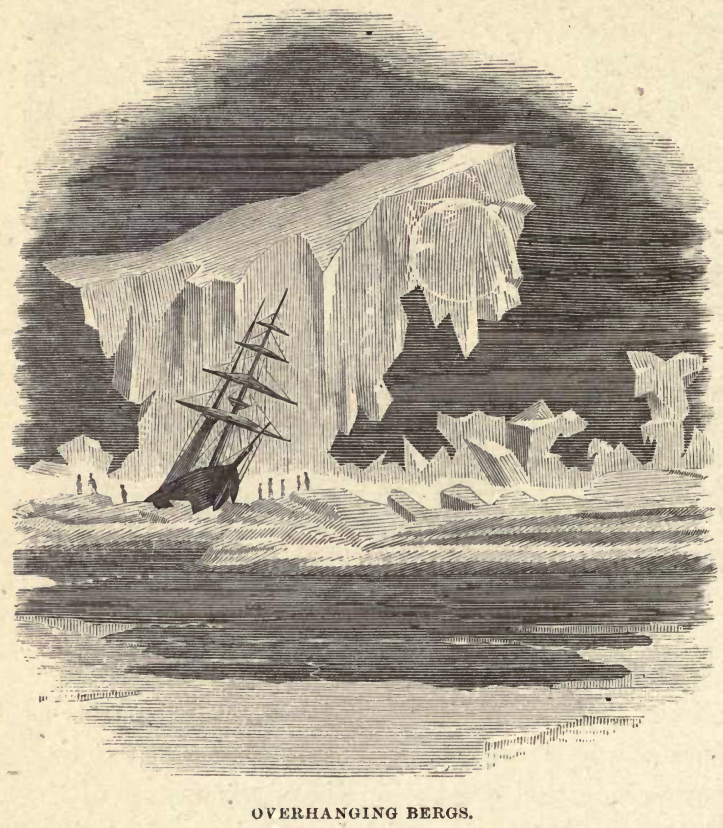

In size they vary from one hundred to seven or eight hundred feet in height. One iceberg, seen by Ross in Baffin's Bay, was above two miles in length, nearly the same in width, and fifty feet 
high. But in stating this, we have not given the reader any idea of its vast proportions; for it is well known that all icebergs, or masses of ice, have a much greater proportion of their bulk under than above water-in other words, they sink very deep. The relative proportion that sinks depends on the nature of the ice. Of some kinds, there is usually ten times as much below as there is above water; of other kinds, there may be eight or five parts below. In all cases there is much more below than above; so that a mountain of a hundred feet high-if afloat-may be safely calculated to be a mass of ice not far short of a thousand feet thick.

As these bergs float southward with the currents, they melt very rapidly. The heat of the sun and the action of the waves gradually round off the sharp angles and topple down the spires that characterized them in the land of their birth. The process of dissolution, too, is carried on internally; for rain and melted water on the surface percolates through the mass, rendering it porous. As the waves cut away the base, the centre of gravity is thrown out, and the whole berg turns over with a terrible crash. Sometimes loud reports like cannonshots are heard, and the huge mountain splits asunder; while, not unfrequently, the whole berg falls into a heap of chaotic ruins, and floats away in a mass of smaller pieces which disappear gradually in their parent sea.

The formation of icebergs has, as we have 
said, puzzled mankind for many years. Their existence has long been known: for, even before men dared to venture their lives in the polar regions, navigators, in crossing the Atlantic Ocean, frequently met with these marble-like mountains; and, what is worse, sometimes ran at full speed against them, and were sunk with all on board. Bergs are frequently enveloped in dense fogs, caused by the cold atmosphere by which they are surrounded condensing the moisture of the warmer atmosphere which they encounter on their voyage southward; hence they are exceedingly dangerous to navigation. But now to speak of their formation.

Many of the great valleys of the far north are completely filled up with solid ice. Observe, we do not say that they are merely covered over with ice; they are absolutely filled up with it from top to bottom. Those ice-masses are known by the name of glaciers ; and they are found in most of the elevated regions of the Earth,- on the Alps and the mountains of Norway, for instance,-but they exist in greater abundance about the poles than elsewhere.

Glaciers never melt. They have existed for unknown ages, probably since the world began; and they will, in all likelihood, continue to exist until the world comes to an end;-at least until the present economy of the world terminates. They began with the first fall of snow, and as falls of snow during the long winters of the polar regions 
are frequent and heavy, the accumulated masses are many feet deep, especially in places where drifts are gathered-sometimes fifteen, twenty, thirty, and even forty feet deep. The summer sun could not melt such drifts entirely. New snow was added each winter, until the valleys of the far north were filled up; and so they remain filled up to this day.

In order to understand the nature of glaciers clearly, let us turn back to those remote ages that rolled over this Earth long before man was created. Let us in spirit leap back to the time when no living creature existed, even before the great mastodon began to leave his huge foot-prints on the sands of time.

We have reached one of the large valleys of the arctic regions. It is solemn, grand, and still. No merry birds, no prowling creatures, are there to disturb the universal calm. The Creator has not yet formed the living creatures and pronounced them "very good." It is the world's first winter. As we look upward to the sky, we observe the first white snow-flakes falling gently to the ground. They reach it, and, for tiue first time, that valley is covered with a garment of virgin snow. The valley is upwards of two miles broad. It rises from the sea, and goes far back into the mountains, perhaps to the extent of ten or twelve miles. The mountains that flank it are five or six thousand feet high. We have seen such valleys in Norway, 
within the arctic circle. Before that first winter has passed, many and many a fall of snow has thickened and pressed down that first coat; and many a furious storm has caught up the snow from the mountain-tops and swept it into the valley, adding to and piling up the mass, and packing it firmly down.

Spring arrives. The short but warm arctic summer bursts upon that vale, melting the surface of the snow; and the water thus produced sinks through the mass, converting it into a sort of thick slush-half snow, half water, - not liquid, yet not solid; just solid enough to lie there apparently without motion; yet just liquid enough to creep by slow, absolutely imperceptible degrees, down the valley. The snow in all the mountain gorges is similarly affected : it creeps (it cannot be said to flow) out and joins that in the vale. But we cannot perceive any of the motion of which we are writing. The mass of snow seems to be as still and motionless as the rocks on which we stand; nay, if we choose we may walk on its hard surface almost without leaving the slightest print of our foot. But if we throw a arge stone on the surface of the snow and mar's the spot, and return again after many days :ve shall find that the stone has descended the valley a short distance. We shall also observe that the snow has now a variety of markings on its surface; which might lead us to fancy, had we not known better, that it had once been a 
river, which, while raging down to the sea with all its curling rapids and whirling eddies, had been arrested in an instant by the ice-king and frozen solid,-in fact, it has all the graceful lines and forms of fluidity, with all the steady, motionless aspect of solidity. It really moves, this vast body of snow; but, like the hour hand of a watch, its motion cannot be recognised, though we should observe it with prolonged, unflagging attention. We have called it a vast body of snow, but this is only comparatively speaking. It will be vaster yet before we have done with it. At present it is but a thick semi-fluid covering, lying at the bottom of this ancient arctic vale.

The brief summer ends. Much of the winter snow has been melted and returned to the sea; but much, very much more, is still lying deep upon the ground. The world's second winter comes. The first frost effectually puts a stop to all the melting and moving that we have been describing. The snow-river no longer moves-it is arrested. The water no longer percolates through the snow-it is frozen. The mass is no longer semi-fluid-it is solid ice; and the first step in the process of a glacier's formation is begun.

Thereafter this process is continued from year to year, each winter adding largely to its bulk, each summer deducting slightly therefrom. The growing mass of ice ascends the mountain-sides, swallows the rocks and shrubs and trees in its progress, 
until its body becomes a thousand feet thick : the extreme summits of the mountain-peaks alone tower above the snowy waste, and the mass at the bottom is now, by the pressure of superincumbent masses, pure ice, hard and clear as crystal.

When the great glacier grows old it still maintains its stealthy downward motion during every summer. It has reached the shore, and has been pushed, like a huge white tongue, out into the sea.

"But what has all this to do with icebergs?" it may be inquired. Much, very much. It is common enough, in commenting on a child, to speak of the parent. The glacier is the mother of the iceberg.

When, in the world's early morning, the embryo glacier reached the sea, its thin edges were easily broken off by the waves; but as it increased and still further encroached, these edges became thicker and thicker, until at last a wall of pure ice, several hundred feet high, presented its glittering front to the ocean. It was hard and massive; the sun of summer had little effect on its frigid face, and it seemed to bid defiance to the sea itself. But things often are not what they seem. Each billow sapped its foundation; it soon began to overhang its base. At length the cohesion of the mass was not sufficient to sustain its weight. A rending, accompanied by sounds like heaven's artillery, took place; the crystal mountain bowed its brow and fell with thunderous crash upon the water; then, rocking 
slowly under the impulse of its dread plunge, the first iceberg floated off to sea!

It is right to remark here that this explanation is, to some extent, disputed-at least there is a difference of opinion as to the manner in which the iceberg leaves its parent glacier. There is no dispute as to its origin. This difference will be explained shortly in a quotation from Dr. Kane's work ; mean while, in support of the present theory, let us listen to the words of one who saw with his own eyes something similar to what has been described. Dr. Scoresby, than whom a better man never explored the arctic seas, says :-

"In July 1818, I was particularly fortunate in witnessing one of the grandest effects which these polar glaciers erer present. A strong northwesterly swell, having for some hours been beating on the shore, had loosened a number of fragments attached to the iceberg, and various heaps of broken ice denoted recent shoots of the seaward edge. As we advanced towards it, with a view of proceeding close to its base, I observed a few little pieces fall from the top; and while my eye was fixed upon the place, an immense column, probably fifty feet square, and one hundred and fifty feet high, began to leave the parent ice at the top, and, leaning majestically forward, with an accelerated velocity fell, with an awful crash, into the sea.

"The water into which it plunged was converted into an appearance of vapour or smoke, like that 
from a furious cannonading. The noise was equal to that of thunder, which it nearly resembled. The column which fell was nearly square, and in magnitude resembled a church. It broke into thousands of pieces. This circumstance was a happy caution, for we might inadvertently have gone to the very base of the icy cliff, from whence masses of considerable magnitude were continually breaking."

Now, this incident suggests the probability, that, had the face of the glacier projected into deep water, the mass which broke off might have fallen into the sea without being broken to pieces, and might have floated away as a berg. We confess, however, to be partial to the view expressed by some writers, that the great glaciers continue year by year to thrust their thick tongues out to sea, until the projecting masses reach water sufficiently deep to float them, when they are quietly cracked off from their parent and carried away without any fall or plunge. The following remarks by Dr. Kane will make this more clear. Writing of the iceberg, he says :-

"So far from falling into the sea, broken by its weight from the parent glacier, it rises from the sea. The process is at once gradual and comparatively quiet. The idea of icebergs being discharged, so universal among systematic writers, and so recently admitted by myself, seems to me at variance with the regulated and progressive action 
of nature. Developed by such a process, the thousands of bergs which throng these seas should keep the air and water in perpetual commotionone fearful succession of explosive detonations and propagated waves. But it is only the lesser masses falling into deep waters which could justify the popular opinion. The enormous masses of the Great Glacier [of Greenland] are propelled step by step, and year by year, until, reaching water capable of supporting them, they are floated off, to be lost in the temperatures of other regions......

"The height of the ice-wall at the nearest point was about three bundred feet, measured from the water's edge; and the unbroken right line of its diminishing perspective showed that this might be regarded as its constant measurement. It seemed, in fact, a great icy table-land, abutting with a clean precipice against the sea. This is, indeed, characteristic of all those arctic glaciers which issue from central reservoirs, or mers de glace, upon the fiords or bays, and is strikingly in contrast with the dependent or hanging glacier of the ravines."

Elsewhere the same writer speaks of this glacier as a line of cliff, rising in a solid glassy wall to a height of three hundred feet above the water-level, and with an unfathomable depth below it; and its curved face, sixty miles in length, from Cape Agassiz to Cape Forbes, vanished into unknown space at not more than a single day's rail-road travel from the pole. The interior with which it 
communicated, and from which it issued, was an unsurveyed mer de glace, or sea of ice, of apparently boundless dimensions; and from one part of this great cliff he saw long lines of huge bergs floating slowly away.

Here, we think, is ice enough and of sufficient dimensions to account for the largest bergs that were ever beheld.

It will be at once seen, then, that icebergs, though found floating in the sea, are not necessarily of the sea. They are composed entirely of fresh water, and arctic ships can at any time procure a plentiful supply of good soft drinkable water from the pools that are formed in the hollows of the bergs.

The risk of approaching icebergs in the arctic regions is not so great as when they are found floating further south; because when in their native regions they are comparatively tough, whereas on their southern journeys they become more or less disintegrated-in fact, the blow of an axe is sometimes sufficient to cause a rent, which in its turn will induce other rents and fallings asunder, so that the whole mass runs the risk of being entirely broken up. Hence the danger of ships, in certain circumstances, venturing to anchor to them. Nevertheless this is a common practice-sometimes a necessity-among discovery ships and whalers. It - is a convenient practice too ; for many a vessel has been saved from absolute destruction by getting 
under the lee of a good sound iceberg, where she has lain as safely, for the time being, as if in a harbour.

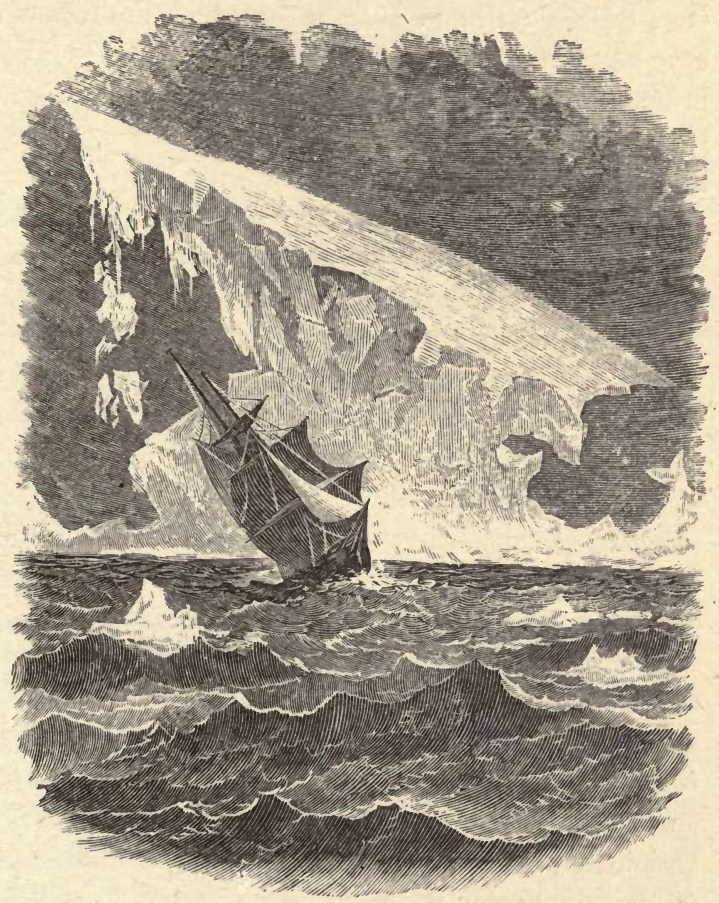

PROTECTED BY AN ICEBERG.

When Captain M'Clure was endeavouring to make the north-west passage in 1851, he was saved, from what appeared to be at least very probable 
destruction, by a small iceberg. - On the 17 th of September he writes:-

"There were several heavy floes in the vicinity. One, full six miles in length, passed at the rate of two knots, crushing everything that impeded its progress, and grazed our starboard-bow. Fortunately there was but young ice upon the opposite side, which yielded to the pressure; had it otherwise occurred, the vessel must inevitably have been cut asunder. In the afternoon we secured to a moderately-sized iceberg, drawing eight fathoms, which appeared to offer a fair refuge, and from which we never afterwards parted."

To this lump of ice the ship cling with the tenacity of a bosom friend, and followed it, literally, through thick and thin! There is something almost ludicrous, as well as striking, in M'Clure's account of-their connection with this bit of ice. It conveyed them to their furthest north-east position, and back round the Princess Royal Islands-passed the largest within five hundred yards-returned along the coast of Prince Albert's Land-and finally froze in at lat. $70^{\circ} 50^{\prime}$ north, long. $117^{\circ} 55^{\prime}$ west, on the 30th September; during which circumnavigation they received many severe "nips," and were frequently driven close to the shore, from which their dear friend the iceberg, small though he was, kept them off.

Icebergs assume almost every conceivable form, and are seen of every size-sometimes, also, in great 
numbers. Scoresby mentions one occasion on which he was surrounded by bergs to the number of several hundreds.

Now, all this ice that we have been speaking of, besides being, in a secondary way, a passive agent in the affairs of man (chiefly in barring his progress northward), is one of the most potent agents in the economy of nature. It is the means by which the world is kept cool enough for man and beast to dwell in. The polar regions-north and southare, as it were, the world's refrigerators; tempering the heated air of the south, and, in connection with the torrid zone, spreading throughout the Earth those beneficial influences which gladden the sphere of man's temporal existence.

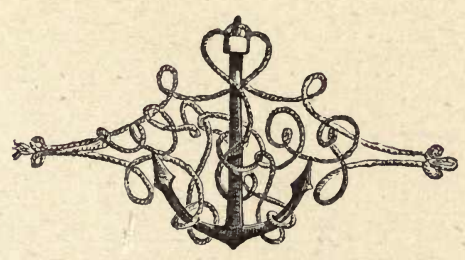




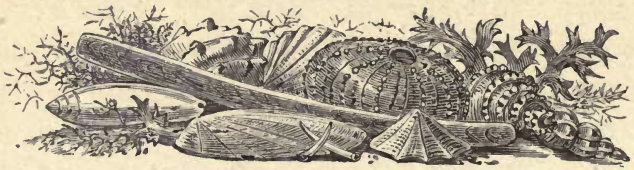

CHAPTER XI.

ICE AN AGENT IN TRANSPORTING BOULDERS-HOW THIS COMES ABOUT -DR. KANE'S OBSERVATIONS-LONG NIGHT IN WINTER AND LONG DAY IN SUMMER-EXTREME DARKNESS-INFLUENCE ON DOGS -INTENSE COLD-EFFECT ON THE SEA.

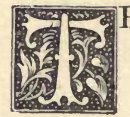

HERE are many things in this world which, up to within a few years back, have been to men a source of surprise and mystery. Some of these problems have been solved by recent travellers, and not a few of them are referable to polar oceans and ice.

In many parts of our coasts we find very striking and enormously large boulder-stones lying on the beach, perfectly isolated, and their edges rounded away like pebbles, as if they had been rolled on some antediluvian beach strewn with Titanic stones. These boulders are frequently found upon the loose sands of the sea-shore, far removed from any rocks or mountains from which they might be supposed to have been broken; and, more than that, totally different in their nature from the geological formations of the districts in which they are found. "Whence 
came these?" has been the question of the inquisitive of all ages, "and how came they there?"

There may, for aught we know to the contrary, be more than one answer to these questions; but there is at least one which is quite satisfactory as to how and whence at least some of them have come. Ice was the means of conveying these boulders to their present positions.

It has been said that once upon a time a large part of this country was under the dominion of ice, even as the polar regions and some of the mountains and valleys of Norway are at the present day; that the boulders we see in elevated places were conveyed thither by glacier action; and that when the glacial period passed away, they were left there on the hill-sides-sometimes almost on the mountain-tops. But this is not the question we are considering just now. We are now inquiring into the origin of those huge boulders that are found upon our coasts and on the coasts of other landsboulders which could not have rolled down from the hills, for there are no hills at all near many of them; and those hills that are near some of them are of different geological formation.

This question will be answered at once, and one of the phenomena of arctic ice and oceanic agency will be exhibited, by reference to the recent discoveries of the celebrated arctic voyager, Dr. Kane of the American Navy.

While wintering far beyond the head of Baffin's 
Bay, and beyond the most northerly point, in that direction, that had at that time been reached by any previous traveller, Dr. Kane made many interesting observations and discoveries. He seems to have penetrated deep into the heart of Nature's northern secrets. Among other things, he ascertained the manner in which boulders are transported from their northern home.

The slow, creeping movement of glaciers, to which we have already referred, is one means whereby large boulders are formed. At the lower edge of one of the glaciers of Norway we saw boulders, thirty or forty feet in diameter, which had been rolled and forced, probably for ages, down the valley by the glacier, and thrust out on the sea-beach, where they lay with their angles and corners rubbed off, and their surfaces rounded and smoothed as completely as those of the pebbles by which they were surrounded.

Had these boulders been formed in the arctic regions, they might have been thrust out upon the thick solid crust of the frozen sea, which in time would have been broken off and floated away; thus rafting the boulders to other shores. The formation of boulders, and their positions, are facts that we have seen. Their being carried out to sea by ice-rafts is a fact that Dr. Kane has seen and recorded. On the wild rocky shores where his ship was set fast, there was a belt of ice lining the margin of the sea, which he termed the "ice-belt," or the "ice-foot." 
This belt never melted completely, and was usually fast to the shore. In fact it was that portion of the sea-ice which was left behind each spring when the general body of ice was broken up and swept away. Referring to this, he writes :-

"The spot at which we landed I have called Cape James Kent. It was a lofty headland, and the land-ice which hugged its base was covered with rocks from the cliffs above. As I looked over this ice-belt, losing itself in the far distance, and covered with its millions of tons of rubbish, greenstones, limestones, chlorite, slates, rounded and angular, massive and ground to powder, its importance as a geological agent, in the transportation of drift, struck me with great force.

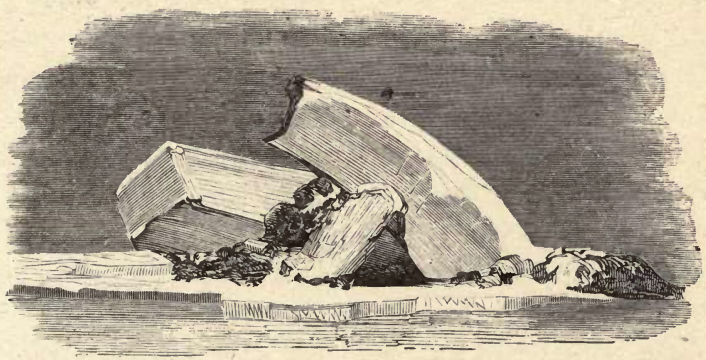

ICE RAFT.

"Its whole substance was studded with these varied contributions from the shore; and further to the south, upon the now frozen waters of Marshall Bay, I could recognise raft after raft from the last 
year's ice-belt which had been caught by the winter, each one laden with its heavy freight of foreign material.

"The water torrents and thaws of summer unite with the tides in disengaging the ice-belt from the coast; but it is not uncommon for large bergs to drive against it and carry away the growths of many years. I have found masses that had been detached in this way, floating many miles out at sea-long, symmetrical tables, two hundred feet long by eighty broad, covered with large angular rocks and boulders, and seemingly impregnated throughout with detrited matter. These rafts in Marshall Bay were so numerous, that could they have melted as I saw them, the bottom of the sea would have presented a more curious study for the geologist than the bouldercovered lines of our middle latitudes. One boulder in particular had had its origin in a valley where rounded fragments of water-washed greenstone had been poured out by the torrents and frozen into the coast-ice of the belt. The attrition of subsequent matter had truncated the great egg-shaped rock, and worn its sides into a striated face, whose scratches still indicated the line of water-flow."

So, then, when we next meet with a huge isolated boulder on any of our flat beaches, we may gaze at it with additional interest, when we reflect that, perchance, it was carried thither by the ocean, countless ages ago, from the arctic regions, on a gigantic raft of ice; after having been, at a still more remote 
period, torn from its cliffs by some mighty glacier and slowly rolled and rounded, for hundreds of years perhaps, down the scarred slopes of its native valley.

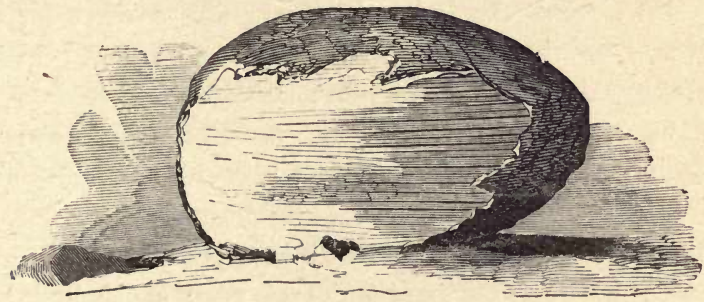

THE GREAT EGG-SHAPED ROCK.

The primary cause of the intense and prolonged cold of the arctic regions is the shortness of the time during which they are under the influence of the sun's rays. For a few months in summer the sun shines brightly, but, owing to the position of the globe, obliquely on the poles. During part of that period it shines at mid-night as well as at mid-day. But during the greater part of the year its beams throw but a feeble light there, and for several months in winter there is absolutely no day at all-nothing but one long dismal night of darkness, that seems as if the bright orb of day had vanished from the heavens for ever.

The length of this prolonged day in summer, and this dreary night in winter, depends, of course, upon latitude. The length of both increases as we approach the poles. The long daylight in summer is exceedingly delightful. We once saw the sun de- 
scribe an almost unbroken circle in the sky for many days and nights, and had we been a few degrees further north we should have seen it describe an entire circle. As it was, it only disappeared for twenty minutes. It set about midnight, and in twenty minutes it rose again; so that there was no night, not even twilight, but a bright, beautiful blazing day, for several weeks together.

Dr. Kane describes the midnight sun thus : "On our road we were favoured with a gorgeous spectacle, which hardly any excitement of peril could have made us overlook. The midnight sun came out over the northern crest of the great berg, our late 'fast friend,' kindling variously-coloured fires on every part of its surface, and making the ice around us one great resplendency of gem-work-blazing carbuncles and rubies, and molten gold."

Very different indeed is the aspect of the winter night. Let the same authority speak, for he had great experience thereof.

On December 15th he writes: "We have lost the last vestige of our mid-day twilight. We cannot see print, and hardly paper. The fingers cannot be counted a foot from the eyes. Noonday and midnight are alike; and, except a vague glimmer on the sky, that seems to define the hill-outlines to the south, we have nothing to tell us that this arctic world of ours has a sun. In one week more we shall reach the midnight of the year......

"The influence of this long intense darkness was 
most depressing. Even our dogs, although the greater number of them were natives of the arctic circle, were unable to withstand it. Most of them died from an anomalous form of disease, to which, I am satisfied, the absence of light contributed as much as extreme cold." Quoting from his journal he says: "I am so afflicted with the insomnia of this eternal night, that I rise at any time between midnight and noon. I went on deck this morning at five o'clock. It was absolutely dark; the cold not permitting a swinging lamp, there was not a glimmer came to me through the ice-crusted windowpanes of the cabin. While I was feeling my way, half puzzled as to the best method of steering clear of whatever might be before me, two of my Newfoundland dogs put their cold noses against my hand, and instantly commenced the most exuberant antics of satisfaction. It then occurred to me how very dreary and forlorn must these poor animals be, at atmospheres $10^{\circ}$ above zero in-doors and $50^{\circ}$ below zero without-living in darkness, howling at an accidental light, as if it reminded them of the moon -and with nothing, either of instinct or sensation, to tell them of the passing hours, or to explain the long lost daylight. They shall see the lantern more frequently."

Yet this state of midnight darkness is not altogether unmitigated. There are a few ameliorating influences at work, the nature of some of which we will treat of in the next chapter. Among others, 
the moon frequently shines there with great brilliancy in winter. Dr. Kane says that in October the moon had reached her greatest northern declination: "She is a glorious object. Sweeping around the heavens, at the lowest part of her curve she is still $14^{\circ}$ above the horizon. For eight days she has been making her circuit with nearly unvarying brightness. It is one of those sparkling nights that bring back the memory of sleigh-bells and songs and glad communings of hearts in lands that are far away."

Butıdespite all the varied and transient beauties of the northern skies in winter, the long arctic night is undoubtedly depressing in the extreme. In these regions men speak of being able to read the thermometer on the 7 th of November at noonday "without a light," as being matter for gratulation. The darkness still before them at that time would be of about three months' duration, and even then they would only get back to a species of twilight.

The cold experienced by these navigators of the northern seas is terribly intense. Their thermometers have frequently indicated a temperature as low as $75^{\circ}$ below zero, or 107 degrees of frost, on Fahrenheit's scale. The thermometers of arctic explorers are always filled with spirits of wine, as quicksilver freezes at about $40^{\circ}$ below zero, and is therefore unsuitable. It would be frozen, indeed, the greater part of the winter.

Dr. Kane says: "At such temperatures chloric ether became solid, and carefully prepared chloroform 
exhibited a granular pellicle on its surface. Spirits of naphtha froze at $54^{\circ}$ below zero, and oil of sassafras at $49^{\circ}$. The oil of winter-green was in a flocculent state at $56^{\circ}$, and solid at $63^{\circ}$.

"The exhalations from the surface of the body invested the exposed or partially clad parts with a wreath of vapour. The air had a perceptible pun. gency upon inspiration, but I could not perceive the painful sensation which has been spoken of by some Siberian travellers. When breathed for any length of time, it imparted a sensation of dryness to the air-passages. I noticed that, as it were involuntarily, we all breathed guardedly, with compressed lips."

Now, strange to say, this extremely low temperature does not affect the ocean to any great depth. Just below the ice, in cold such as the above, the sea was found to be $29^{\circ}$ above zero. No doubt, deeper down, the temperature was still warmer. We have heard it said, that when men chance to fall into the water in cold regions, in the depth of winter, it feels at first rather warm and agreeable! On scrambling, out again, however, their condition is not enviable; for in a few minutes the keen frost causes their garments to become as hard as boards.

Much light has been thrown on the fact of the existence of under and upper currents in the sea, by the phenomena of the arctic regions, and some of the questions to which these currents give rise are so interesting that we shall treat of them in a new chapter. 


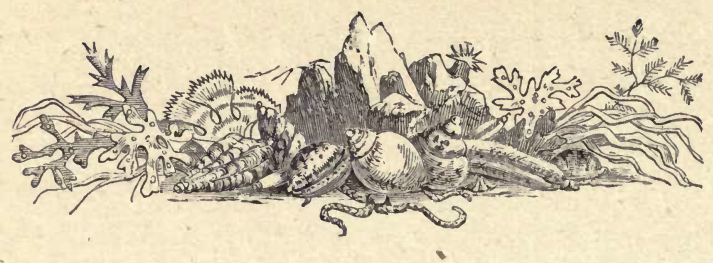

CHAPTER XII.

QUESTION OF AN OPEN SEA ROUND THE POLES-UPPER AND UNDEB CURRENTS OF THE OCEAN-CAUSE THEREOF-HABITS OF THE WHALE AS BEARING ON THE QUESTION-DR. KANE'S DISCOVERY OF AN OPEN SEA IN THE FAR NORTH-NOTES ON THE EXPEDITION-A BEAR-HUNT.

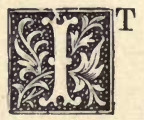

was long and very naturally supposed that the impenetrable ice of the arctic regions extended to, and, as it were, sealed up the pole. But from time to time philosophic observers of Nature's laws began to hint their opinion that there is an open ocean around the pole; and of late years this opinion has all but been converted into a firm belief.

Maury remarks, that like air-like the bodythe ocean must have a system of circulation for its waters. And an attentive study of the currents of the sea, and a close examination of the laws which govern the movements of the waters in their channels of circulation through the ocean, will lead us irresistibly to the conclusion that always, in summer and winter, there must be, somewhere within the arctic circle, a large body of open water. 
There is an under-current setting from the Atlantic, northward through Davis' Straits, into the Arctic Ocean, and a surface-current setting out. The fact is proved beyond a doubt by the observations of arctic explorers, who have seen immense icebergs drifting rapidly northward against a strong current. This apparent anomaly could only be accounted for by the fact that a powerful undercurrent carried them northward; and as at least seven times more of these bergs must have been under than above water, we can easily understand how the under-current, acting on the larger mass of each berg, had power to carry it against the surface-current.

This under-current is warm, while the uppercurrent is cold. Now we know that, according to Nature's laws, heated water, like heated air, rises to the surface, and cold water sinks to the bottom. How, then, comes this warm current to be underneath the cold, as soundings have proved it to be? It is owing to the fact that the under-current is much salter, and therefore heavier (despite its warmth), than the surface-current; which latter, being mingled with the drainage and ice-masses of the arctic regions, is comparatively fresh, and therefore light as well as cold.

The hot and salt waters of the tropics are carried north by the Gulf Stream. There are here two counteracting agents at work. Heat inclines the Gulf Stream to rise; saltness inclines it to (451) 
sink. During the first part of its journey, as we know, its great heat prevails over the other influence, and it flows as a surface-current. But, at a certain point in its northward route, it meets with the cold, brackish, ice-bearing currents that flow out of the arctic basin. Having lost much of its heat (though still possessing a great deal more than the arctic currents), the saltness of the Gulf Stream prevails ; it dips below the polar waters, and thenceforth continues its course as an under-current, salt, and comparatively warm.

To state the matter briefly: The hot water, which ought to keep on the surface because of its heat, is sunk by its superabundant salt; and the cold water, which ought to sink because of its 'cold, is buoyed on the surface because of its want of salt.

Now arises the question-What becomes of the great quantity of salt that is thus being carried perpetually into the polar basin? Manifestly it must be carried out again by the surface-current, otherwise the polar basin would of necessity become a basin of salt. The under-current must, therefore, rise to the surface somewhere near the pole, with its temperature necessarily only a little, if at all, below the freezing-point - which, be it observed, is a warm temperature for such regions. Here, then, where the warm waters from the south rise to the surface, it is supposed this open Arctic Ocean must exist. 
So much for theory. Now for facts that have been observed, and that tend, more or less, to corroborate this proposition of an open polar sea. The habits of the whale have gone far to prove it. The log-books of whalers have for many years been carefully examined and compared by scientific men. These investigations have led to the discovery "that the tropical regions of the ocean are to the 'right' whale as a sea of fire, through which he cannot pass, and into which he never enters." It has also been ascertained that the same kind of whale which is found off the shores of Greenland, in Baffin's Bay, \&c., is found in the North Pacific, and about Behring's Straits; and that the "right" whale of the southern hemisphere is a different animal from that of the northern. How, then, came the Greenland whales to pass from the Greenland seas to the Pacific? Not by the Capes Horn or Good Hope; the "sea of fire" precluded that. Clearly there was ground here for concluding that they did so through the (supposed) open sea lying beyond, or rather within, the frozen ocean.

It is true the objection might be made, that the same kind of whale which exists in the North Pacific exists also in the North Atlantic, although they never cross over to see each other. But another discovery has met this objection.

It is the custom among whalers to have their harpoons marked with date and name of ship, and Dr. Scoresby, in his work on arctic voyages men- 
tions several instances of whales having been taken near Behring's Straits, with harpoons in them bearing the stamp of ships that were known to cruise in the Greenland seas; and the dates on the harpoons were so recent as to preclude the supposition that the said whales had, after being struck, made a voyage round the capes above mentioned, even were such a voyage possible to them. All this does not, indeed, absolutely prove the existence of an open arctic sea, but it does, we think, prove the existence of at least an occasionally open sea there, for it is well known that whales cannot travel such immense distances under ice.

But the most conclusive evidence that we have in regard to this subject is the fact, that one of the members of Dr. Kane's expedition, while in search of Sir John Franklin, did actually, on foot, reach what we have every reason to believe was this open sea; but not being able to get their ship into it, the party had no means of exploring it, or extending their investigations. The account of this discovery is so interesting, and withal so romantic, that we extract a few paragraphs relating to it from Kane's work.

After spending the dreary winter in the icelocked and unexplored channels beyond the head of Baffin's Bay, Kane found his little ship still hopelessly beset in the month of June; he therefore resolved to send out a sledge-party under Morton, one of his best men, to explore the channel to the 
north of their position. After twelve days' travelling they came to the base of the "Great Glacier," where Morton left his party, and, in company with an Esquimaux named Hans, set out with a dogsledge to prosecute the journey of exploration.

They walked on the sea-ice in a line parallel with the glacier, and proceeded twenty-eight miles that day, although the snow was knee-deep and soft. At the place where they encamped a crack enabled them to measure the ice. It was seven feet five inches thick! And this in June. We may mention here, in passing, that Dr. Kane never got his vessel out of that frozen strait, which seems to be bound by perpetual ice. He and his party escaped with their lives; but the vessel that bore them thither is probably still embedded in that ice.

Next day Morton and Hans came to a region of icebergs, which had arrested a previous sledgingparty of the same expedition. "These [icebergs] were generally very high, evidently newly separated from the glacier. Their surfaces were fresh and glassy, and not like those generally met with in Baffin's Bay,-less worn, and bluer, and looking in all respects like the face of the Great Glacier. Many were rectangular, some of them regular squares, a quarter of a mile each way ; others more than a mile long."

To pass amidst these bergs was a matter of labour, difficulty, and danger. Sometimes the sides of them came so close together, that the men could 
scarcely squeeze between them, and they were obliged to search for other passages; in doing which, the variation of their compass confused them. At other times, " a tolerably wide passage would appear between two bergs, which they would gladly follow; then a narrower one; then no opening in front, but one to the side. Following that a little distance, a blank ice-cliff would close the way altogether, and they were forced to retrace their steps and begin again."

Thus they puzzled their way through, "like a blind man in the streets of a strange city ;" but more difficulties awaited them beyond. After advancing many miles they were arrested by broad rents in the ice, and were obliged to diverge frequently far out of their course, or to bridge the chasms over by cutting down the ice hummocks and filling them up with loose ice, until the dogs were able to haul the provision-sledge over.

Advancing thus for several days, and encamping on the snow at night, they at last came to a spot where the ice was dangerous. "It was weak and rotten, and the dogs began to tremble." Proceeding at a brisk rate, they had got upon unsafe ice before they were aware of it. 'Their course was at the time nearly up the middle of the channel; but as soon as possible they turned, and by a backward circuit reached the shore. The dogs, as their fashion is, at first lay down and refused to proceed, trembling violently. The only way to 
induce the terrified, obstinate brutes to get on, was for Hans to go to a white-looking spot, where the ice was thicker, the soft stuff looking dark; then calling the dogs coaxingly by name, they would crawl to him on their bellies. So they retreated from place to place, until they reached the firm ice they had quitted. A half mile brought them to comparatively safe ice, a mile more to good ice again.

In the midst of this danger they had, during the liftings of the fog, sighted open water. Soon after they saw it plainly. So many long and dreary months had these men passed since they were gladdened by the sight of open water, that they could scarcely believe their eyes ; and Morton declared, that but for the birds which were seen flying about it in great numbers, he would not have believed it.

They made for the land-ice as fast as possible, and quickly gained it; but the sea-ice had cracked off and sunk so much, that the land-ice presented a wall along the whole coast of about eight or nine feet high. It was quite perpendicular, in some places overhanging, so that it was a matter of the greatest difficulty they managed to throw up the provisions, clamber up themselves, and haul the dogs and sledge up afterwards. This accomplished, however, they were safe, and could advance with confidence. But this mass of land-ice became narrower as they proceeded, till at last it dwindled to a mere narrow ledge, clinging to the 
high, perpendicular cliffs, and looking as if at any moment it might crumble off, and fall with them into the open water between it and the floating sea-ice.

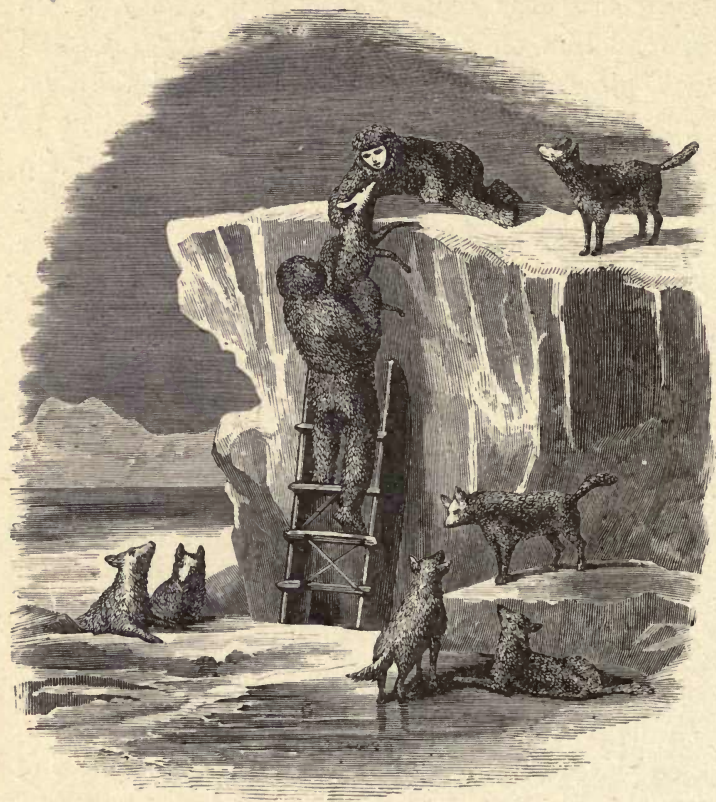

MORTON CLIMBING ON TO THE LAND-ICE.

The sea here was very deep and clear. They could see the bottom quite plainly, although a stone they cast in, the size of a man's head, took twentyeight seconds to reach it.

Being now afraid of the ice-ledge, they attempted 
to find a path along the face of the cliff; but failing in this, Morton determined to leave part of the provisions in "cache," and proceed with a lighter load. The cape round which they were travelling, and on the other side of which lay the open water, was extremely bold, and the ice-ledge at the end of it was barely three feet wide; so they were obliged to unloose the dogs, and drive them forward alone, then tilted the sledge on one runner, and thus pushed it past the worst place.

Here the ice on the sea was partly broken up, and a strong tide was running from the southward. The night before it had been running from the north. As they advanced, the channel became still more open, and after passing the cape they saw nothing but open water, with innumerable wild seabirds of every description flying overhead, or disporting in the pools. Let it be observed here, however, that this was the open water of a strait or channel,-not the great Arctic Sea, about the probable existence of which we have been writing. Upon the ice-masses near them numerous seals were seen basking.

One thing that struck them much here was, that although strong north winds, amounting to a gale at times, had been blowing for several days, no ice had been brought down from the north into the channel, along the shore of which they travelled. Thick, damp fogs prevailed, preventing them from seeing far in advance at any time. 
At last they came to a place where the broken ice of the shore rendered passage for the sledge impossible. They therefore tied the dogs, intending to push forward a short way alone. But they had not been sufficiently careful to secure them; for the poor animals, supposing themselves deserted, no doubt, succeeded in breaking their lines, and rejoined the two men in about an hour after. This, as it turned out, was rather a fortunate circumstance.

Preparatory to quitting their sledge, the men had loaded themselves with eight pounds of pemmican and two of biscuit, besides the artificial horizon, sextant, and compass, a rifle, and a boathook. They had not been an hour gone when, as above stated, four of the dogs overtook them. An hour afterwards they came upon a polar bear with her cub.

The fight that followed, although somewhat foreign to our subject, is so graphically described by Dr. Kane, that we think it quite unnecessary to apologize for inserting it here.

"The bear instantly took to flight; but the little one being unable to keep pace with her, she turned back, and, putting her head under its haunches, threw it some distance. The cub safe for the moment, she would then wheel round and face the dogs, so as to give it a chance to run away; but it always stopped, just as it alighted, till she came up and threw it ahead again; it seemed to expect 
her aid, and would not go on without it. Sometimes the mother would run a few yards ahead, as if to coax the young one up to her, and when the dogs came up she would turn and drive them back; then, as they dodged her blows, she would rejoin the cub and push on, sometimes putting her head under it, sometimes catching it in her mouth by the nape of the neck.

"For a time she managed her retreat with great celerity, leaving the two men far in the rear. They had engaged her on the land-ice; but she led the dogs in-shore, up a small stony valley which opened into the interior. After she had gone a mile and a half, her pace slackened, and, the little one being jaded, she soon came to a halt.

"The men were then only half a mile behind, and running at full speed. They soon came up to where the dogs were holding her at bay. The fight was now a desperate one. The mother never went more than two yards ahead, constantly looking at the cub. When the dogs came near her, she would sit upon her haunches, and take the little one between her hind-legs, fighting the dogs with her paws, and roaring so that she could have been heard a mile off. Never was an animal more distressed. She would stretch her neck and snap at the nearest dog with her shining teeth, whirling her paws like the arms of a windmill. If she missed her aim, not daring to pursue one dog lest the others should harm the cub, she 
would give a great roar of baffled rage, and go on pawing and snapping, and facing the ring, grinning at them with her mouth stretched wide.

"When the men came up the little one was perhaps rested, for it was able to turn round with its dam, no matter how quick she moved, so as to keep always in front of her belly. The five dogs were all the time frisking about her actively, tormenting her like so many gad-flies. Indeed they made it difficult to take an aim at her without killing them. But Hans, lying on his elbow, took a quiet aim, and shot her through the head. She dropped and rolled over dead, without moving a muscle.

"The dogs sprang towards her at once; but the cub jumped upon her bolly and reared up, for the first time growling hoarsely. They seemed quite afraid of the little creature, she fought so actively, and made so much noise; and, while tearing mouthfuls of hair from the dead mother, they would spring aside the minute the cub turned towards them. The men drove the dogs off for a time, but were obliged to shoot the cub at last, as she would not quit the body.

"Hans fired into her head. It did not reach the brain, though it knocked her down; but she was still able to climb on her mother's body, and try to defend it, her mouth bleeding like a gutterspout. They were obliged to despatch her with stones." 


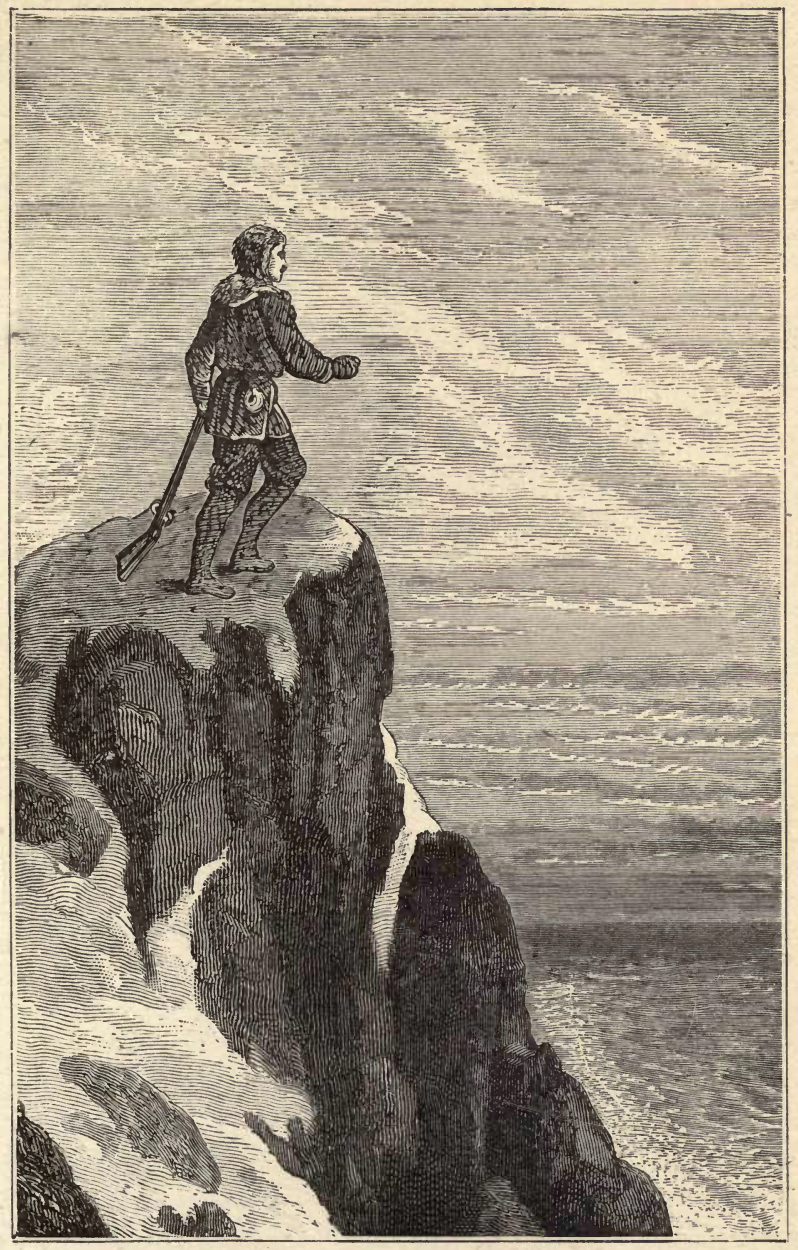

MORTON DISCOVERS THE OPEN SEA. 
After skinning the old one they gashed its body, and the dogs fed upon it ravenously. The little one they cached for themselves against their return.

This little fight quite knocked up Hans the Esquimaux, Morton therefore advanced alone, in the hope of being able to get beyond a huge cape that lay before him. On reaching it, the grand sight of an apparently boundless ocean of open water met his eye. Only "four or five small pieces" of ice were seen on the glancing waves of this hitherto unknown sea. "Viewed from the cliffs," writes Dr. Kane, "and taking thirty-six miles as the mean radius open to reliable survey, this sea had a justly-estimated extent of more than 4000 square miles."

Here, then, in all probability, is the great Arctic Ocean that has been supposed to exist in a perpetually fluid state round the pole, encircled by a ring of ice that has hitherto presented an impenetrable barrier to all the adventurers of ancient and modern times. There were several facts connected with this discovery that go far to prove that this ocean is perpetually open.

Further south, where Dr. Kane's brig lay in ice that seemed never to melt, there were few signs of animal life-only a seal or two now and then; but here, on the margin of this far northern sea, were myriads of water-fowl of various kinds.

"The Brent goose," writes the Doctor, "had not 
been seen before since entering Smith's Strait. It is well known to the polar traveller as a migratory bird of the American continent. Like the others of the same family, it feeds upon vegetable matter, generally on marine plants, with their adherent molluscan life. It is rarely or never seen in the interior; and from its habits may be regarded as singularly indicative of open water. The flocks of this bird, easily distinguished by their wedge-shaped line of flight, now crossed the water obliquely, and disappeared over the land to the north-east.

"The rocks on shore were crowded with seaswallows, birds whose habits require open water; and they were already breeding......The gulls were represented by no less than four species. The kittiwakes - reminding Morton of 'old times in Baffin's Bay'-were again stealing fish from the water (probably the small whiting), and their grim cousins, the burgomasters, enjoying the dinner thus provided at so little cost to themselves. It was a picture of life all round.

"Here, for the first time, Morton noticed the arctic petrel, - a fact which shows the accuracy of his observation, though he had not been aware of its importance. This bird had not been met with since we left the north water of the English whalers, more than two hundred miles south of the position on which he stood. Its food is essentially marine; and it is seldom seen in numbers, except in the highways of open water 
frequented by the whale and the larger representatives of ocean life. They were in numbers flitting and hovering over the crests of the waves, like their relatives of kinder climates,-the Cape of Good Hope pigeons, Mother Carey's chickens, and the petrels everywhere else.

"It must have been an imposing sight, as Morton stood at this termination of his journey, looking out upon the great waste of waters before him. Not a speck of ice could be seen. There, from a height of 480 feet, which commanded a horizon of almost forty miles, his ears were gladdened with the novel music of dashing waves; and a surf, breaking in among the rocks at his feet, stayed his further progress."

Strong presumptive evidence, all this, that there is an ocean of open water round the pole, and a milder climate there than exists nearer to the arctic circle. Had the short barrier of ice that intervened between the brig and that mysterious sea been removed, as, perchance, it is sometimes removed by a hot summer, Dr. Kane might have been the first to reach the North Pole. This, however, is reserved for some other navigator. The gallant Kane now lies in an early grave; but some of his enterprising comrades have returned to those regions, bent on solving this problem; and it is possible that, even while we now write, their adventurous keel may be ploughing the waters of the hitherto untraversed and mysterious polar sea. 


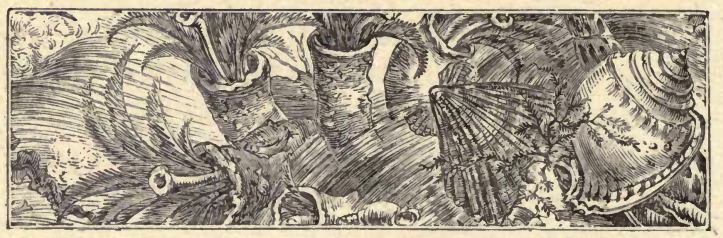

\section{CHAPTER XIII.}

MISCELlaNeOUS PHENOMENA OF THE POLAR SEAS AND REgIONSTHE AURORA BOREALIS - ICE-BLINK - OPTICAL ILLUSIONSANECDOTE OF SCORESBY - HALOS - CORONA-MOCK SUNSREFRACTION-FROSTS.

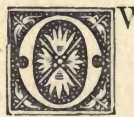

WING to the intensity of the cold in the arctic regions, there are, as we may readily believe, many singular appearances connected with the ocean and the atmosphere, which are worthy of special notice.

Chief, perhaps, among the phenomena of those regions is the Aurora Borealis.

Ever mindful of the welfare of the creatures whom he has formed, the Almighty has appointed a light to mitigate the darkness of the polar regions when the sun, in its appointed course, withdraws for a season.

What the aurora borealis is no one knows, although many have hazarded opinions regarding it. What it is like is known even to ourselves, though the faint indications of it which sometimes beam in our own heavens are not to be compared to the 
brilliancy of the spectacle that is occasionally presented in the northern skies.

The most ordinary aspect of the aurora is that of a band of pale-green light extending irregularly over part of the sky, and marked by wavy motions, as well as by varying brightness. Sometimes one

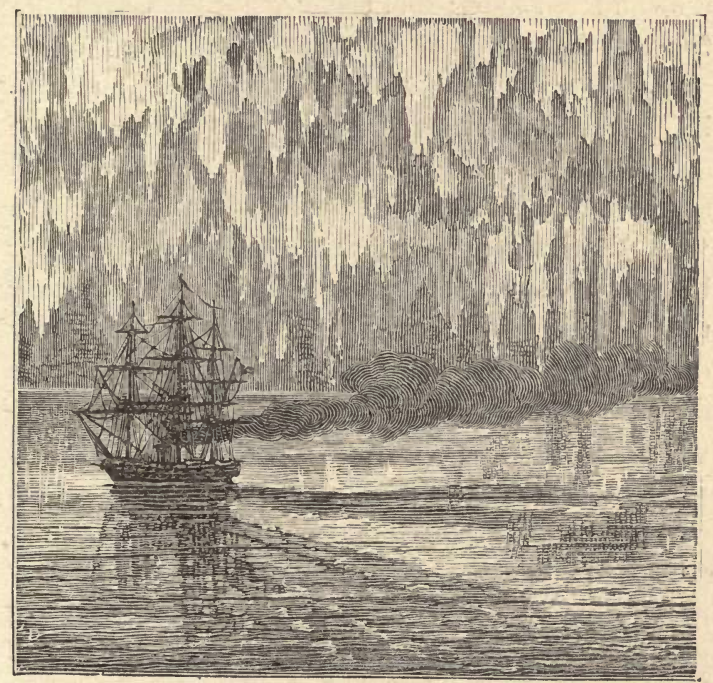

AURORA BOREALIS.

part of this band becomes more bright than another part. Sometimes the whole seems to move gently, - like the undulations of a flag in a light breeze ; at other times more vigorous action takes place, and pointed tongues of light shoot vividly up into the 
zenith. This sometimes takes place so frequently, and the tongues are so long and numerous, that the aurora has been popularly termed the " northern streamers."

Although pale-green is the most frequent colour, the aurora borealis has often been observed with blue and red hues; and the sky has been seen suffused with an intense crimson colour by it.

Captains Parry and Lyon saw these northern lights in full splendour during their residence in the arctic regions. They tell us that "the aurora had a tendency to form an irregular arch, which, in calm weather, was very often distinct, though its upper boundary was seldom well defined; but whenever the air was agitated, showers of rays spread in every direction with the rapidity of lightning, but always appearing to move to and from a fixed point, somewhat like a ribbon held in the hand and shaken with an undulatory motion. No rule, however, could be traced in the movement of those lighter parcels called the 'merry dancers,' which flew about perpetually towards every quarter; becoming in stormy weather more rapid in their motions, and sharing all the wildness of the blast. They gave an indescribable air of magic to the whole scene, and made it not wonderful that, by the untaught Indian, they should be viewed as "the spirits of his fathers roaming through the land of souls.'"

We are told by some that the aurora borealis is accompanied by a loud hissing and crackling sound; 
and Captain Lyon says that the sudden glare and rapid bursts of those wondrous showers of fire make it difficult to believe that their movements are wholly without sound. Yet such would seem to be the case, for the same authority tells us that he stood on the ice for hours listening intently and could hear nothing. He was thoroughly convinced that no sound proceeds from the aurora, and most intelligent voyagers support him in this opinion.

That the aurora dims the lustre of the stars seen through it, is a fact which was ascertained clearly by the same gentleman; and that it moves in a region beyond the clouds is also evident from the fact that when the latter covered the sky the aurora disappeared.

But some of the most singular appearances of the sea and sky in the polar regions are presented in summer. During that season the perpetual presence of the sun and the large tracts of ice floating about on the sea exert their opposing influences so as to produce the most astonishing results.

One part of the sea being covered with ice, produces a cold atmosphere; another part being free from ice, produces a warmer atmosphere. Refraction is the result of viewing objects through those different media, and very curious appearances follow. When Scoresby was in Greenland a singular atmospheric phenomenon occurred, whereby he became aware of the approach of his father's ship some time before it rose above the horizon. He had reached 
Greenland before his father, who followed him in the Fame. The following is his account of the circumstance :-

"On my return to the ship, about eleven o'clock, the night was beautifully fine and the air quite mild. The atmosphere, in consequence of the warmth, being in a highly refractive state, a great many curious appearances were presented by the land and icebergs. The most extraordinary effect of this state of the atmosphere, however, was the distinct inverted image of a ship in the clear sky, over the middle of the large bay or inlet, the ship itself being entirely beyond the horizon. Appearances of this kind I have before noticed, but the peculiarities of this were the perfection of the image, and the great distance of the vessel that it represented. It was so extremely well defined, that, when examined with a telescope, I could distinguish every sail, the general 'rig of the ship,' and its peculiar character; insomuch that I confidently pronounced it to be my father's ship the Fame, which it afterwards proved to be, though, on comparing notes with my father, I found that our relative positions at the time gave our distance from one another very nearly thirty miles, being about seventeen miles beyond the horizon, and some leagues beyond the line of direct vision."

Scoresby was, perhaps, one of the most persevering and intelligent observers of nature that ever went to the polar seas. His various accounts of 
what he saw are most interesting. We cannot do better than quote his remarks upon ice-blink, that curious appearance of white light on the horizon, whereby voyagers are led to infer the presence of ice :-

"This appearance of the ice-blink," says he, " occurred on the 13th of June 1820, in latitude $76^{\circ}$ north. The sky aloft was covered with dense, uniform, hazy cloud, which indeed occupied the whole of the heavens, excepting a portion near the horizon, where it seemed to be repelled. The upper white blink referred to ice about six miles distant, being beyond the horizon; the narrow yellowish portions referred to floes and compact ice; the lowest yellow blink, which in brightness and colour resembled the moon, was the reflection of a field at the distance of thirty miles, to which, directed by the blink, we made way in the Baffin, through the channels of water represented in the sky by bluish-gray streaks. The field we found to be a sheet of ice $\mathbf{1 5 0}$ miles in circumference !"

Another very singular appearance observed occasionally in foggy weather is a series of bright circles, or coronæ, surrounding the heads or persons of individuals in certain positions. We have, while standing at the mast-head of a vessel in Hudson's Straits, observed our own shadow thrown on the sea with a bright halo round it. The day was bright and hazy at the time. Referring to a particular case of this kind, Scoresby says :-

"During the month of July 1820, the weather 
being often foggy, with a bright sun sometimes shining at the height of the day, some extraordinary coronæ were observed from the mast-head. These occurred opposite to the sun, the centre of all the circles being in a line drawn from the sun through the eye of the observer. On one occasion four coloured luminous circles were observed. The exterior one might be twenty degrees in diameter. It exhibited all the colours of the spectrum. The next, a little within it, was of a whitish-gray colour; the third was only four or five degrees in diameter, and though it exhibited the colours of the spectrum, these colours were not very brilliant. The fourth was extremely beautiful and brilliant. The interior colour was yellow, then orange, red, violet, \&c. The colours of the whole three coronæ were, I think, in the same order, but of this I am not very certain. Indeed, on reflection, I suspect that the second circle must have been in the reverse order of the first; the first and the fourth being the same. The third was not coloured. In the midst of these beautiful coronæ I observed my own shadow, the head surrounded by a glory. All the coronæ were evidently produced by the fog; my shadow was impressed on the surface of the sea."

The cause of these phenomena is "the reflection of the sun's rays, decomposed by different refractions in minute globules of water, of which the mist, wherein the coronæ occur, in a great measure appears to consist." 
Mock suns, or parhelia, are common appearances in northern skies. Sometimes two of these mock suns are seen, one on each side of their great original, glowing so brightly that either of them, if we could suppose it to have shone in the sky alone, would have made a very respectable sun indeed!

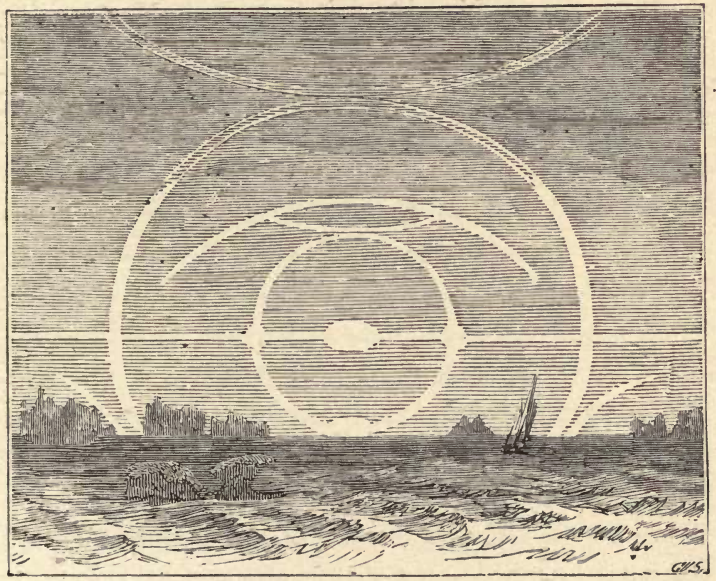

MOCK SUNS.

Even four of these "sun-dogs"-as they are sometimes called-have been seen surrounding the sun; one on each side of it, one directly above, and one immediately below, with a ring of light connecting them together, a streak of light passing horizontally and another passing perpendicularly between them, thus forming a luminous cross, in the centre of 
which was the sun itself. This magnificent spectacle is sometimes enhanced by a second circle of light enclosing the whole, and the edges of several outer circles springing in faint light therefrom until gradually lost, leaving the imagination to call up the idea of an endless series of glories extending over the whole sky.

Refraction frequently causes grotesque as well as wonderful and beautiful appearances. Ships are sometimes seen with their hulls flattened and their masts and sails drawn out to monstrous dimensions ; or the hulls are heightened so as to appear like heavy castle walls, while the masts and sails are rendered ludicrously squat and disproportioned; and not only so, but ships are often seen with their images inverted over their own masts, so that to the observer it appears as if one ship were balancing another upside down - mast-head to mast-head. Land and icebergs assume the same curious appearancespeaks touching peaks, one set pointing upwards, the other set pointing down, while the broad bases are elevated in the air. At other times the whole mass of land and ice on the horizon is more or less broken up and scattered about as if in confusion, yet with a certain amount of regularity in the midst of it all, arising from the fact of every object being presented in duplicate, sometimes triplicate, and occasionally, though seldom, four-fold.

When sharp sudden frosts occur in those regions, the splendour of the scenery is still further en- 
hanced by the formation of innumerable minute crystals which sparkle literally with as much lustrous beauty as the diamond. On one occasion Scoresby's ship was decorated with uncommon magnificence, and in a peculiarly interesting manner.

"In the course of the night," he writes, "the rigging of the ship was most splendidly decorated with a fringe of delicate crystals. The general form of these was that of a feather having half of the vane removed. Near the surface of the ropes was first a small direct line of very white particles, constituting the stem or shaft of the feather; and from each of these fibres, in another plane, proceeded a short delicate range of spiculæ or rays, discoverable only by the help of a microscope, with which the elegant texture and systematic construction of the feather were completed. Many of these crystals, possessing a perfect arrangement of the different parts corresponding with the shaft, vane, and rachis of a feather, were upwards of an inch in length, and three-fourths of an inch in breadth. Some consisted of a single flake or feather, but many of them gave rise to other feathers, which sprang from the surface of the vane at the usual angle. There seemed to be no limit to the magnitude of these feathers, so long as the producing cause continued to operate, until their weight became so great, or the action of the wind so forcible, that they were broken off; and fell in flakes to the deck of the ship."

It is impossible for the mind to conceive the effect 
of such a galaxy of curious, and bright, and eminently beautiful combinations as are sometimes displayed in the arctic regions. None of the fabulous conceptions of man, even though profoundly elaborated and brightly gilded with the coruscations of the most sparkling genius and fancy, ever produced so gorgeous a spectacle as may be witnessed there every summer day. Four or five suns in the blue sky, with lines and circles of light shooting from or circling round them! Ice in all its quaint, majestic, and shining forms, rendered still more quaint and grand by the influence of refraction; and, by the same power, ships sailing in the sky, sometimes, as if Nature's laws were abrogated, with their keels upwards, and their masts pointing to the sea! Walls of pure ice hundreds of feet high, many miles in extent, clear as crystal, and sending back the rays of heaven's luminaries in broad blazing beams; while the icebergs' pinnacles reflect them in sparkling points! White luminous fogs, like curtains of gauze, too thin to dim the general brightness, yet dense enough to invest the whole scene with a silver robe of mystery, and to refract the light and compel it to shine in great circles of prismatic colours! And everything-from the nature of the materials of which the gay scenery is composed-either white or blue, varying in all gradations from the fairest snow to the deepest azure, save where the rainbow's delicate hues are allowed to intermingle enough of pink, yellow, purple, orange, and green 
to relieve the eye and enable it more fully to appreciate the virgin drapery of the scene. All this, seen in detail - seen frequently in rapid succession-sometimes seen almost all at one moment,- all this is absolutely beyond conception, and utterly beyond adequate description. Yet all this is seen at times in those realms of ice and snow; which are, as we have already said, too much represented as the "gloomy, forbidding, inhospitable polar regions."

There are two sides to every picture. We take leave of this particular branch of our subject with the remark, that if the shady side of the far north is dreadfully dark and dreary, its bright side is intensely brilliant and beautiful.

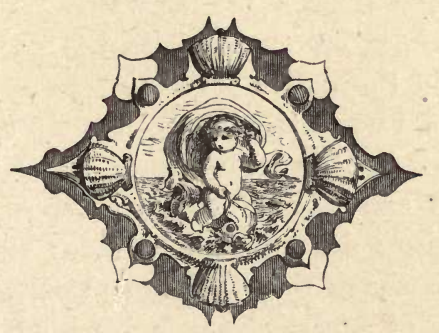




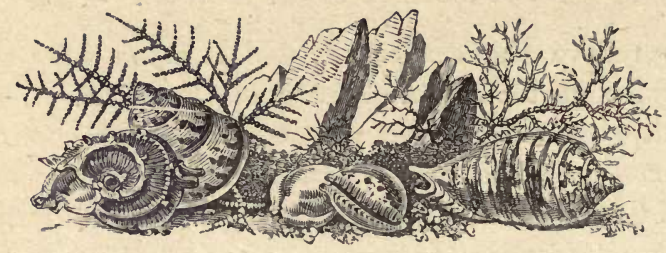

CHAPTER XIV.

ANIMAL LIFE IN THE SEA-MEDUSA-FOOD OF THE WHALE-PHOSPHORIC LIGHT-CAUSE THEREOF-LUMINOSITY OF THE OCEAN.

0 EFERENCE has elsewhere been made in 17 this volume to the immense amount of 203. animal life that exists in the ocean, not only in the form of fish of all sizes, but in that of animalcules, which, although scarcely visible to the naked eye, are, in some cases, so innumerable as to give a distinct colouring to the water.

The Medusce, or, more familiarly, sea blubbers, are seen in the waters that lave our own shores. They are of various sizes, from that of a large plate to a pin-head. They are almost colourless, like clear jelly, and when carelessly observed, seem to be dead objects drifting with the tide; but a closer observation shows that they are possessed of life, though not of a particularly active kind, and that they swim by alternate contractions and expansions of their bodies. These creatures constitute a large part of the whale's food. Some of them are flat, some semi-globular, others are bell-shaped, while 
some have got little heads and small fins. Of these last it is said that each little creature has no fewer than three hundred and sixty thousand minute suckers on its head with which it seizes its prey. When we think of the exceeding smallness of the creatures thus preyed upon, and consider the fact that each little thing must obtain food by making war upon some creatures still smaller than itself,we are led almost in spite of ourselves into that mysteriously metaphysical question-infinitesimal divisibility; which may be translated thus-the endless division and subdivision of atoms. This subject has puzzled the heads of the profoundest philosophers of all ages ; we will not, therefore, puzzle our readers with it any further.

Scoresby tells us that the colour of the Greenland Sea varies from ultramarine blue to olive-green, from the purest transparency to striking opacity; and that these colours are permanent, and do not depend on the state of the weather, but on the quality of the water. $\mathrm{He}$ observed that whales were found in much greater numbers in the green than in the blue water; and he found, on examining the former with the microscope, that its opacity and its colour were due to countless multitudes of those animalcules on which the whale feeds.

We need scarcely remark that it is utterly beyond the power of man to form anything approaching to a correct conception of the amount of life that is thus shown to exist in the ocean. Although it has pleased 
the Creator to limit our powers, yet it has also pleased him to leave the limit of those powers undefined. We may not, indeed, ever hope in this life to attain to perfect knowledge, nevertheless, by "searching" we may "find out wisdom;" and certain it is, that, although there undoubtedly must be a point of knowledge on any given subject which man cannot reach, there is in man a power incessantly to extend his knowledge and increase his powers of conception, by each successive effort that he makes in his course from the cradle to the grave.

Even although we were told the exact number of the little creatures that inhabit the sea, we could not, by any simple effort of the mind, however powerful, form a conception of what that number implied. We might shut ourselves up like the hermits of old, abstract our thoughts from all other things, and ponder the subject for weeks or months together, and at the termination of our effort we should be as wise as we were at its commencement, but no wiser. But by searching round the subject, and comparing lesser things with greater, although we should still fail to arrive at a full comprehension of the truth, we may advance our powers of conception very considerably beyond the point attained by our first effort; and which point, as we have said, could not be surmounted by a hair's breadth by the mere exertion of simple or abstract thought.

Dr. Scoresby's remarks on the subject of animal life in the ocean, are so graphic and curious that we 
extract the passages verbatim from the admirable memoir of that gentleman, written by his nephew. He says :-

"I procured a quantity of snow from a piece of ice that had been washed by the sea, and was greatly discoloured by the decomposition of some peculiar substance upon it. A little of this snow dissolved in a wine-glass appeared perfectly nebulous-the water being found to contain a great number of semi-transparent spherical substances, with others resembling small portions of fine hair. On examining these substances with a compound microscope, -I was enabled to make the following observations :-

"The semi-transparent globules appeared to consist of an animal of the medusa kind. It was from one-twentieth to one-thirtieth of an inch in diameter. Its surface was marked with twelve distinct patches, or nebulæ, of dots of a brownish colour. These dots were disposed in pairs, four pairs or sixteen pairs alternately, composing one of the nebula. The body of the medusa was transparent. When the water containing these animals was heated, it emitted a very strong odour, in some respects resembling the smell of oysters when thrown on hot coals, but much more offensive.

"The fibrous or hair-like substances were more easily examined, being of a darker colour. They varied in length from a point to one-tenth of an inch; and when highly magnified, were found 
beautifully noniliform. Whether they were living animals, and possessed of locomotion, I could not ascertain. They possessed the property of decomposing light, and in some cases showed all the colours of the spectrum very distinctly.

- "I afterwards examined the different qualities of sea water, and found these substances very abundant in that of an olive-green colour ; and also occurring, but in lesser quantity, in the bluish-green water. The number of medusæ in the olive-green water was found to be immense. They were about one-fourth of an inch asunder. In this proportion, a cubic inch of water must contain 64 ; a cubic foot 110,592 ; a cubic fathom $23,887,872$; and a cubic mile about $23,888,000,000,000,000$."

Of course we have, in the last two numbers, reached the utterly incomprehensible; but Dr. Scoresby goes into comparisons which help us a little, at least to ascertain how hopelessly beyond our conceptions such numbers are.

"From soundings made in the situation where these animals were found, it is probable the sea is upwards of a mile in depth; but whether these substances occupy the whole depth is uncertain. Provided, however, the depth to which they extend be but two hundred and fifty fathoms, the above immense number of one species may occur in the space of two miles square. It may give a better conception of the amount of medusæ in this extent, if we calculate the length of time that would be requisite, 
with a certain number of persons, for counting this number. Allowing that one person could count a million in seven days, which is barely possible, it would have required that eighty thousand persons should have started at the creation of the world to complete the enumeration at the present time!

"What a stupendous idea this gives of the immensity of creation, and of the bounty of Divine Providence in furnishing such a profusion of life in a region so remote from the habitations of men!

"The larger portion of these medusæ, consisting of transparent substances of a lemon-yellow colour, and globular form, appeared to possess very little power of motion. Some of them were seen advancing by a slight waving motion, at the rate of a hundred and eightieth of an inch in a second; and others, spinning round with considerable celerity, gave great interest and liveliness to the examination. But the progressive motion of the most active, however distinct and rapid it might appear under a high magnifying power, was, in reality, extremely slow ; for it did not exceed an inch in three minutes. At this rate they would require one hundred and fifty-one days to travel a nautical mile.

"The vastness of their numbers, and their exceeding minuteness, are circumstances, discovered in the examination of these animalcules, of uncommon interest. In a drop of water examined by a power of 28.224 (magnified superficies) there were fifty in number, on an average, in each square of the mi- 
crometer glass, of an eight hundred and fortieth of an inch; and as the drop occupied a circle on a plate of glass containing 529 of these squares, there must have been, in this single drop of water, taken out of the yellowish-green sea, in a place by no means the most discoloured, about 26,450 animalcules. Hence, reckoning sixty drops to a dram, there would be a number in a gallon of water exceeding, by one half, the amount of the population of the whole globe! It gives a powerful conception of the minuteness and wonders of creation, when we think of mme than twenty-six thousand animals living, obtairing subsistence, and moving perfectly at their ease, without annoyance to one another, in a single drop of water......A whale requires a sea, an ocean, to sport in. About one hundred and fifty millions of these animalcules would have abundant room in a tumbler of water !"

But besides furnishing food to the whale, and, no doubt, to many other of the inhabitants of the deep, those medusæ are the cause of the phosphorescent light that sometimes glows on the ocean with resplendent brilliancy. We see this light oftentimes on our own coasts. It is usually of a pale bluishwhite colour, more or less intense, apparently, according to the condition of the creatures by which it is emitted. It can only be seen at night. We have seen it on the west coast of Scotland, so bright that the steamer in which we sailed left behind her what appeared to be a broad highway of liquid fire. 
At times it requires vigorous motion, such as takes place when an oar is dipped, a stone thrown, or paddle-wheels dashed into the water; but at other times, the mere motion of the ocean swell, even in calm weather, is sufficient to stir up the lambent light and cause the crest of every undulation to glitter as if tipped with burnished silver. In such circumstances we have seen the ends of the oars of a boat silvered with it when lifted out of the wave, and the drops which fell from them before being redipped resembled the most beautiful diamonds.

Mr. P. H. Gosse, in his interesting work, "The Ocean," gives the following account of this luminosity of the sea, as witnessed by himself on one occasion :-

"In a voyage to the Gulf of Mexico, I saw the water in those seas more splendidly luminous than I had ever observed before. It was indeed a magnificent sight, to stand on the fore-part of the vessel and watch her breasting the waves. The mass of water rolled from her bows as white as milk, studded with those innumerable sparkles of blue light. The nebulosity instantly separated into small masses, curdled like clouds of marbles, leaving the water between of its own clear blackness; the clouds soon subsided, but the sparks remained. Sometimes one of these points, of greater size and brilliancy than the rest, would suddenly burst into a small cloud of superior whiteness to the mass, and be then lost in it. The curdling of the milky appearance into clouds 
and masses, and its quick subsidence, were what I had never before observed elsewhere."

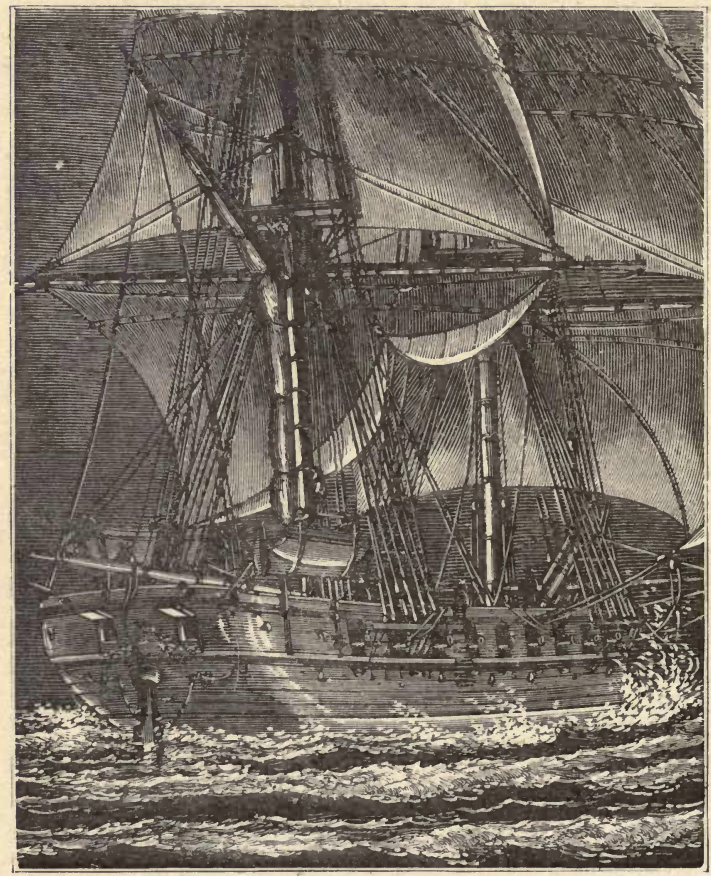

PHOSPHORESCENT SEA.

Many scientific travellers have carefully examined this subject, and we believe that all agree in referring this beautiful appearance to the medusæ. One gentleman drew a bucketful of water from the sea 
while it was in this condition, and found, on examining it in a dark place, that the little creatures "could be distinetly seen emitting a bright speck of light. Sometimes this was like a sudden flash, at others appearing like an oblong or round luminous point, which continued bright for a short time, like a lamp lit beneath the water, and moving through it, still possessing its definite shape, and then suddenly disappearing. When the bucket was sharply struck on the outside, there would appear at once a great number of these luminous bodies, which retained their brilliant appearance for a few seconds, and then all was dark again. They evidently appeared to have it under their own will, giving out their light frequently, at various depths in the water, without any agitation being given to the bucket. At times might be seen minute but pretty bright specks of light, darting across a piece of water and then vanishing; the motion of the light being exactly that of the cyclops through the water. Upon removing a tumblerful from the bucket, and taking it to the light, a number of cyclops were accordingly found swimming and darting about in it."

We have given the above quotation at full length, because it proves, in an interesting manner, the fact that phosphorescence, or luminosity, of the sea is actually produced by multitudes of living creatures. We cannot pass from it, however, without expressing our difference of opinion in regard to the power of the medusæ to emit their light " at will." 
It seems much more probable that the light is the result of passion and action. When a man's feelings are strongly roused, whether pleasurably or otherwise, he usually starts into action under a sudden impulse which sends the blood violently through his veins, causing his face to become flushed and red. This reddening is not the result of will. It is the unavoidable result of passionate impulse, and could not possibly be produced by an effort of the will.

It is well known that electric fluid permeates the bodies of all animals, more or less; and it is quite conceivable that under the influence of nervous impulse one creature should become luminous, while another only becomes red. Man leaps and sings for joy ; and the result is, that the actions cause his countenance to glow with colour. The marine animalcule, experiencing a sudden influx of delight, darts hither and thither under the strong impulse of its exuberant glee; and the result is, that its little body gleams with light. Vigorous action is the direct cause of the emission of light in the one case, just as vigorous action is the direct cause of the suffusion of the countenance in the other. But in both cases the primary cause is passion-at least so it seems to us.

No doubt fear as well as joy may create vigorous action, and produce the same result; but as we know that, as a general rule, there is much more of joy than of fear dwelling at all times in the hearts of God's creatures, we can well believe that the 
amount of luminosity produced in the sea by the latter passion is immeasurably smaller than that produced by the former. We are thus, therefore, set free to indulge in the pleasing reflection that when we behold that magnificent gleaming of the sea, which almost resembles liquid silver reflecting the stars of heaven, we are witnessing the frolicsome and joyous gambols of those myriads of little beings to whom the beneficent Creator has assigned the ocean as their dwelling-place.

The theory which we have ventured to propound in regard to vigorous impulse (whether of joy or fear) being the cause of eliciting luminosity, is supported in some degree by the remark in our last quotation, that when the bucket was sharply struck, there appeared at once a number of luminous bodies, which shone for a few seconds, and then disappeared. Undoubtedly the poor little things got a fright when their residence was sharply assailed in such an unusual manner; their energies were roused, and their light emitted. Then, as they gradually calmed down, their light disappeared.

We are further told that when a drop of sulphuric acid was put into a tumbler of water, "several bright flashes were seen." This, we venture to think, was somewhat similar to the putting of a few drops of brandy and water into the human stomach; the usual result of which is, as we all know, to produce several bright flashes - of wit, if not of light, or of something at least meant to be remarkably luminous! 
But this luminosity is not entirely confined to the minute creatures of the sea. Some fish have the power of emitting light. Some species of the shark emit a greenish light; and the sun-fish is said, when seen down in the sea on a dark night, to glow like a white-hot cannon-ball. Fish when dead and putrid frequently glow in the dark with a truly magnificent light, as can be proved by every one who will take the trouble to procure several kinds of fish, and keep them, for the purpose of proving the fact, in a dark closet.

Of all the minute inhabitants of the deep, that which is to our mind the most curious, both as to its nature and its stupendous works, is the coral insect. This creature is much too important to be dragged in at the tail of a chapter. We will, therefore, commence its history in a new one.

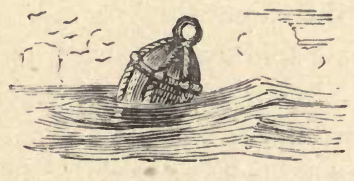




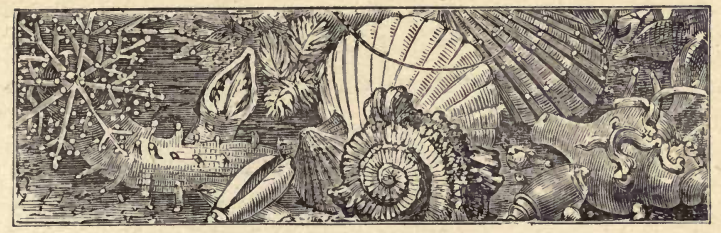

\section{CHAPTER XV.}

CORAL INSECTS AND CORAL ISLANDS - POLYNESIA-OPERATIONS OF THE CORAL INSECT-GROWTH OF CORAL REEFS.

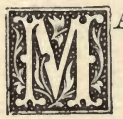

ANY of the large and beautiful islands that stud the Pacific Ocean, like emeralds in a field of blue, are artificial; that is to say, they were made by artists-they were actually built by artisans!

These artisans are the coral insects; and as they not only affect the face of the sea by raising large islands above it, but also, in consequence of their labours, assist in causing the circulation of the ocean, we think they are justly entitled to very special attention.

The great archipelago called Polynesia covers an area of the Pacific nearly 5000 miles in length, and not far short of 2000 in breadth. Some of the islands of this group are of volcanic origin, and some are crystal; but by far the greater number are of coral formation-the work of those curious little insects, which are so small that they inhabit a dwelling sometimes little larger than a pin-point. 
The manner in which these islands are made is, to some extent, a matter of uncertainty. The most generally received opinion is, that the insects fasten round the summit of a submarine mountain, and build upwards until they reach the surface of the sea, where they die, and their labours cease. As, however, the sea is sometimes unfathomable close to those islands, it has been supposed that the submarine islands on which the corallines began to build have gradually subsided, and that, as they did so, the insects always built a little more, so as to keep the top of their structures on a level with the sea. Above the sea they cannot build. To be washed by the waves is essential to their existence.

We do not think this a very satisfactory theory, because it supposes a prolonged subsiding of these islands, and then an unaccountably sudden stoppage. For although the corallines might continue to build during the whole time of subsidence, it were utterly impossible that the coral island, with its luxuriant herbage, could be formed until that subsidence should have ceased. The manner in which the islands are formed makes this obvious.

When the coral reef, as it is called, reaches the surface, it advances no further. Soon the action of the waves breaks off the branches of the upper portions of coral, which are tossed upon the reef, and pulverized into fine sand. This goes on increasing until the island rises a little above the waves. When this happens, birds alight there; sea-drift 


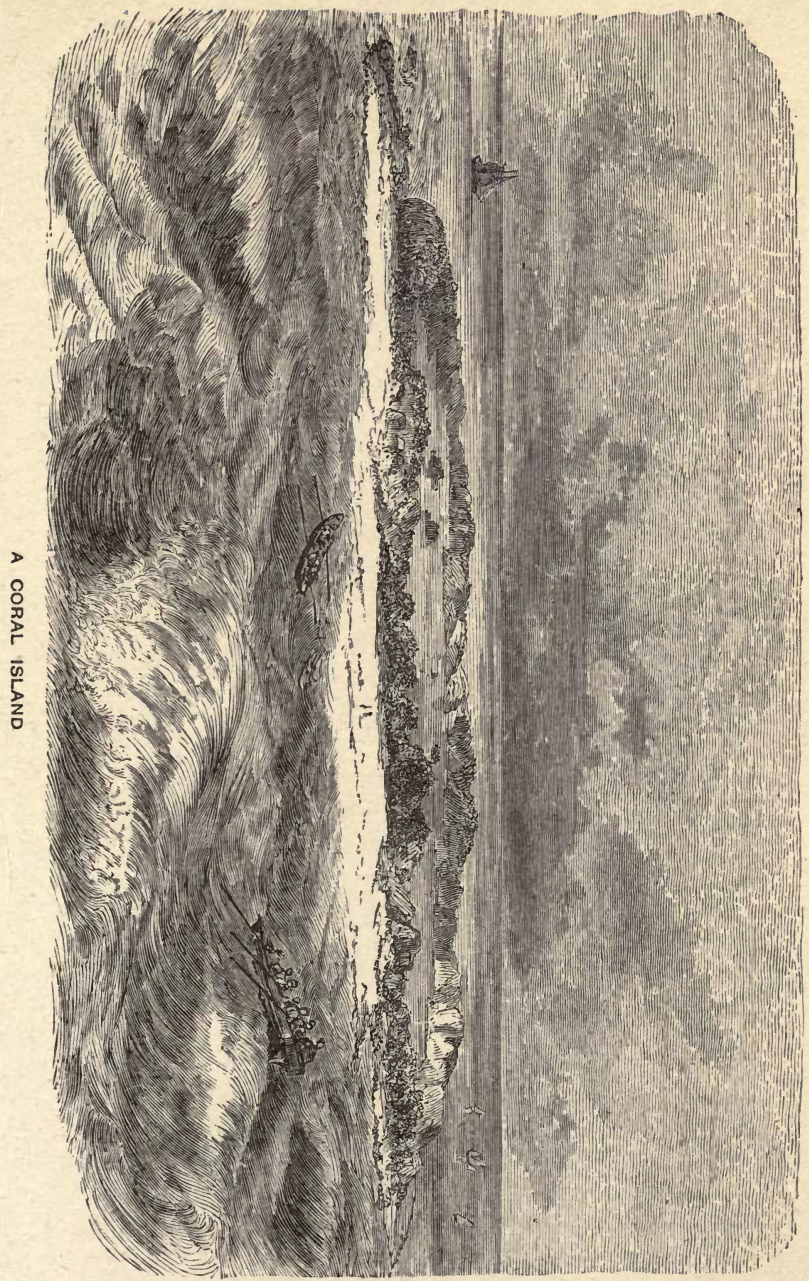




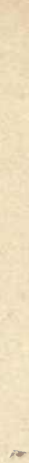


is carried thither; seeds are blown to it by the wind; and gradually a few green blades arise. From this little beginning it is easy to conceive the process by which at last a flourishing island springs up. At the same time, it is not easy to see how such islands could ever be formed on the supposition that the submarine rocks on which they were founded were perpetually subsiding.

But be that as it may, we have no difficulty in understanding the fact that the coral insect does build those islands. It possesses the power of secreting the lime held in solution by sea water, and depositing the same on the rocks below the waves. The coral rock is the edifice of the coralline. The insect itself is a soft and very minute worm, which, when washed by the waves, thrusts its head out of its tiny little door, and spreading abroad its numerous feelers, so that it resembles a beautiful little star, moves these about as if enjoying itselfthough, doubtless, it is actu-

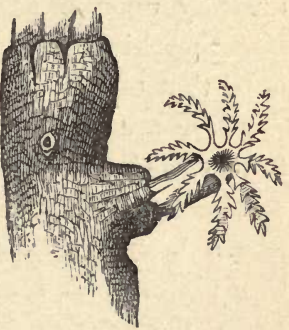

CORAL INSECT. ally engaged in the process of manufacturing its little atom of coral rock.

It is extremely interesting to think of the immense power of union thus exhibited. Singly, those little creatures could not produce a sufficient result to attract the attention of any creature save 
such as chanced to come in direct and close contact with its little cell. United, they have formed vast islands, which have become the abode of man, and which, in the aggregate, form no inconsiderable portion of the globe.

The consideration of this leads us to perceive that God has ordained that units cannot, separately, accomplish much; and that united effort, in order to be successful, requires the harmonious action of units. "A house divided against itself cannot stand." The innumerable and eminently beautiful isles of the Pacific had never stood where they now stand if the curious, and separately insignificant, little architects that reared them had not wrought unitedly upon a fixed and systematic plan-each insect working its utmost from the hour of its birth until that of its death.

There are various kinds of coral insects, which form varied species of coral rock. Some kinds of coral assume the form of rounded masses ; some are like a branching shrub; others are in layers, or thin plates; and some are shaped like the human brain, from which they derive their name-brainstones. These different kinds differ also in colour, and thus present a beautiful appearance when seen at the bottom of clear and shallow water.

In regard to the rate at which the corallines build their cells there is some diversity of opinion-some asserting that the process is imperceptible, while others state as positively that it is rapid. There 


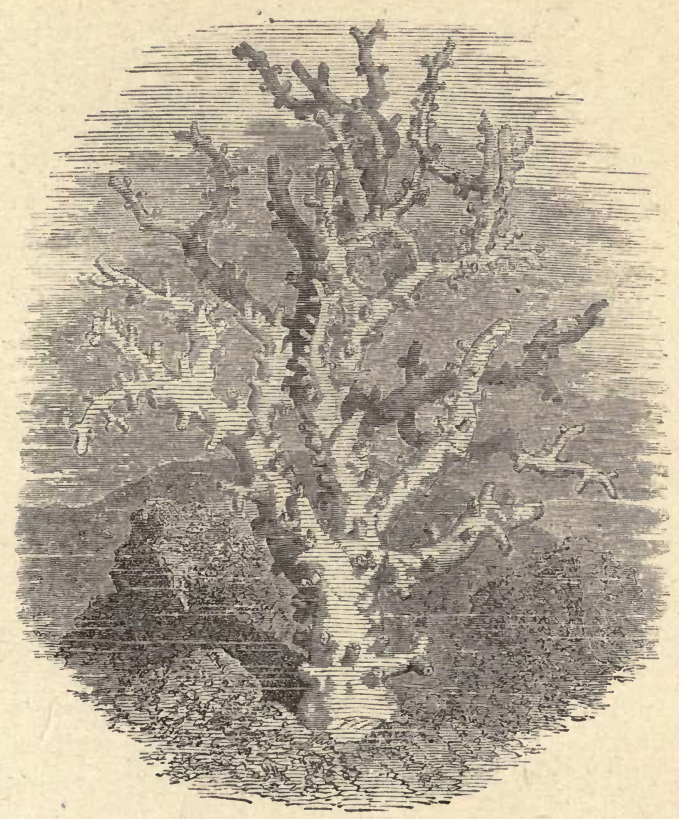

BRANCHING CORAL.

can be no doubt that some localities and positions are more favourable to the growth of coral than others. Dr. Allan, while at Madagascar, made several experiments to test this. He selected several masses of coral, each weighing about ten pounds, and of different species. These he placed three feet below the surface of the sea, and staked them in to prevent removal. In a little more than six months (451) 


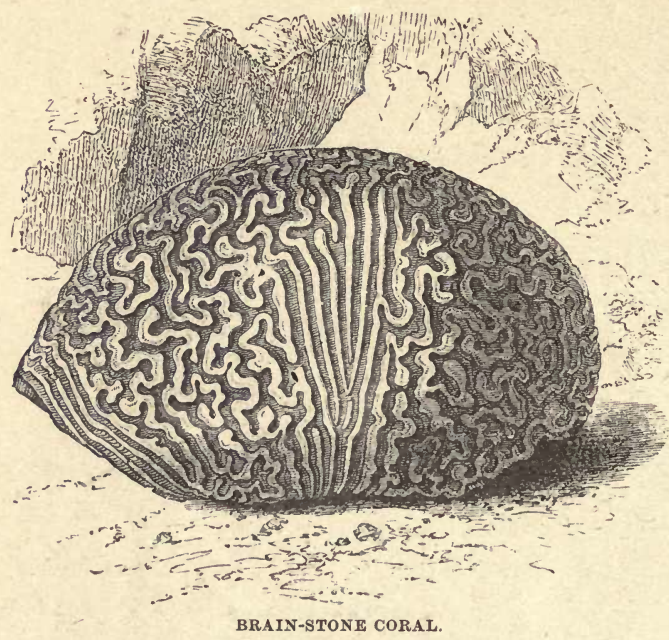

they were found to have risen nearly to the surface, and to have attached themselves to the solid rock.

There is also a case mentioned of a ship in the Persian Gulf which, in the course of twenty months, had her copper encased with living coral to the thickness of two feet.

On the other hand, it is asserted, and we doubt not with equal truth, that many reefs do not seem to increase in size in the course of many years.

When a coral reef has reached the surface, the formation of an island instantly begins; but it necessarily takes a long time ere this island becomes habitable by man. Among the first plants that raise their heads to the sea-breeze is the grace- 
ful cocoa-nut palm. This tree is exceedingly hardy, and is found growing on reefs which are so low that at a distance the trees seem to be standing on the surface of the water. Indeed many of them spring out of the pure white sand, and their roots are washed perpetually by the salt spray. Nevertheless, the fruit of such trees is sweet and good.

Coral islands of the kind we have just described seldom rise more than a few feet above the level of the sea; but most of them are clothed with luxuriant vegetation.

We might easily fill a volume on the subject of the ocean's inhabitants, small and great; but we think the few to which we have made reference is sufficient for the purpose of showing that one set of creatures accounts for that strange luminosity of the ocean which is seen at times in all marine parts of the globe, while another set accounts not only for the sudden appearance of coral islands in the sea where no such islands existed in days of old, but also, partly, for that circulation of the waters of the ocean which is absolutely necessary to the wellbeing of all the creatures on this earth.

There are other animals in the sea, besides medusæ, which assist in giving luminosity to its waters ; and there are other insects, besides corallines, which extract its lime, destroy its equilibrium, and assist in causing its perpetual motion; but the two species which we have described are the best types of the respective classes to which they belong. 


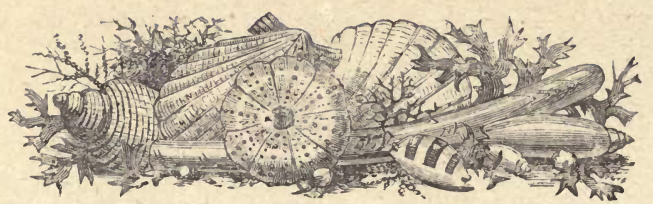

\section{CHAPTER XVI.}

VOLCANIC ISLANDS-OPINIONS OF THE ANCIENTS-"ATL.ANTIS"INSTANCE OF THE FORMATION OF A VOLCANIC ISLAND-CONCLUSION.

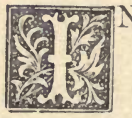

the last chapter we described the manner in which a certain class of islands in the South Seas are formed; in the present we will make a few observations on another class, which have sprung up from the bottom of the sea, as if by magic, under the irresistible influence of fire.

There are volcanoes in the sea, as well as on the land; and these volcanoes have in former times upheaved huge masses of land so as to form large islands, while in other cases they have caused islands formerly in existence to subside and disappear.

In the writings of the ancients we find reference made to an island which, if it ever did exist, now exists no longer. It was situated opposite the Straits of Gibraltar, was nearly two hundred miles in length, and was called "Atlantis"-hence the name of the Atlantic Ocean. Many believe, and 
with some reason, we think, that this island was not altogether a myth, although much that is said of it is undoubtedly fabulous.

Plato tells us that it was a large island in the Western Ocean, situated before or opposite to the Straits of Gades; and that out of this island there was an easy passage into some others which liay near a large continent, exceeding in bigness all Europe and Asia. So far Plato may have told the truth, and from this passage it is conjectured that the existence of the continent of America was known to the ancients. But he goes on, immediately after, to draw upon his imagination, and to tell us that Neptune settled on this island, and that his posterity dwelt there for a period of nine thousand years in the midst of fertility and abundance. But, not content with their ample possessions and prolific soil, they went over to Africa and Europe, and even penetrated into Asia, bent on conquest.

Passing from this mixture of probable truth and undoubted fable, Plato then asserts that the island of Atlantis finally sank and disappeared. This may or may not be true, but there is more reason for our crediting the statement than many people would suppose. Certain it is that no such island exists at the present time, but it is believed by some that the Azores, which are volcanic in their formation, are the summits of the mountain ranges of the Atlantis of the ancients.

But the best evidence we have of the possible 
existence of such an island is the fact that in modern times an island has been seen to rise out of the sea, and, after a time, to disappear, under the influence of volcanic action.

This remarkable event is related by Captain Tillard, an officer of the British Navy, who saw it on the 12 th of June 1811, when approaching the island of St. Michael. On this occasion smoke was seen to rise from the surface of the sea, and, soon after, showers of cinders to burst forth. We cannot do better than give the captain's own words, as follows :-

"Imagine an immense body of smoke rising from the sea, the surface of which was marked by the silvery rippling of the waves. In a quiescent state - it had the appearance of a circular cloud revolving on the water, like a horizontal wheel, in various and irregular involutions, expanding itself gradually on the lee side; when, suddenly, a column of the blackest cinders, ashes, and stones, would shoot up in the form of a spire, at an angle of from ten to twenty degrees from a perpendicular line, the angle of inclination being universally to windward. This was rapidly succeeded by a second, third, and fourth shower, each acquiring greater velocity, and overtopping the other, till they had attained an altitude as much above the level of our eye as the sea was below it.

"As the impetus with which the several columns were severally propelled diminished, and their ascend- 


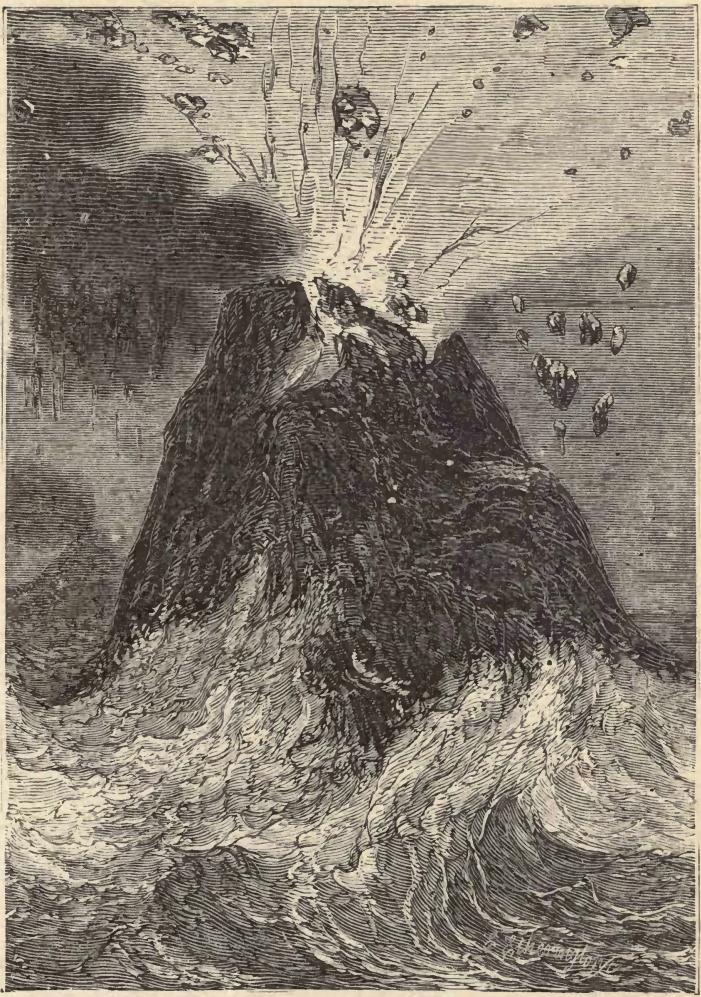

SUBMARINE VOLCANO.

ing motion had nearly ceased, they broke into various branches resembling a group of pines. These again formed themselves into festoons of white feathery 
smoke, in the most fanciful manner imaginable, intermixed with the finest particles of falling ashes; which at one time assumed the appearance of innumerable plumes of black and white ostrich feathers surmounting each other; at another, that of the light wavy branches of a weeping willow.

"During these bursts the most vivid flashes of lightning continually issued from the densest part of the volcano; and the cloud of smoke now ascending to an altitude much above the highest point to which the ashes were projected, rolled off in large masses of fleecy clouds, gradually expanding themselves before the wind, in a direction nearly horizontal, and drawing up to them a quantity of waterspouts, which formed a most beautiful and striking addition to the general appearance of the scene."

Such is the description given of this submarine volcano in action; and the crater which was thrown up at the time was about twenty feet above the level of the sea. As Captain Tillard could not, however, delay his voyage to make further observations at that time, the action that subsequently took place is not known; but its results were seen shortly afterwards.

In about three weeks after the date of his passing the spot, Captain Tillard returned to it and found an island of about a mile in circumference, with a height of between two and three hundred feet at its highest point. There was no violent eruption going on, although the craters still emitted smoke. 
He therefore landed, and, on reaching the largest crater, found it to be full of boiling water, which overflowed and found its way to the ocean in a river of about six yards in width. This island, however, was not a permanent addition to the world's archipelago. It sank into the ocean again, and disappeared in October of the same year in which it rose.

In commencing this little book we set out with the intention of rambling hither and thither, among things that relate to the sea, without regard to order. We have carried out our intention; and now, at the close of our task, find that the more we listen to the Ocean's Voice, the more we find its tale to be interminable, though the reverse of uninteresting.

In these rambles we have sought to treat chiefly of those scientific facts relating to the sea and the atmospheric ocean, which are not so frequently made the subject of books for the young, as are the wild and daring deeds of man upon the surface of the mighty deep.

It is not sufficient that man should become acquainted with the doings of his fellows on the sea. This is but one branch of general knowledge, and a very secondary one compared with that infinitely higher branch which treats of the workings of the Almighty in the ocean; workings which render it what it is-not merely a means of commercial enterprise for man and a home for fish, 
but also a great purifier and revivifier of the earth and sweetener of the atmosphere. God is the great first cause of all that is and that operates in the universe. It were an act of presumption to inquire into what we may term the first acts of the Almighty's power. But there is no presumption-on the contrary there is propriety, as well as the highest gratification of which the human mind is capablein penetrating through the paths of knowledge up to that first series of second causes which circle like a glory round the fountain-head, We may not put the question, "How did God create all things out of nothing?" but, all things having been created, it is quite legitimate to inquire how the circles of their manifold operations are carried on, and in what respect the things that be do affect each other.

No book that has of late years issued from the press treats more eloquently and interestingly of such subjects of inquiry than that admirable work of Captain Maury of the United States Navy, entitled "The Physical Geography of the Sea." Much of the substance of what we have written has been culled from the pages of that fascinating volume. But we have merely plucked one or two leaves, as it were, and presented them to our readers in the hope that they may be tempted by their fragrance to pluck the flower. The mysteries of the atmospheric and aqueous oceans are here treated of fully, yet so agreeably, that one is frequently apt to fancy one is ferusing the pages of romance. 
In our own little book we have been compelled to skim lightly, and, in many places, to pass over subjects of great interest.

As for other subjects connected with the sea, of which we may not treat, they are innumerable. Of the sea-weeds that clothe the bottom of the deep with the rich profusion and glowing colours of the gardens of earth-of the myriads of animalcules (besides those we have mentioned) that disport in its waters and fill the abyss with life and lambent fire - of the great whales and other huge creatures that revel in its depths and lash its waters in their terrible might - of these and a host of kindred subjects, our space forbids our saying more than that the Voice of Ocean has much to tell us in regard to them, and in regard to the provident care of their beneficent Creator. 






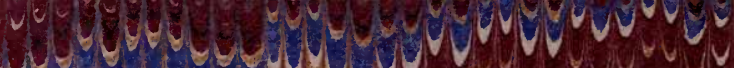

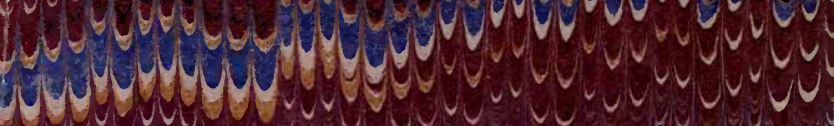

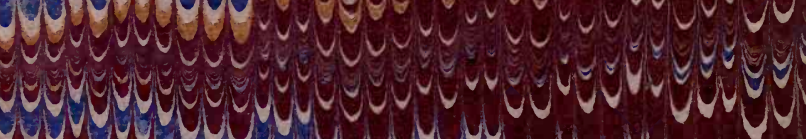

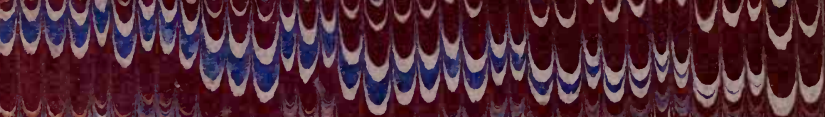
Wy

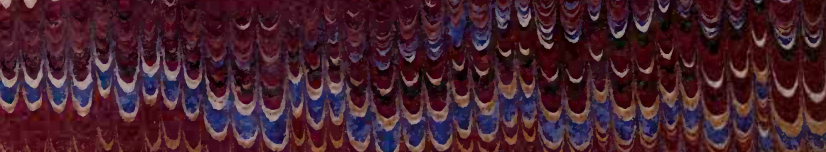

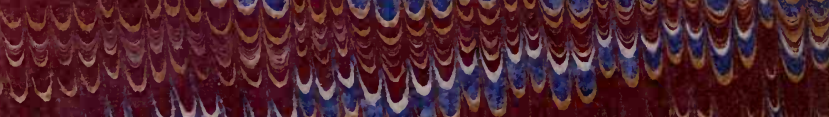

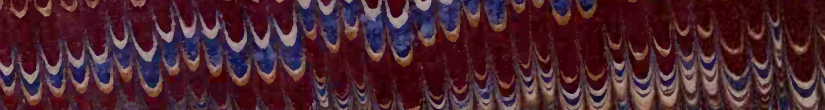
W 70.0

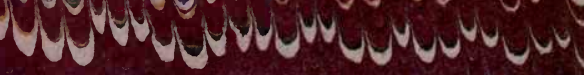

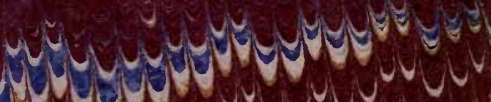

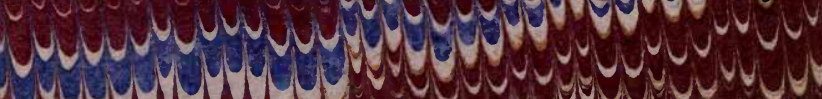

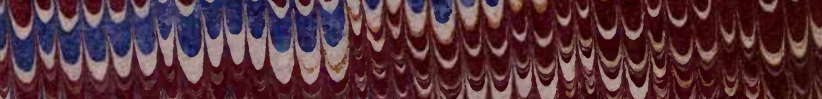

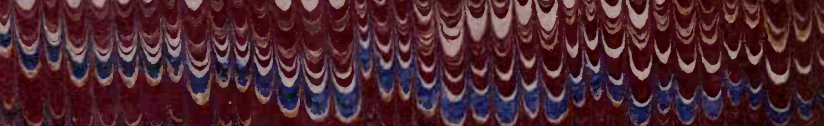

$$
y \text { yes: }
$$

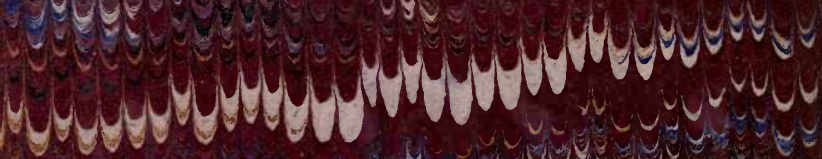

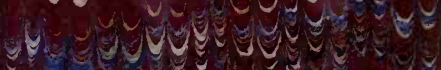

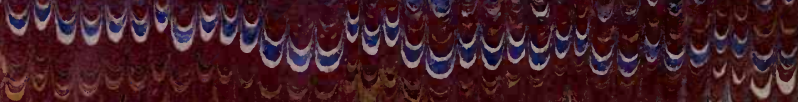

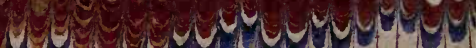




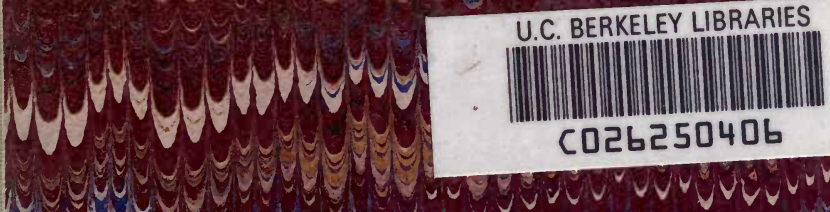

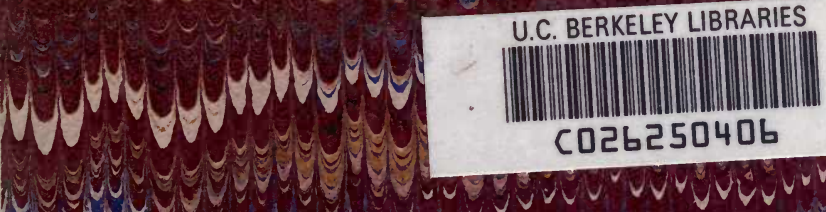

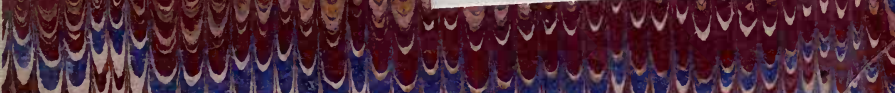
a M (a)

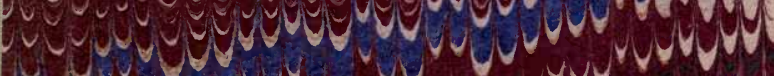

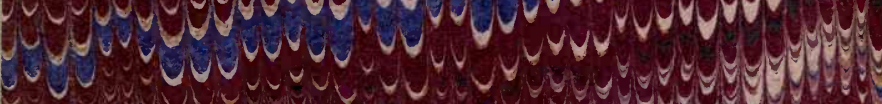
Ec 0 -

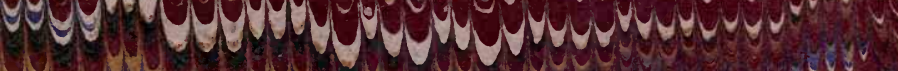

\section{Cyan:}

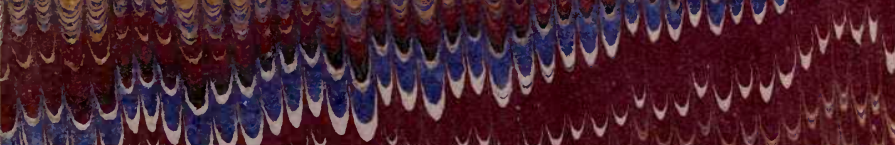

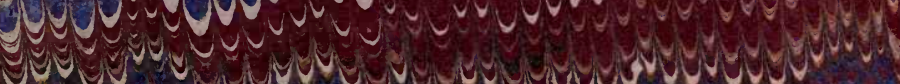

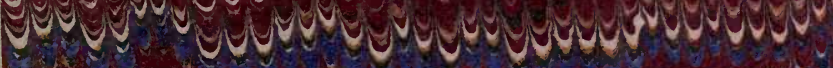

ere

$y$ you

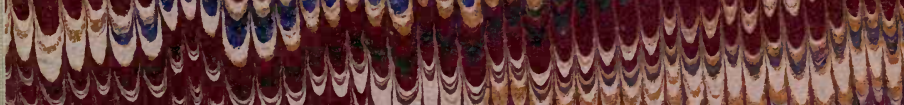
- -0 o ¿ Co

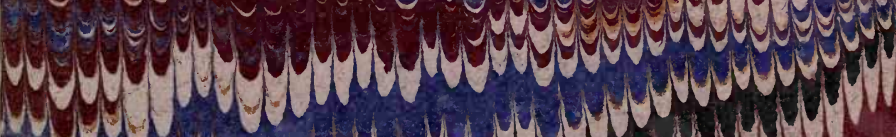
-

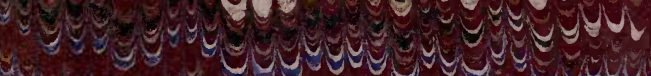




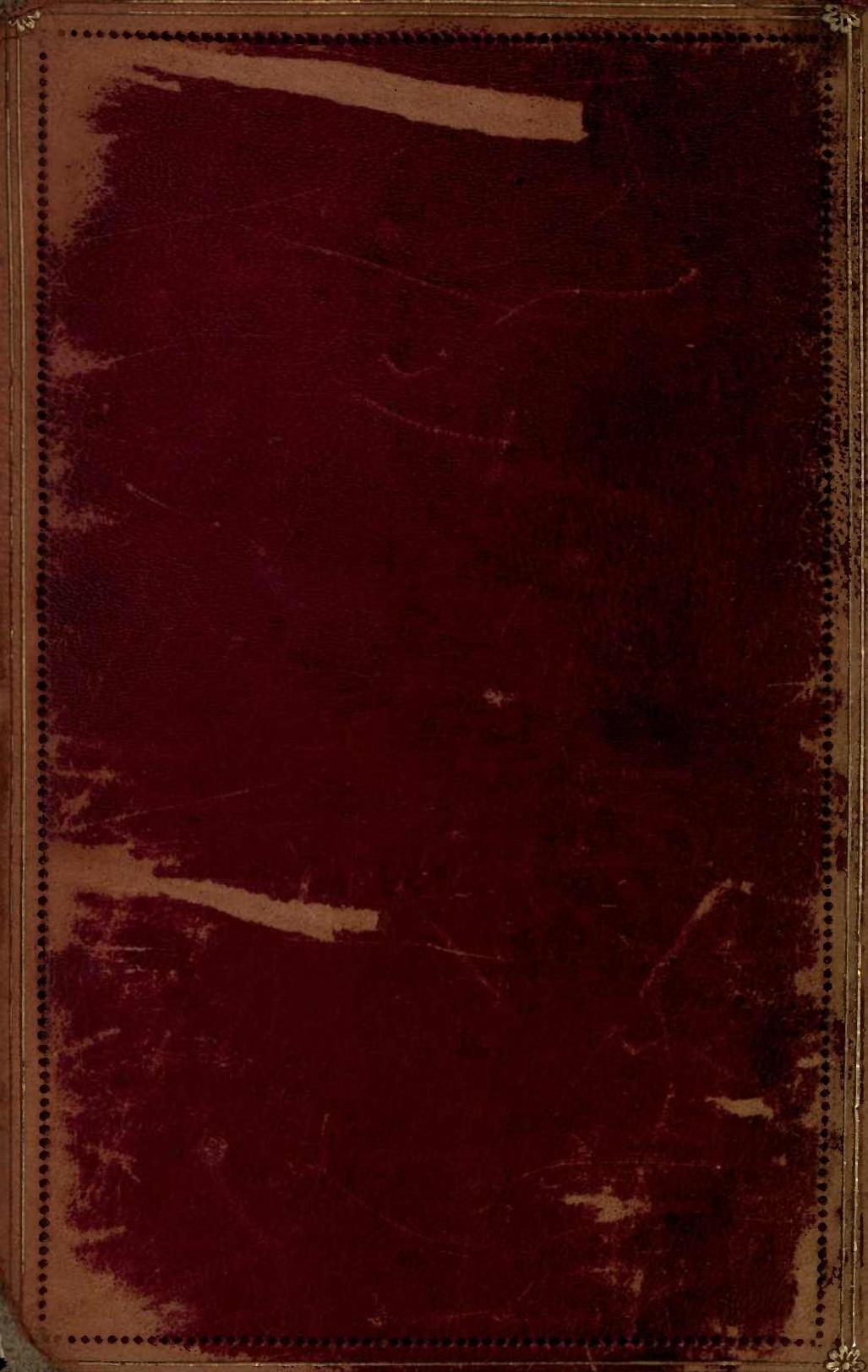

